Prepared for:

United States Department of Energy National Energy Technology Laboratory Contract No. DE-AC26-99FT40342

\section{Gasification Plant Cost and Performance Optimization}

\section{Final Report}

Submitted By:

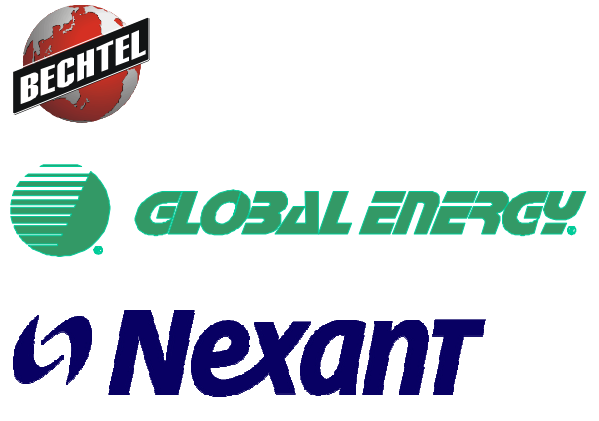

SEPTEMBER 2003 


\section{U. S. Department of Energy \\ National Energy Technology Laboratory (NETL)}

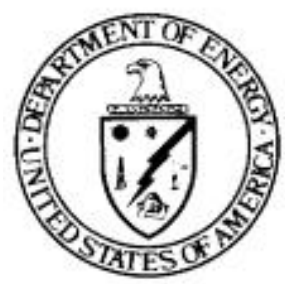

\section{Gasification Plant Cost and Performance Optimization (Contract No. DE-AC26-99FT40342)}

\section{Final Report}

September 2003

Work Performed from September 1999 to September 2003

Prepared by:

Bechtel Corporation 3000 Post Oak Boulevard Houston, TX 77056
Global Energy Inc.

Suite 3800

1000 Louisiana Street

Houston, TX 77002
Nexant Inc. 101 Second Street $11^{\text {th }}$ Floor San Francisco, CA 94105

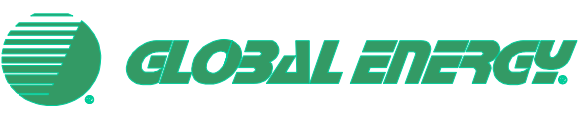




\section{DISCLAIMER}

This report was prepared as an account of work sponsored by an agency of the United States Government. Neither the United States Government nor any agency thereof, Bechtel Corporation, Global Energy Incorporated, Nexant Incorporated, nor any of their employees, makes any warranty, express or implied, or assumes any legal liability or responsibility for the accuracy, completeness, or usefulness of any information, apparatus, product, or process disclosed, or represents that that its use would not infringe privately owner rights. Reference herein to any specific commercial product, process, or service by trade name, trademark, manufacturer, or otherwise does not necessarily constitute or imply its endorsement, recommendation, or favoring by the United States Government or any agency thereof. The views and opinions of authors expressed herein do not necessarily state or reflect those of the United States Government or any agency thereof. 


\section{PREFACE}

This report was prepared as an account of work on Contract DE-AC26-99FT40342 by Bechtel, Global Energy, and Nexant. Since all the technical work under this contract was completed, ConocoPhillips acquired the proprietary gasification technology from Global Energy Inc. on August 7, 2003. Thus, the patents and intellectual property associated with the E-GAS ${ }^{T M}$ technology for gasification now are the property of ConocoPhillips who should be contacted for further information concerning the technology. 


\begin{abstract}
This project developed optimized designs and cost estimates for several coal and petroleum coke IGCC coproduction projects that produced hydrogen, industrial grade steam, and hydrocarbon liquid fuel precursors in addition to power. The as-built design and actual operating data from the DOE sponsored Wabash River Coal Gasification Repowering Project was the starting point for this study that was performed by Bechtel, Global Energy and Nexant under Department of Energy contract DE-AC26-99FT40342.
\end{abstract}

First, the team developed a design for a grass-roots plant equivalent to the Wabash River Coal Gasification Repowering Project to provide a starting point and a detailed mid-year 2000 cost estimate based on the actual as-built plant design and subsequent modifications (Subtask 1.1). This non-optimized plant has a thermal efficiency to power of 38.3\% (HHV) and a mid-year 2000 EPC cost of $1,681 \$ / \mathrm{kW}^{1}$

This design was enlarged and modified to become a Petroleum Coke IGCC Coproduction Plant (Subtask 1.2) that produces hydrogen, industrial grade steam, and fuel gas for an adjacent Gulf Coast petroleum refinery in addition to export power. A structured Value Improving Practices (VIP) approach was applied to reduce costs and improve performance. The base case (Subtask 1.3) Optimized Petroleum Coke IGCC Coproduction Plant increased the power output by $16 \%$ and reduced the plant cost by $23 \%$. The study looked at several options for gasifier sparing to enhance availability. Subtask 1.9 produced a detailed report on this availability analyses study. The Subtask 1.3 Next Plant, which retains the preferred spare gasification train approach, only reduced the cost by about $21 \%$, but it has the highest availability (94.6\%) and produces power at $30 \$ / \mathrm{MW}-\mathrm{hr}$ (at a $12 \% \mathrm{ROI})$. Thus, such a coke-fueled IGCC coproduction plant could fill a near term niche market. In all cases, the emissions performance of these plants is superior to the Wabash River project.

Subtasks 1.5A and B developed designs for single-train coal- and coke-fueled IGCC power plants. A side-by-side comparison of these plants, which contain the Subtask 1.3 VIP enhancements, shows their similarity both in design and cost $(1,318 \$ / \mathrm{kW}$ for the coal plant and 1,260 \$/kW for the coke plant). Therefore, in the near term, a coke IGCC power plant could penetrate the market and provide a foundation for future coal-fueled facilities.

Subtask 1.6 generated a design, cost estimate and economics for a four-train coal-fueled IGCC power plant, also based on the Subtask 1.3 cases. This plant has a thermal efficiency to power of $40.6 \%(\mathrm{HHV})$ and cost $1,066 \$ / \mathrm{kW}$.

The single-train advanced Subtask 1.4 plant, which uses an advanced "G/H-class" combustion turbine, can have a thermal efficiency to power of $44.5 \%(\mathrm{HHV})$ and a plant cost of $1,116 \$ / \mathrm{kW}$. Multi-train plants will further reduce the cost. Again, all these plants have superior emissions performance.

Subtask 1.7 developed an optimized design for a coal to hydrogen plant. At current natural gas prices, this facility is not competitive with hydrogen produced from natural gas. The preferred scenario is to co-produce hydrogen in a plant similar to Subtask 1.3, as described above.

Subtask 1.8 evaluated the potential merits of warm gas cleanup technology. This study showed that selective catalytic oxidation of hydrogen sulfide (SCOHS) is promising.

Subtask 2.1 developed a petroleum coke IGCC power plant with the coproduction of liquid fuel precursors from the Subtask 1.3 Next Plant by eliminating the export steam and hydrogen production and replacing it with a Fischer-Tropsch hydrocarbon synthesis facility that produced

\footnotetext{
${ }^{1}$ All plant costs mentioned in this report are mid-year 2000 EPC costs which exclude contingency, taxes, licensing fees and owners costs (such as land, operating and maintenance equipment, capital spares, operator training, and commercial test runs. These excluded items are included in the subsequent discounted cash flow financial analyses.
} 
4,125 bpd of liquid fuel precursors. By maximizing liquids production at the expense of power generation, Subtask 2.2 developed an optimized design that produces 10,450 bpd of liquid fuel precursors and $617 \mathrm{MW}$ of export power from 5,417 tpd of dry petroleum coke. With 27 \$/MW-hr power and $30 \$ / \mathrm{bbl}$ liquids, the Subtask 2.2 plant can have a return on investment of $18 \%$.

Subtask 2.3 converted the Subtask 1.6 four-train coal fueled IGCC power plant into one that coproduced $12,377 \mathrm{bpd}$ of liquid fuel precursors in addition to $676 \mathrm{MW}$ of export power. Adding the coproduction of liquid fuel precursors can enhance the profitability of an IGCC power plant when oil prices are high relative to power prices.

As gasification technology matures, improvements identified in this study will lead to further cost reductions and efficiency improvements that will make IGCC power plants more competitive in the marketplace. 


\section{Table of Contents}

No. Chapter

Page

$$
\text { Executive Summary }
$$

$$
\text { EXECUTIVE SUMMARY }
$$

ES-1

INTRODUCTION

I Background

$\begin{array}{ll}\text { I.1 } & \text { Introduction } \\ \text { I.2 } & \text { Contract Overview }\end{array}$

EXPERIMENTAL

II

\section{Methodology}

II.1 The Wabash River Repowering Project 8

II.2 Optimization Methodology 9

II.3 Availability Analysis 9

II.4 Commodity Pricing 11

II.5 Financial Analysis 13

III Task 1 Gasification Plants 14

III.1 Wabash River Greenfield Plan 14

III.2 Petroleum Coke IGCC Coproduction Plant 15

III.3 Optimized Petroleum Coke IGCC Coproduction Plan 15

III.4 Next Optimized Petroleum Coke IGCC Coproduction Plant 16

III.5 Advanced IGCC Coal Power Plant 17

III.6 Single Train Coal and Coke IGCC Power Plants 17

III.7 Nominal 1,000 MW Coal IGCC Power Plant 18

III.8 Coal to Hydrogen Plant 19

IV Task 2 Gasification Coproduction Plants 23

IV.1 Non-Optimized Coke Gasification Power Plant with Liquids Coproduction 23

IV.2 Optimized Coke Gasification Power Plant with

IV.3 Optimized Coal Gasification Power Plant with

$\begin{array}{lll}V & \text { Emissions } & 28\end{array}$

VI Financial Results 31

VI.1 Introduction 31

VI.2 Petroleum Coke IGCC Coproduction Plants 31

VI.3 Coal and Petroleum Coke IGCC Power Plants 35

VI.4 Coal to Hydrogen Plant 40

VI.5 Petroleum Coke IGCC Power Plants with Liquids

VI.6 Coal IGCC Power Plant with Liquids Coproduction 45 


\section{Table of Contents (Continued)}

№. $\quad$ Chapter

CONCLUSION

VII Summary, Conclusions and Recommendations 50

VII.1 Summary $\quad 50$

VII.2 Conclusions

VII.3 Recommendations $\quad 56$

$\begin{array}{lll}\text { VIII References } & 57\end{array}$

IX List of Acronyms and Abbreviations 58

$\begin{array}{lll}\text { X Acknowledgements } & 61\end{array}$

\section{Tables}

No. Title of Table $\quad \underline{\text { Page }}$

I.1 Task 1 Coal and Coke Gasification Plant Case Summaries 5

I.2 Task 2 Coal and Coke Gasification Plant Case Summaries 6

II.1 Basic Economic Parameters 12

VI.1 Comparison of the Subtask 1.2 and Subtask 1.3

Petroleum Coke IGCC Coproduction Plants

VI.2 Design and Daily Average Feed and Product Rates for the Subtask 1.1, 1.4 1.5A and 1.6 Coal IGCC Power Plants

VI.3 Design and Daily Average Feed and Product Rates for the Subtask 1.5A Coal and Subtask 1.5B Coke IGCC Power Plants 38

VI.4 Return on Investment and Required Power Selling Price for the Subtask 1.3 Next Plant, Subtask 2.1 and Subtask 2.2 Coproduction Plants (with a Natural Gas Price of 2.60 \$/MMBtu)

VI.5 Required Power Selling Prices for the for the Subtask 1.6 Power Plant and the Subtask 2.3 Optimized Coal Gasification Power Plant with Liquids Coproduction With and Without Backup Natural Gas

\section{Graphical Materials}

No. $\quad$ Title of Figure

I.1 Schematic Diagram Showing the Chronological Development of the Gasification Plant Designs 


\section{Table of Contents (Continued)}

No. $\quad$ Title of Figure

Page

III.1 Subtask 1.1 Wabash River Greenfield Plant - Simplified

Block Train Diagram

20

III.2 Subtask 1.2 Petroleum Coke IGCC Coproduction Plant Simplified Block Train Diagram

20

III.3A Subtask 1.3 Optimized Petroleum Coke IGCC Coproduction Plant - Base Case - Simplified Block Train Diagram

III.3B Subtask 1.3 Optimized Petroleum Coke IGCC Coproduction Plant - Minimum Cost Case - Simplified Block Train Diagram 21

III.3C Subtask 1.3 Optimized Petroleum Coke IGCC Coproduction Plant - Spare Train Case - Simplified Block Train Diagram

III.4 Subtask 1.3 Next Optimized Petroleum Coke IGCC Coproduction Plant - Simplified Block Train Diagram

III.5 Subtask 1.4 Advanced IGCC Coal Power Plant - Simplified Block Train Diagram

III.6 Subtask 1.5 Single-Train Coal or Coke IGCC Power Plant - Simplified Block Train Diagram

III.7 Subtask 1.6 Nominal 1,000 MW Coal IGCC Power Plant - Simplified Block Train Diagram

III.8 Subtask 1.7 Coal to Hydrogen Plant - Simplified Block Train Diagram

IV.1 Subtask 2.1 Coke Gasification Power Plant with Liquids Coproduction

IV.2 Subtask 2.2 Optimized Coke Gasification Power Plant with Liquids Coproduction

IV.3 Subtask 2.3 Optimized Coal Gasification Power Plant with Liquids Coproduction

VI.1 Design and Daily Average Coke Consumptions for the Subtask 1.2 and Subtask 1.3 Petroleum Coke IGCC Coproduction Plants

VI.2 Return on Investment vs. Power Selling Price for the Subtask 1.2 and Subtask 1.3 Petroleum Coke IGCC Coproduction Plants

VI.3 Return on Investment vs. Power Selling Price for the Subtask 1.1, 1.4, 1.5A and 1.6 Coal IGCC Power Plants

VI.4 Effect of Syngas Availability on the Required Power Selling Price for a $12 \%$ Return on Investment for the Subtask 1.6 Coal IGCC Power Plant

VI.5 Return on Investment vs. Hydrogen Selling Price for the Subtask 1.6 Coal to Hydrogen Plant

VI.6 Effect of Hydrogen Availability on the Required Hydrogen Selling Price for a $12 \%$ Return on Investment for the Subtask 1.6 Plant 


\section{Table of Contents (Continued)}

No. Title of Figure $\quad$ Page

VI.7 Return on Investment vs. Power Price for the Subtask 2.1

[Non-optimized] and Subtask 2.2 Optimized Coke Gasification

Power Plants with Liquids Coproduction and the Subtask 1.3

Next Optimized Petroleum Coke IGCC Coproduction Plant

VI.8 Return on Investment vs. Power Price Showing the Effect

of the Liquids Price for the Subtask 2.2 Optimized Coke

Gasification Power Plant with Liquids Coproduction

VI.9 Return on Investment vs. Syngas Availability for the Subtask 2.1

[Non-optimized] and Subtask 2.2 Optimized Coke Gasification

Power Plants with Liquids Coproduction and the Subtask 1.3

Next Optimized Petroleum Coke IGCC Coproduction Plant

VI.10 Return on Investment vs. Power Price for the Subtask 2.3

Optimized Coal Gasification Power Plant with Liquids

Coproduction and the Subtask 1.6 Nominal 1,000 MW Coal

IGCC Power Plant

VI.11 Return on Investment vs. Power Price Showing the Effect of the Liquids Price for the Subtask 2.3 Optimized Coal Gasification Power Plant with Liquids Coproduction and the Subtask 1.6 Coal IGCC Power Plant

VI.12 Effect of Syngas Availability on the Required Power Selling

Price for a 12\% Return on Investment for the Subtask 2.3

Optimized Coal Gasification Power Plant with Liquids

Coproduction and the Subtask 1.6 Power Plant

\section{Appendix}

List of Technical Publications 


\section{Executive Summary}

This "Gasification Plant Cost and Performance Optimization" project, contract number DE-AC26-99FT40342, examines the current state-of-the-art of coal gasification to provide baseline optimized design cases from which the Department of Energy can measure future progress towards commercialization of gasification processes and achievement of the Vision 21 program goals. This optimization focus or metric was to minimize the cost of electric power produced by IGCC plants primarily by reducing the plant capital cost, increasing the efficiency, increasing the overall system availability, co-producing products, and reducing the operating and maintenance costs.

The Vision 21 concept is the approach being developed by the U. S. Department of Energy to promote energy production from fossil fuels in the 21st century. The objective is to integrate advanced concepts for high efficiency power generation and pollution control into a new class of fuel-flexible facilities capable of co-producing electric power, process heat, high value fuels, and chemicals with virtually no emissions of air pollutants. Also, it will be capable of a variety of configurations to meet different marketing needs, including both distributed and central power generation.

Tables I.1 and I.2 in Chapter I summarize all these cases. The cases described in these tables are planning studies that show some options and applications of the E-GAS ${ }^{\mathrm{TM}}$ gasification technology to produce power, industrial grade steam, hydrogen and/or hydrocarbon liquid fuel precursors.

An optimized petroleum coke IGCC coproduction plant (Subtask 1.3 Next Plant) located on the U. S. Gulf Coast can dispatch power at 30.0 \$/MW-hr while having a $12 \%$ ROI. Such a plant will produce $474 \mathrm{MW}$ of export power, $980,000 \mathrm{lb} / \mathrm{hr}$ of $750^{\circ} \mathrm{F} / 700$ psig steam, and 80 MMscfd of $99.0 \%$ hydrogen from 5,417 tpd of dry petroleum coke. Because these plants use a low-value feed and co-produce high value products, they currently are economically attractive, and several projects presently are under development. Furthermore, they provide stable long-term costs for the power, steam and hydrogen that are independent of the volatile price of natural gas.

Adding the coproduction of liquid fuel precursors by Fischer-Tropsch hydrocarbon synthesis can enhance the profitability of IGCC plants when oil prices are high relative to power prices. A modification of the above multi-train IGCC power plant (Subtask 2.3) which produced $12,377 \mathrm{bpd}$ of liquid fuel precursors and only $676 \mathrm{MW}$ of export power was more profitable only when the liquid product could be sold for $32.3 \$ / \mathrm{bbl}$ or above.

Subtask 2.2 developed an optimized design for a petroleum coke IGCC power plant with hydrocarbon liquids coproduction from the Subtask 1.3 Next Plant by eliminating the export steam and hydrogen production and reducing the power production. This plant will produce $10,450 \mathrm{bpd}$ of liquid fuel precursors and $367 \mathrm{MW}$ of export power from the same amount of petroleum coke. With 27 \$/MW-hr power and 30\$/bbl liquids, this plant has an $18.2 \% \mathrm{ROI}$.

The economics for a current day, multi-train IGCC power plant (Subtask 1.6) having a design power output of $1,155 \mathrm{MW}$ are almost as good. It will produce a $12 \% \mathrm{RO}$ with a current power selling price of $40.2 \$ / M W-h r$, and it costs even less at $1,066 \$ / \mathrm{kW}^{1}$. The plant has a thermal efficiency of $40.8 \%$ (HHV) including the byproduct sulfur. 
Significant reductions were achieved. On a $\$ / \mathrm{kW}$ basis, the cost of the $416 \mathrm{MW}$ advanced Subtask 1.4 single-train IGCC power plant was reduced by $34 \%$ compared to the $269 \mathrm{MW}$ Wabash River base case $(1,116 \$ / \mathrm{kW} \text { vs. } 1,681 \$ / \mathrm{kW})^{2}$. The required power selling price for a $12 \%$ after tax ROI was reduced by about $41 \%$ to 39.8 \$/MW-hr using a conservative economic scenario.3 Additional improvements have to potential to further reduce the cost to $1,096 \$ / \mathrm{kW}-\mathrm{hr}$, the power price to $39.0 \$ / \mathrm{MW}-\mathrm{hr}$, and to increase the thermal efficiency to power to $45.4 \%$ (HHV).

Gasification systems are inherently clean, relatively efficient, and commercially demonstrated for converting inexpensive fuels such as coal and petroleum coke into electric power, steam, hydrogen, and chemicals. However, the gasification system also is relatively complex and costly. Optimization should allow IGCC to become the preferred low cost power generation option.

Starting from the DOE sponsored Wabash River Coal Gasification Repowering Project (at Terre Haute, Indiana), a design and mid-year 2000 cost were developed for a grass-roots plant equivalent to the Wabash River facility. This case updates the then current Wabash River plant by including all modifications and improvements that were made since the initial startup. The mid-year 2000 cost of the grass-roots plant was developed based on the actual construction cost of the Wabash River facility and subsequent modifications; thereby providing a sound cost basis for the subsequent cases.

This study report contains general non-confidential information for each of the study cases, such as basic process information, plant layout schedule, and costs. Interested parties who wish to obtain current, detailed confidential project specific information and explore IGCC further, should contact either Bechtel, Global Energy or Nexant.

The above cost reductions were achieved by application of Value Improving Practices. Value Improving Practices are focused activities aimed at removing non-value adding investment from a project scope. This study utilized the following nine practices.

1. Technology Selection

2. Process Simplification

3. Classes of Plant Quality

4. Value Engineering

5. Availability (Reliability) Modeling

6. Design-to-Capacity

7. Plant Layout Otimization

8. Schedule (Constriction and Procurement) Optimization

9. Operating and Maintenance Savings

Employing Value Improving Practices outside of a specific project removes the limitations of schedule constraints and allows a more thorough examination of the ideas that were generated during the process. The Value Improving Practices team, which consisted of operating and maintenance personnel from the Wabash River plant, Global Energy's gasification experts, and Bechtel's engineers and construction specialists, examined all

\footnotetext{
${ }^{2}$ All costs are mid-year 2000 costs. They are presented here to show the relative differences between the cases. Current cost estimates should be developed for any proposed application.

${ }^{3}$ All power costs are current year 2000 power costs which increase at $1.7 \%$ year.
} 
aspects of the proposed plant and generated almost 300 value engineering ideas. Those that were economically viable were incorporated into the optimized designs. Others that require further research are being developed for future applications which will lead to further cost reductions and efficiency improvements.

As more IGCC plants, either with or without coproduction facilities, are built and operated, their performance should improve which will enhance their economics. At low power prices relative to oil prices, IGCC power plants with liquids coproduction will be favored, and conversely when power prices are high relative to oil prices, IGCC power only power plants will be preferred.

Based on the above results, in order for a gasification power plant with liquids coproduction to have a better ROI than a conventional IGCC power plant, the plant design must be balanced. Some features that contribute to this balanced design include

- The use of large, cost efficient gasification trains to minimize cost

- Inclusion of a spare gasification train for maximum availability

- The syngas should have high $\mathrm{CO}$ and $\mathrm{H}_{2}$ contents and a low methane content to allow the F-T area to produce an offgas with a minimal Btu content and a high $\mathrm{CO}_{2}$ content, which is advantageous for NOx control

- The ability to process all, or almost all, of the syngas in the F-T reactors

- A large, efficient combustion turbine that is correctly sized to process all the fuel gas with minimum additional steam dilution for NOx control

The Subtask 2.2 Optimized Petroleum Coke IGCC Power Plant with Liquids Coproduction does a good job of satisfying most of the above criteria. However, the Subtask 2.3 coal plant produces a syngas with a methane content that is about 2.6 times greater than the syngas produced by the gasification of coke because of the higher volatiles content of the coal. As a result, the F-T offgas has a higher Btu content and requires more steam dilution for NOx control. Furthermore, the total amount of F-T offgas contains too much energy for one GE 7FA+e turbine, and not enough for two turbines. Consequently, about $18 \%$ of the syngas has to be bypassed around the F-T reactors to fully load the two GE 7FA+e turbines. This significantly reduces the liquids production. Ideally, a single larger turbine [or two smaller turbines] that would require bypassing only very little, if any, syngas around the F-T reactors would result in a better balanced plant that could have a better return on investment.

Gasification is viewed as the environmentally superior process for power generation from coal. The Wabash River facility demonstrated the superior environmental performance of gasification in terms of SOx, NOx, and particulate emissions. In a carbon constrained environment, the $\mathrm{CO}_{2}$ easily can be captured for sequestration or other uses. Even without $\mathrm{CO}_{2}$ capture, $\mathrm{CO}_{2}$ emissions are minimized because gasification plants are more efficient. The future Subtask 1.4 plant has a thermal efficiency to power of $44.5 \%$ (HHV) compared to the $35 \%$ to $37 \%$ thermal efficiencies of conventional coal power plants. Compared to a $36 \%$ efficient conventional power plant, the Subtask 1.4 plant will generate $24 \%$ less $\mathrm{CO}_{2}$ because it consumes $24 \%$ less coal. As gasification technology matures, further efficiency improvements are expected (approaching $50 \%$ on a HHV basis); whereas little, if any, improvement appears likely in conventional combustion power plants.

In the near term, for plants starting up in the 2005-2008 time period, the E-GAS ${ }^{\text {TM }}$ technology has been demonstrated and commercialized. Achievement of the installed cost 
goals through application of the optimization techniques shown in the study should be realized in the first plants built, and they will provide a demonstrated basis for additional projects. Operating cost levels already have been demonstrated to a great extent at Wabash River.

Petroleum coke gasification projects could be the first to enter the marketplace. Several of these have already started development. Wabash River has already demonstrated petroleum coke gasification at a commercial scale. The new plants will demonstrate the integration with petroleum refineries and the necessary reliability required to support refinery operations. New capital cost and operating cost standards will be set. Furthermore, they will support the technology and confirm the economics for the coal fueled IGCC power plants that will follow.

As natural gas and power prices increase and environmental constraints for coal fired generation tighten, coal IGCC should also penetrate the power market. As more coal and coke IGCC plants are built, further improvements can be expected which will lead to additional cost reductions that will make IGCC the preferred option for new base-load power plants.

The gasification plant concepts developed in this study for the Subtask 1.6 1,000 MW coal power plant may be competitive in today's market or in the near future. Other applications will develop as the technology matures. With these tools in hand, the United States can move closer to energy independence based on utilizing our domestic resources of coal and eliminating the export of petroleum coke.

The economics of coal-to-power IGCC facilities may be enhanced by federal and state incentive programs which are aimed at increasing the fuel diversity of our power generation resources. Such programs could speed the wider application of IGCC technologies in new facilities and promote the repowering of older plants. Additional demonstration work may be necessary to convince the financial community of the economic viability of IGCC facilities.

The following developments will be key to the long term commercialization of gasification technologies and integration of this environmentally superior solid fuels technology into the existing mix of power plants.

- Development of the "G/H-class" combustion turbine for syngas applications

- Testing gasifier advancements including slurry feed vaporization in the second stage

- Demonstration of warm gas clean-up technologies (e.g., SCOHS)

- Testing of advanced wet and dry filtration options

- Additional optimization work for the lower rank, sub-bituminous and lignite coals

- Development and implementation of large capacity fuel cells; optimization of the integration of gasification with advanced fuel cell processes

- Develop a lower cost means of producing oxygen such as the ITM ceramic membrane system

- Equipment modifications and revised operating procedures to improve overall plant availability.

- Further advances in Fischer-Tropsch technology or other gas-to-liquids technologies for the production of liquid transportation fuels from coal or coke

- Improved Fischer-Tropsch catalysts that produce a product distribution with less methane and light ends and can operate at high once-through conversions 
- Verification that activated carbon can reduce the residual sulfur in the syngas going to the F-T reactor to a level where it will not be detrimental to catalyst performance

- Development of a design for a balanced IGCC Coproduction power plant that coproduces hydrogen based on the balanced approach developed in this study.

In summary, this study shows the potential of IGCC based systems to be competitive with, if not superior to, conventional combustion power plants because of their higher efficiency, superior environmental performance, and competitive cost. 


\section{Background}

\section{I.1 Introduction}

The Vision 21 concept is the approach being developed by the U. S. Department of Energy (DOE) to promote energy production from fossil fuels in the 21st century. It will integrate advanced concepts for high efficiency power generation and pollution control into a new class of fuel-flexible facilities capable of coproducing electric power, process heat, high value fuels, and chemicals with virtually no emissions of air pollutants. It will be capable of a variety of configurations to meet different marketing needs, including both distributed and central power generation.

Vision 21 includes plans to give integrated gasification combined cycle (IGCC) systems a major role for the continued use of solid fossil fuels. Gasification systems are inherently clean, relatively efficient, and commercially available for converting inexpensive fuels such as coal and petroleum coke into electric power, steam, hydrogen, and chemicals. However, the gasification system also is relatively complex and costly to build and operate. The goal of this study is to improve the profitability of gasification projects by optimizing plant performance, capital cost, and operating costs. The key benefit of doing this methodical cost optimization process off-line is that it removes the schedule constraints associated with project development that tend to inhibit innovation and implementation of new ideas.

Vision 21 will not be a single configuration. It will be a series of interconnected modules. Future designers will integrate these modules to meet specific market needs. A Vision 21 plant might serve as the hub of an industrial complex, providing steam and/or heat in addition to electric power. Another Vision 21 configuration might co-produce high-value chemicals or fuel gases for neighboring manufacturing facilities. Or it might be a power plant-coal refinery combination, producing electricity and liquid transportation fuels.

One of the core technologies in the Department of Energy's Vision 21 program is coal gasification because it produces a gas stream that can be used as a source of

- energy to produce electric power, or

- hydrogen for fuel cells or chemical processes, or

- carbon and hydrogen for making high-value chemicals, or

- carbon and hydrogen for making high-quality liquid transportation fuels, or

- energy as a fuel gas for industrial plants.

In late 1999, the National Energy Technology Laboratory awarded Nexant Inc. (a Bechtel Technology \& Consulting Company) and Global Energy, Inc. (which acquired the gasification related assets of Dynegy Inc., of Houston, Texas including the E-Gas gasification technology, formerly the Destec Gasification Process) a contract to optimize IGCC plant performance. ${ }^{1}$ This contract was divided into three tasks. Task 1 of this contract developed two optimized IGCC plant configurations: (1) petroleum coke gasification for electric power with the coproduction of hydrogen and industrial-grade steam, and (2) coal gasification for electric power generation or hydrogen production. Task 2 developed two different optimized IGCC plant configurations: (1) petroleum coke gasification for electric power with the coproduction of liquid transportation fuel precursors, and (2) coal gasification

\footnotetext{
${ }^{1}$ Contract No. DE-AC26-99FT40342, "Gasification Plant Cost and Performance Optimization”
} 
for electric power with the coproduction of liquid transportation fuel precursors. Task 3 was planned to develop conceptual designs and projected costs for advanced gasification plants including the integration with fuel cells and/or the addition of carbon dioxide control technologies. However, as the project progressed, the scope of Task 1 was expanded, and Task 3 was deleted.

This document is the final technical report for the project. It is in the form of an extended executive summary report for the project. The complete technical details for the project have been reported previously in the Task 1 Topical Report and the Task 2 Topical Report. ${ }^{2,3}$ They are not repeated in this report. By reference, these two reports should be considered part of this final report.

\section{I.2 Contract Overview}

This objectives of this Gasification Plant Cost and Performance Optimization contract was to examine the current state-of-the-art of coal gasification and to develop designs that would reduce the cost of power generated by IGCC plants by reducing their capital and operating costs, increasing their efficiency, and making them less polluting. Cases using a petroleum coke feedstock and coproducing hydrogen and steam also were developed as part of a market entry strategy for lowering the technical risk and the capital and operating costs of future coal gasification plants. A secondary benefit is to provide baseline cases from which the Department of Energy can measure future progress towards achieving their Vision 21 goals.

This contract is divided into two tasks. Task 1 had nine subtasks, and Task 2 had three subtasks. This section briefly describes these two tasks and their subtasks.

The primary objective of Task 1 was to develop optimized engineering designs and costs for five Integrated Gasification Combined Cycle (IGCC) plant configurations fueled by either coal or petroleum coke. Starting from the as-built design, operation, and cost information from the commercially proven Wabash River Coal Gasification Repowering Project, the following eleven cases were developed:

- Wabash River Greenfield Plant (Subtask 1.1)

- Non-optimized Petroleum Coke IGCC Coproduction Plant (Subtask 1.2)

- Optimized Petroleum Coke IGCC Coproduction Plants that produce hydrogen and industrial-grade steam in addition to electric power (Subtasks 1.3 and 1.3 Next Plant - four cases)

- A future Advanced Coal IGCC Power Plant producing only power using a next generation gas turbine (Subtask 1.4)

- Single-train Coal and Coke IGCC Power Plants (Subtask 1.5 - two cases) A Nominal 1,000 MW Coal IGCC Power Plant (Subtask 1.6)

- A Coal to Hydrogen Plant (Subtask 1.7)

\footnotetext{
2 “Topical Report - Task 1 Topical Report, IGCC Plant Cost Optimization," Gasification Plant Cost and Performance Optimization, United Stated Department of Energy, National Energy Technology Laboratory, Contract No. DE-AC2699FT40342, May 2002, http://www.netl.doe.gov/coalpower/gasification/projects/systems/docs/40342R01.PDF.

3 “Topical Report - Task 2 Topical Report, Coke/Coal Gasification With Liquids Coproduction," Gasification Plant Cost and Performance Optimization, United Stated Department of Energy, National Energy Technology Laboratory, Contract No. DE-AC26-99FT40342, August 2003.
} 
The left side of Figure I.1 shows the chronological development of the above Task 1 gasification plant designs.

In addition there were two other subtasks. Subtask 1.8 had the objective to develop a review of various warm gas cleanup methods that are applicable to IGCC systems. The Subtask 1.8 cases covered a variety of processes and provided a look at future syngas cleanup methods. Subtask 1.9 documented the method and results of the availability calculations for the design subtasks.

The results of the Task 1 study have been previously reported in a Topical Report. ${ }^{2}$ Table I.1 summarizes the main results for each of the Task 1 designs. It is presented here to provide an overview of Task 1 and to be used as a reference for the remainder of this report.

Task 2 had the objectives of developing optimized designs, cost estimates and economics for a petroleum coke gasification power plant with liquids fuel precursors coproduction and a coal gasification power plant with liquids fuel precursors coproduction. Based on the results of Task 1 , the following three cases were developed.

- A non-optimized petroleum coke IGCC power plant with liquid fuel precursors coproduction (Subtask 2.1)

- An optimized petroleum coke IGCC power plant with liquid fuel precursors coproduction (Subtask 2.2)

- An optimized coal IGCC power plant with liquid fuel precursors coproduction (Subtask 2.3)

The right side of Figure I.1 shows the chronological development of the three Task 2 subtasks and the Task 1 subtasks on which they are based.

The Subtask 1.3 Next Optimized Petroleum Coke IGCC Coproduction Plant was the basis for the two petroleum coke cases of Subtasks 2.1 and 2.2. The Subtask 1.6 1,000 MW Coal IGCC Power Plant and the Subtask 2.2 Optimized Coke Gasification Power Plant with Liquids Coproduction were the bases for the Subtask 2.3 Optimized Coal Gasification Power Plant with Liquids Coproduction. Building the Task 2 cases on the previous Task 1 cases provides a common basis for comparison between the cases with and without liquid fuel precursors coproduction.

The results of the Task 2 study have been previously reported in a Topical Report. ${ }^{3}$ Table I. 2 summarizes the main results for each of the Task 2 cases and comparable Task 1 cases. It is presented here to provide an overview of these cases and, along with Table I.1, to be used as a reference for the remainder of this report.

This report is the Final Report for the Gasification Plant Cost and Performance Optimization contract. It is intended to be a summary report that briefly describes the primary results of each task and subtask. The details are contained in the Task 1 and Task 2 Topical Reports, and by reference; these two reports should be considered part of this final report.

This report is divided into the following eight chapters. 


\begin{tabular}{|c|c|}
\hline Chapter & Title \\
\hline I & $\overline{\text { Background }}$ \\
\hline II & Methodology \\
\hline III & Task 1 Gasification Plants \\
\hline IV & Task 2 Gasification Coproduction Plants \\
\hline $\mathrm{V}$ & Emissions \\
\hline VI & Financial Results \\
\hline VII & Summary, Conclusions and Recommendations \\
\hline VIII & Acknowledgements \\
\hline
\end{tabular}

Chapter II describes the methodology used in this study.

Chapter III summarizes the Task 1 petroleum coke and coal gasification plants.

Chapter IV summarizes the Task 2 petroleum coke and coal gasification power plants with hydrocarbon liquid fuel precursors coproduction.

Chapter $\mathrm{V}$ summarizes the emissions performance of the Task 1 and Task 2 plants and discusses additions for improvements.

Chapter VI summarizes the results of the financial analyses of the Task 1 and Task 2 designs.

Chapter VII summarizes the work that was done under this contract, lists the major conclusions, and provides recommendations for further investigation.

Chapter VIII acknowledges the contributions of others and of those members of the Bechtel, Global Energy and Nexant who contributed their talents to this project

In addition this report contains one Appendix, Appendix A, which lists the public technical presentation that were generated as a result of this study.

Because this report describes plant designs that are based on proprietary information, some key details are omitted. However, this report contains sufficient information to allow the reader to assess the performance of Global Energy's gasification section design for each subtask. Basic heat and material balance information can be found in the block flow diagrams and the tables. This information was taken from detailed PFD's and heat and material balances developed by the project team for each subtask. Design development included line sizes and marked up P\&IDs for piping takeoffs. This information can be used to check the overall mass, carbon, and energy balances for the gasification plant and the power block, and possibly to adapt these to new cases. However, the project team, particularly Global Energy, would prefer to generate project specific mass and energy balances under a secrecy agreement. Such an agreement will allow Global Energy to provide additional details and to share confidential information. 
Table l.1

Task 1 Coal and Coke Gasification Plant Case Summaries

Case

Description

$\frac{\text { Configuration }}{\text { Plant Location }}$

Number of Air Separation Units

Number of Gas Turbines

Number of Gasification Trains

Number of Gasification Vessels

No of Syngas Processing Train

Number of $50 \% \mathrm{H} 2$ trains

Feedstock Type

Coal or Coke, TPD dry

Feed, MMBtu HHV/hr

Feed, MMBtu LHV/hr

Flux, TPD

Condensate, Mlb/hr

Oxygen, TPD of $\mathrm{O} 2$

$\frac{\text { Design Product Rates }}{\text { Electric Power, MW }}$

Steam $\left(750^{\circ} \mathrm{F} / 700 \mathrm{psig}\right), \mathrm{Mlb} / \mathrm{hr}$

Hydrogen, MMscfd

Sulfur, TPD

Fuel Gas, MMBtu HHV/h

Solid Waste to Disposal, TPD

\section{Gas Turbine}

Fype

Steam Injection, Mlb/hr

Cold Gas Efficiency (HHV), \%

Steam Turbine Power, MW

Internal Power Use, MW

Heat Rate, HHV Btu/kW-hr

Thermal Efficiency, \% HHV

without Sulfur Byproduct

Emissions

$\mathrm{SOx}$ as $\mathrm{SO} 2, \mathrm{lb} / \mathrm{hr}$

$\mathrm{NOx}$ as NO2, lb/h

$\mathrm{CO}, \mathrm{lb} / \mathrm{hr}$

Sulfur Removal, \%

\section{Torformance Parameters}

Gross MW / Ton of Dry Feed

Emissions

$\mathrm{NOx}(\mathrm{NO2})$ as lb/MW-hr

$\mathrm{CO}, \mathrm{lb} / \mathrm{MW}$-hr

O, Ib/MMBtu (HHV)

$\mathrm{CO}$, lb/MW-hr

CO2, lb/MMBtu (HHV)
Design Feed Rates

Coal or Coke, TPD as received

Oxygen, TPD of $95 \%$ O2

Slag (@ 15\% water),TPD

Heat Input, MMBtu/hr LHV

Gross Power Output, MW

Net MW / Ton of Dry Feed

SOx (SO2) as lb/MW-hr

$\mathrm{SOx}(\mathrm{SO} 2)$ as $\mathrm{Ib} / \mathrm{MMBTU}$ (HHV)

$\mathrm{NOx}$ (NO2) as lb/MMBTU (HHV)

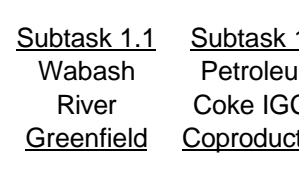

Midwest Gulf Coast Gulf Coast Gulf Coast Gulf Coast Gulf Coast

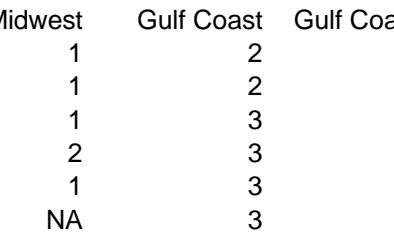

$\begin{array}{rrrr}2 & \text { Gulf Coast } & \text { Gulf Coast } & \text { Gulf Coast } \\ 2 & 2 & 2 & 2 \\ 2 & 2 & 2 & 2 \\ 4 & 2 & 3 & 3 \\ 2 & 2 & 3 & 3 \\ 2 & 2 & 2 & 2 \\ & 2 & 2 & 2\end{array}$
Subtask 1.4 Coal to $\underline{\text { Singl }}$ Subtask $1.5-\frac{\text { Subtask } 1.6}{1,000 \mathrm{MW}}$ Coal Coke Power Plant

Coal to Hydrogen

Midwest Gulf Coast Gulf Coast

Midwest

Midwest $\begin{array}{rrrr}1 & 1 & 1 & 3 \\ 1 & 1 & 1 & 4 \\ 1 & 1 & 1 & 4 \\ 1 & 2 & 2 & 4 \\ 1 & 1 & 1 & 2 \\ \text { NA } & \text { NA } & \text { NA } & \text { NA }\end{array}$

1
2
1

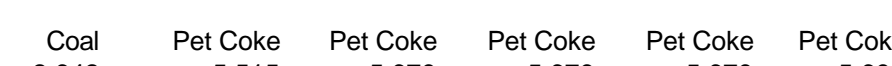

$\begin{array}{rrrrrr}\text { Coal } & \text { Pet Coke } & \text { Pet Coke } & \text { Pet Coke } & \text { Pet Coke } & \text { Pet Coke } \\ 2,642 & 5,515 & 5,679 & 5,679 & 5,679 & 5,692 \\ 2,259 & 5,249 & 5,399 & 5,399 & 5,399 & 5,417 \\ 2,400 & 6,495 & 6,680 & 6,680 & 6,680 & 6,703 \\ 2,310.61 & 6,364 & 6,545 & 6,545 & 6,545 & 6,567 \\ 0 & 107 & 110.2 & 110.2 & 110.2 & 110.6 \\ 2,790 & 4,830 & 5,146 & 5,146 & 5,146 & 5,223 \\ -- & 686 & 686 & 686 & 686 & 686 \\ 2,130 & 5,962 & 5,917 & 5,917 & 5,917 & 5,954 \\ 2,008.69 & 5,622 & 5,580 & 5,580 & 5,580 & 5,615\end{array}$

Coal Coal Pet Coke

$\begin{array}{llr}3,517 & 2,754 & 2,077 \\ 3,007 & 2,355 & 1,977\end{array}$

3,195

3,076

0
3,079

3,079
---
2,294

2,389

2,397
40.3

$2,840 \quad 2,525$

$\begin{array}{lll}2,294 & 2,015 & -\cdots\end{array}$

2,143
2,021

Coal
10,837

10,837
9,266

9,844

9,478

0
9,752

2,457

$8,009 \quad 2,522(99.5 \%)$

\begin{tabular}{|c|c|}
\hline \multirow{2}{*}{\multicolumn{2}{|c|}{$\begin{array}{r}269.3 \\
---\end{array}$}} \\
\hline--- & \\
\hline 57 & \\
\hline & \\
\hline
\end{tabular}

$\begin{array}{rrrrr}395.8 & 460.7 & 460.7 & 460.7 & 474.0 \\ 980.0 & 980.0 & 980.0 & 980.0 & 980.0 \\ 79.4 & 80.0 & 80.0 & 80.0 & 80.0 \\ 367 & 372 & 372 & 372 & 373 \\ 190 & 195 & 195 & 195 & 1 \\ 363 & 0 & 0 & 0 & \end{array}$

$\begin{array}{rrr}416.5 & 284.6 & 291 . \\ --- & --- & - \\ -- & -- & - \\ 77 & 60 & 136 \\ 462 & 364 & 7 \\ --- & -- & - \\ 3.0 & -- & -\end{array}$

$1,154.6$

$-18.4$

-..

1,423

141.2
76

76
474

GE 7FA

411.4
1,675
111.0

GE 7FA GE 7FA+e

$\begin{array}{ll}3,374 & 3,580 \\ 1642 & 429.1\end{array}$

GE 7FA+e GE

A+e GE 7FA+e

-class" GE 7FA+e GE 7FA+e GE 7FA+e

NA

$76.9 \quad 77.4$

429.1

$\begin{array}{rr}984.6 & 1,016.8 \\ 3,580 & 3,592\end{array}$

"G/H-class"

$7+7.0$
447.0

$\begin{array}{rr}426.7 & \text { GE } 7 F A+e \\ 1,741.6\end{array}$

$1,741.6$
7,184
$1,037.8$

$\begin{array}{rrrr}20.1 \text { of N2 } & 246.8 & 272.3 & 1,037.8 \\ 300 & 210 & 210 & 840\end{array}$

76.9

76.9

7.4

77.4

$420 \quad 420$

80.8

78.0

76.5

41

118.8
107

150
109

109

$\begin{array}{rr}150 & 164.3 \\ 109 & 110\end{array}$

164.
48

77.8

77.4

465.2

70.6

89.0

38.3

NA NA

NA

7,67

8,526$$
\text { NA }
$$

49
486.4
96.7

$\begin{array}{rr}306 & 385 \\ 325 & 166 \\ 99 & 88 \\ 1,019 & 1,438 \\ 99.5 & 99.4\end{array}$

$385 \quad 385$

$\begin{array}{rrrrr}99.5 & 1,438 & 88 & 88 & 89 \\ 99.438 & 1,438 & 1,443 \\ & 99.4 & 99.4 & 99.4 & \end{array}$

0.889

0.889
0.137
0.119

$\begin{array}{ll}1.071 & 1.034 \\ 0.096 & 0.1 \\ 0.075 & 0.085\end{array}$

$\begin{array}{lll}1.034 & 1.034 & 1.037\end{array}$

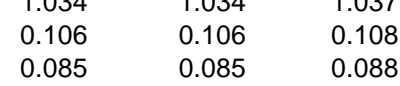

0.15

$\begin{array}{rr}37 & 1 \\ 127 & \\ 42 & \\ 640.4 & 497.1\end{array}$

$\begin{array}{rr}640.4 & 497.1 \\ 99.7 & 98.5\end{array}$

40.0

$\begin{array}{rrrrrr}1.159 & 0.773 & 0.836 & 0.836 & 0.836 & 0.738 \\ 0.130 & 0.047 & 0.058 & 0.058 & 0.058 & 0.052 \\ 0.598 & 0.821 & 0.360 & 0.360 & 0.360 & 0.350 \\ 0.067 & 0.050 & 0.025 & 0.025 & 0.025 & 0.025 \\ 0.182 & 0.250 & 0.191 & 0.191 & 0.191 & 0.1 \\ 0.020 & 0.015 & 0.013 & 0.013 & 0.013 & 0.013 \\ 1,806 & 2,575 & 3,122 & 3,122 & 3,122 & 3,0 \\ 203 & 157 & 215 & 215 & 215 & 215\end{array}$

$\begin{array}{llll}0.089 & 0.499 & 0.409 & 0.379\end{array}$

$0.305 \quad 0.242$

$0.040 \quad 0.028$

$0.101 \quad 0.116$

1,538

1,747

0.049

0.237

0.028
0.117
0.014

0.014

1,716
215

438
275

131
1.981

1,981

191
27

1,840

638.0
98.5

0.834

0.815

Coal or Coke, TPD dry

Power, \% of design

Steam, Ibs/hr

Steam, \% of design

Hydrogen, \% of design

Fuel Gas, MMBtu HHV/hr

Fuel Gas, \% of design

ckup Natur

(Subtasks 1.1 and 1.7 are without Backup Natural Gas)

$\begin{array}{rrrrrr}1,705 & 4,635 & 4,310 & 3,973 & 4,814 & 4,842 \\ 75.5 \% & 88.3 \% & 79.8 \% & 73.6 \% & 89.2 \% & 89.4 \% \\ 203 & 374.3 & 430.0 & 425.4 & 436.4 & 448.4\end{array}$

$\begin{array}{lllll}2,400 & 1,826 & 1,546 & 7,018 & 2,470\end{array}$

$\begin{array}{llrr}79.8 \% & 77.5 \% & 78.2 \% & 75.7 \%\end{array}$

$269.4-75.7 \%$

$93.6 \%$

$82.2 \%$

$93.1 \% \quad 92.9 \%$

$92.5 \%$

116.7

$\begin{array}{rr}-- & 81.3 \% \\ -- & --\end{array}$

$\begin{array}{rrrrr}99.2 \% & 97.8 \% & 96.6 \% & 99.4 \% & 99.4 \% \\ 78.8 & 77.5 & 76.5 & 78.7 & 78.8\end{array}$

$\begin{array}{rrrrr}78.8 & 77.5 & 76.5 & 78.7 & 78.8 \\ 99.2 \% & 97.8 \% & 96.6 \% & 99.4 \% & 99.4 \% \\ 360.1 & 0 & 0 & 0 & 0\end{array}$

$99.2 \%$

20,000

0

9.303

9,059

$+--$

$-$

NA

529.8

lant Cost, MM mid-2000

Plant Cost, \$/design kW

452.6
1,681

$993.2 \quad 764.0$

746.0

$812.6 \quad 787.3$

$\begin{array}{llll}464.7 & 375.0 & 367.0 & 1,231.3\end{array}$

$---$

Required Electricity Selling

Price for a $12 \%$ ROI, $\$ / M W-h r^{2}$

Without Natural Gas Backup

With Natural Gas Backup

67.5

$\begin{array}{rr}-- & --\end{array}$

36.5

$32.5 \quad 30.0$

$\begin{array}{lll}53.9 & 43.9 & 44.4\end{array}$

NA

$\mathrm{NA}=$ Not Applicable

Revised Sept. 22, 2003

1. All costs are mid-year $2000 \mathrm{EPC}$ costs which exclude contingency, taxes, fees and owners costs. They are presented here to show the relative differences between cases.

Current cost estimates should be developed for any proposed applications.

2. Power selling prices are presented to show a relative comparison between cases. The use of natural gas backup is described in Section II.3.2. 
Table I.2

Task 1 and 2 Coal and Coke Gasification Plant Case Summaries

Case
Descriptio

Configuration

Number of Air Separation Units Number of Gas Turbines

ication Trains

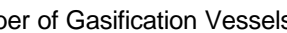

No of Syngas Processing Train

of $50 \%$ H2 trains

Number of F-T Liquid Trains

Design Feed Rates

Coal or Coke, TPD as received

Coal or Coke, TPD dry

Feed, MMBtu HHV/hr

Feed, MMBtu LHV/hr

Flux, TPD

Water, gpm

Oxygen, TPD of $95 \%$ O2

Oxygen, TPD of O2

Design Product Rates

Steam $\left(750^{\circ} \mathrm{F} / 700 \mathrm{psig}\right), \mathrm{Mlb} / \mathrm{hr}$

Hydrogen, MMscfd

Sulfur, TPD

Slag (@ 15\% water), TPD

Fuel Gas, MMBtu HHV/hr

Solid Waste to Disposal, TPD (4)

Liquid Hydrocarbons, bpd

\section{Gas Turbine}

Type

Heat Input, MMBtu/hr LHV

Steam Injection, Mlb/hr

Gross Power Output, MW

Cold Gas Efficiency (HHV), \%

Steam Turbine Power, MW

Internal Power Use, MW

Heat Rate, HHV Btu/kW-hr

Thermal Efficiency, \% HHV (1)

Subtask 1.1
Wabash
River
Greenfield
Midwe

Subtask 1.3 Next Optimized

$\begin{array}{ll}\text { Wabash } & \text { Pet Coke IGCC } \\ \text { River } & \text { Coproduction }\end{array}$ Coproduction
Plant

\begin{tabular}{cc}
\multicolumn{2}{c}{ Subtask 1.5} \\
Single Train Power \\
\hline $1.5 \mathrm{~A}$ & $1.5 \mathrm{~B}$ \\
Coal & Coke \\
Gulf Coast & Gulf Coas \\
1 & \\
1 & \\
1 & \\
2 & \\
1 & \\
0 & \\
0 &
\end{tabular}

Subtask 1.6

$\frac{\text { Subtask } 2.1}{\text { Petroleum }}$

$\frac{\text { Subtask 2.2 Subtask } 2.3}{\text { Optimized }}$

Midwest Gulf Coast

$\begin{array}{ll}1,000 \mathrm{MW} \\ \text { Train Power } & 1.5 \mathrm{~B} \\ \text { Coal IGCC }\end{array}$

Coke Pet Coke

Liquids to Liquids

ke Power Plant

Gulf Coast

Gulf Coast Midwest

$$
3
$$$$
\begin{array}{lll}
2 & 2 & 3 \\
2 & 1 & 2 \\
3 & 3 & 4 \\
3 & 3 & 4 \\
2 & 2 & 2 \\
0 & 0 & 0 \\
1 & 1 & 1
\end{array}
$$

$\begin{array}{rrrrrrrr}\text { Coal } & \text { Pet Coke } & \text { Coal } & \text { Pet Coke } & \text { Coal } & \text { Pet Coke } & \text { Pet Coke } & \text { Coal } \\ 2,642 & 5,692 & 2,754 & 2,077 & 10,837 & 5,649 & 5,684 & 10,837 \\ 2,259 & 5,417 & 2,355 & 1,977 & 9,266 & 5,376 & 5,417 & 9,266 \\ 2,400 & 6,703 & 2,481 & 2,446 & 9,844 & 6,652 & 6,703 & 9,844 \\ 2,311 & 6,567 & 2,389 & 2,397 & 9,478 & 6,518 & 6,567 & 9,478 \\ 0 & 110.6 & 0 & 40.3 & 0 & 109.7 & 110.6 & 0 \\ 2,790 & 5,223 & 2,840 & 2,525 & 9,752 & 6,472 & 5,693 & 7,403 \\ --.- & 686 & --.- & -.- & -. & -. \\ 2,130 & 5,954 & 2,015 & 2,143 & 8,009 & 5,919 & 5,877 & 7,919 \\ 2,009 & 5,615 & 1,900 & 2,021 & 7,553 & 5,582 & 5,542 & 7,468\end{array}$

269.3

$\begin{array}{rrrr}474.0 & 284.6 & 291.3 & 1,154.6 \\ 980.0 & --- & --- & ---\end{array}$

980.0

80.0
373
195

---

617.0

366.9

675.9

57
356

60
364

136
71

237
1,423

371

194

0.95
4,125

373
195

237

1,423

1.31
10,450

2,377

GE 7FA
411.4
1,675
111.0
192

GE 7FA+e GE

GE 7FA+e

GE 7FA+e

GE 7FA+e

$\begin{array}{rrr}7,7.0 & 426.7 & 1,741.6 \\ 1,796 & 1,796 & 7,184\end{array}$

$1,092.8 \quad 1,000.8(5)$

$1,763.3$
0

$1,303.0$
3,532

3,532
510.5

78.3

76.9

77.5

210

78.0

77.5

77.7

118
41

164.3

17.8

121

465.2
151

307.0

274.9

118.8

$\begin{array}{llll}\text { NA } & 8,717 & 8,397 & 8,526\end{array}$

NA

NA

NA
52.6

Emissions

$\mathrm{SOx}$ as $\mathrm{SO} 2, \mathrm{lb} / \mathrm{hr}$

$\mathrm{NOx}$ as NO2, lb/h

$\mathrm{CO}, \mathrm{lb} / \mathrm{hr}$

Sulfur Removal, \%

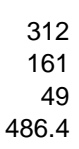

$\begin{array}{rrrr}350 & 142 & 119 & 438 \\ 166 & 69 & 69 & 275 \\ 89 & 33 & 34 & 13 \\ 1,443 & 497.1 & 527.0 & 1,98 \\ 99.4 & 98.5 & 99.4 & 98.9\end{array}$

321
136
66

66
1,279

276
94
37
1,058

329
166
65

1,522
100

Performance Parameters

Tons $02 /$ Ton of Dry Feed

Gross MW/Ton of Di

Emissions

$\mathrm{SOx}$ (SO2) as lb/MW-h

Ib/MMBtu (HHV)

$\mathrm{NOx}$ (NO2) as lb/MW-hr

$\mathrm{NOx}(\mathrm{NO} 2)$ as Ib/MMBtu (HHV)

$\mathrm{CO}, \mathrm{lb} / \mathrm{MW}$ - $\mathrm{h}$

$\mathrm{CO}, \mathrm{lb} / \mathrm{MMBtu}(\mathrm{HHV})$

$\mathrm{CO}, \mathrm{lb} / \mathrm{MW}-\mathrm{hr}$

CO2, lb/MW-hr

0.889
0.137
0.119

$1.037 \quad 0.807$

$\begin{array}{llllll}0.807 & 1.022 & 0.815 & 1.038 & 1.023 & 0.806\end{array}$

$\begin{array}{lllllll}0.108 & 0.137 & 0.168 & 0.141 & 0.135 & 0.088 & 0.088 \\ 0.088 & 0.121 & 0.147 & 0.125 & 0.115 & 0.068 & 0.073\end{array}$

$\begin{array}{llllllll}1.159 & 0.738 & 0.499 & 0.409 & 0.379 & 0.520 & 0.752 & 0.487 \\ 0.130 & 0.052 & 0.057 & 0.049 & 0.044 & 0.048 & 0.041 & 0.033\end{array}$

0.130

0.598

0.067

0.182
0.020

1,806

$\begin{array}{ll}0.4957 & 0.049 \\ 0.242 & 0.237\end{array}$

$\begin{array}{lll}0.242 & 0.237 & 0.238 \\ 0.028 & 0.028 & 0.028\end{array}$

0.117

0.117

$0.028-0.020$

$\begin{array}{ll}0.113 & 0.107 \\ 0.013 & 0.070\end{array}$

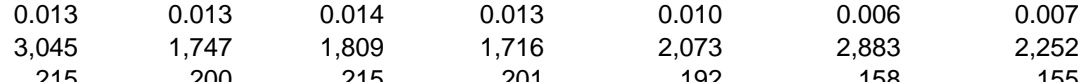

$0.041 \quad 0.033$

$\begin{array}{ll}0.256 & 0.246 \\ 0.014 & 0.017\end{array}$

$\begin{array}{ll}0.014 & 0.017 \\ 0.101 & 0.096\end{array}$

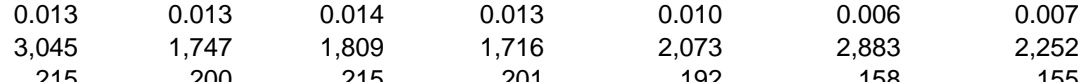

Daily Average Feed/Product Rates with Backup Natural Gas (Subtask 1.1 is without Backup Natural Gas. Subtask 2.2 purchases power.)

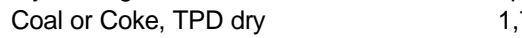

Power, MW

Power, \% of design

Steam, lbs/hr

Steam, \% of design

Hydrogen, $\%$ of design

Fuel Gas, MMBtu HHV/hr

Fuel Gas, \% of design

Natural Gas, Mscfd

Liquid Hydrocarbons, bpd

Liquid Hydrocarbons, \% of design

$4842 \quad 1,826$ Backup Natural Gas

$\begin{array}{rr}4,984 & 6,929 \\ 92.0 \% & 74.8 \%\end{array}$

613.7
$90.8 \%$

$\begin{array}{rrrrrr}89.4 \% & 77.5 \% & 78.2 \% & 75.7 \% & 89.4 \% & 92.0 \% \\ 448.4 & 264.4 & 269.4 & 1,081 & 572.5 & 316.4 \\ 94.6 \% & 92.9 \% & 92.5 \% & 93.6 \% & 92.8 \% & 86.2 \%\end{array}$

$75.5 \%$

$974.6 \quad 92.9 \%$

$99.4 \%$
78.8

$99.4 \%$

$--$

$-$

$\begin{array}{rrrrrrr}---- & -- & -- & -- \\ 9,059 & 6,929 & 6,929 & 34,960 & 8,856 & 0 & 26,466 \\ --- & -- & -- & -- & 3,938 & 9,702 & 10,397 \\ --- & -- & -- & 95.5 \% & 92.8 \% & 84.0 \%\end{array}$

$\begin{array}{rrrrrrr}--- & --- & --- & --- & -- & 0 \\ 9,059 & 6,929 & 6,929 & 34,960 & 8,856 & 0 & 26,466 \\ --- & --- & --- & -- & 3,938 & 9,702 & 10,397 \\ --- & --- & -- & & 95.5 \% & 92.8 \% & 84.0 \%\end{array}$

Plant Cost, MM mid-2000 \$ (2)

Plant Cost, \$/design kW

375.0

$367.0 \quad 1,231.3$

817.9

1159.1

Required Electricity Selling

Price for a 12\% ROI, \$/MW-hr (3)

Without Natural Gas Backup

With Natural Gas Backup

452.6
1,681

NA

67.5

30.0

53.9
48.9

43.9
40.6

44.4

28.8

19.5

48.1
42.0

$\mathrm{NA}=$ Not Applicable

Revised Sept. 22, 2003

1. Without including the sulfur byproduct, but including the F-T liquids, when appropriate

. All costs are mid-year $2000 \mathrm{EPC}$ costs which exclude contingency, taxes, fees and owners costs. They are presented here to show the relative differences between cases. Current cost estimates should be developed for any proposed applications.

. Power selling prices are presented to show a relative comparison between cases. Based on a natural gas price of $\$ 2.60 \$ / M M B t u$

and a liquids price of $30 \$ / b b l$. Subtask 2.2 purchases power at the power selling price rather than natural gas.
. Used COS hydrolysis catalyst, Used ZnO sulfur sorbent, and used F-T catalyst, all on a dry, hydrocarbon free basis. The used activated carbon in

5. Includes $57.8 \mathrm{Mlbhr}$ of steam is added to the turbine fuel to get a net heating value of $147.1 \mathrm{Btu} / \mathrm{scf}$. No additional steam is needed for NOx control. 
Figure I.1

\section{Chronological Development of the Gasification Plant Designs}

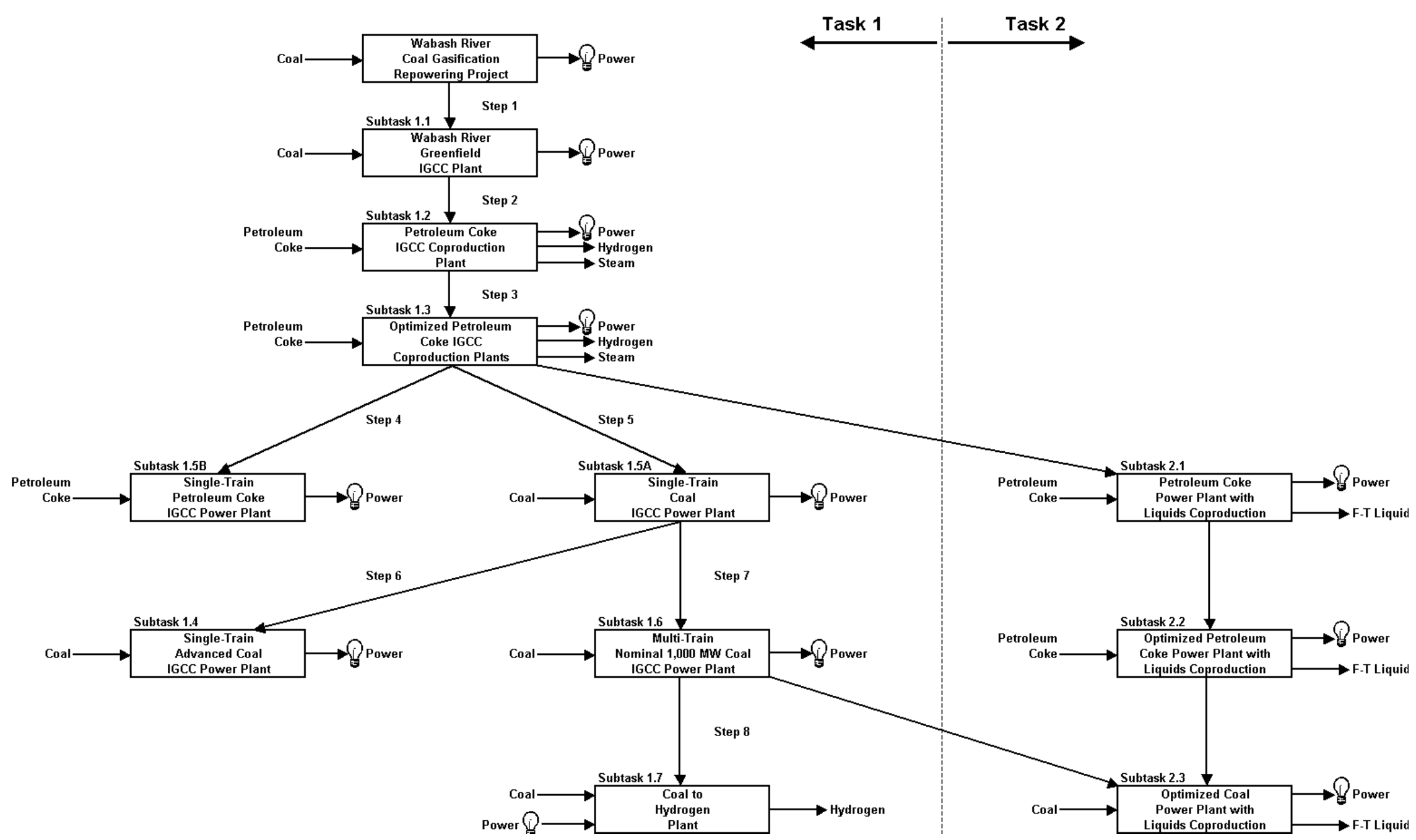




\section{Methodology}

\section{II.1 The Wabash River Repowering Project}

In 1990, Destec Energy, Inc. of Houston, Texas and PSI Energy, Inc. of Plainfield, Indiana formed the Wabash River Coal Gasification Repowering Project Joint Venture to participate in the Department of Energy's Clean Coal Technology Program by demonstrating the coal gasification repowering of an existing 1950's vintage generating unit. In September 1991, the project was selected by the DOE as a Clean Coal Round IV project to demonstrate the integration of the existing PSI steam turbine generator and auxiliaries, a new combustion turbine, a heat recovery steam generator, and a coal gasification facility to achieve improved efficiency and reduced emissions. In July 1992, a Cooperative Agreement was signed with the DOE. Under terms of this agreement, the Wabash River Coal Gasification Repowering Project Joint Venture developed, constructed and operated the coal gasification combined cycle facility. The DOE provided cost-sharing funds for construction and a three-year demonstration period. Construction was started in July 1993, and commercial operation began in November 1995. The demonstration period was completed in January 2000.4

The participants jointly developed, separately designed, constructed, owned, and operated the integrated coal gasification combined-cycle power plant to repower the oldest of the six units at PSI's Wabash River Generating Station in West Terre Haute, IN. The Destec gasification process is integrated with an existing steam turbine generator using some of the pre-existing coal handling facilities, interconnections, and other auxiliaries. The power block consists of an advanced General Electric MS 7001 FA gas turbine unit that produces 192 MW, a Foster Wheeler HRSG, and a 1953 vintage Westinghouse reheat steam turbine. The steam turbine, which was refurbished as part of the repowering project, produces $104 \mathrm{MW}$ of power. Parasitic power is $34 \mathrm{MW}$ giving a net power output of $262 \mathrm{MW}$.

Since the initial startup of the Wabash River Repowering Project, many modifications and improvements have been made to the plant to improve plant performance and to increase availability. The net result of these changes has been a substantial improvement in plant operations. Furthermore, in addition to operation on Illinois coals, the plant has demonstrated successful and reliable operation on petroleum coke.

The design, construction, cost, and operational information obtained from this commercial facility provide the basic information for this project. That is, the sum total of knowledge gained from the plant starting from the initial design through current operations on both coal and petroleum coke have been studied to compile relevant information for this project. Current performance information was analyzed to develop a heat and mass balance model that was the basis for developing models for the subsequent subtasks. As-built cost information provided the cost basis for the cost estimates. Because the cost estimates are based on actual equipment purchases and construction labor use, these cost estimates are more accurate than typical estimates would be for this type of study. Availability and reliability information from the final year of the DOE demonstration period were the basis for the availability analyses.

\footnotetext{
4 Topical Report No. 20, “The Wabash River Coal Gasification Repowering Project - An Update,” U. S. Department of Energy, September 2000.

${ }^{5}$ Global Energy, Inc., “Wabash River Coal Gasification Repowering Project - Final Report,” September 2000.
} 


\section{II.2 Optimization Methodology}

Process Optimization was performed using Value Improving Practices (VIPs) which are focused activities aimed at removing unnecessary investment from a project scope. They have proven to very successful over the years for reducing the cost of facilities, improving their efficiency, conserving raw materials, and being beneficial in many other ways. They generally are implemented in the project development stage when there is time pressure to complete the project, and therefore, only a specific amount of time is allowed for the VIPS procedures. In such situations, the full benefit of the VIPs procedures is not realized. Because of this, there are advantages of doing the VIPs "off-line" where there no time pressure for completion in order to maintain the project schedule. It is in this spirit that the VIPs were applied to Global Energy's IGCC process to develop substantially improved and optimized designs.

Eleven industry standard VIPs were benchmarked by Independent Project Analysis, Inc. (IPA). Eight of these were selected for this project. In addition, a ninth item was added, Plant Layout Optimization. This item encompasses schedule optimization and some aspects of constructability. These nine items are:

1. Technology Selection - A formal, systematic process for finding different production technologies that may be superior to those that are currently employed.

2. Process Simplification - A disciplined analytical method for reducing investment and operating costs by combining or eliminating one or more processing steps.

3. Classes of Plant Quality - Establishment of what quality facility is needed to meet business goals.

4. Value Engineering - Evaluation of alternatives which will allow obtaining the lowest cost facility without sacrificing function, performance, or the ability to carry out a specific mission.

5. Availability (Reliability) Modeling - Use of computer simulation models to quantitatively assess the availability of either all or part of project and to identify major contributors to forced downtime.

6. Design-to-Capacity - Evaluation of the true required maximum capacity of each major piece of equipment relative to the desired overall facility capacity.

7. Plant Layout Optimization - Formalization of the process of developing a plant layout that will satisfy project needs at minimal cost.

8. Schedule (Construction and Procurement) Optimization - A design analysis, usually performed by experienced construction personnel, to save time and reduce costs during the construction period.

9. Operating and Maintenance Savings - Consideration of operating and maintenance costs in the design and construction phases.

The detailed results of the entire VIPs exercise for the Subtask 1.3 and 1.4 IGCC plants are documented in a confidential VIPs report.

\section{II.3 Availability Analysis}

The common measures of financial performance, such as return on investment (ROI), net present value (NPV), and payback period, all are dependent on the project cash flow. The net cash flow is the sum of all project revenues and expenses. Depending upon the detail of the financial analysis, the cash flow streams usually are computed on annual or quarterly 
bases. For most projects, the net cash flow is negative in the early years during construction and only turns positive when the project starts generating revenues by producing saleable products. However, a plant is generating revenue only when it is operating and not when it is shut down for forced outages, scheduled maintenance, or repairs. Therefore, the yearly production (total annual production) is a key parameter in determining the financial performance of a project.

Although the design capacity is the major factor influencing the annual production, other factors including scheduled maintenance, forced outages, equipment reliability, and redundancy influence it. To develop a meaningful financial analysis, an availability analysis that considers all of the above factors must be performed to predict the annual production and annual revenue streams. On this basis, an availability analysis was performed for every case in this study to determine the applicable revenue streams and the ROI.

Appendix $\mathrm{J}$ of the Task 1 Topical Report contains a detailed description of the Task 1 availability analysis studies and their results.

\section{II.3.1 Availability Analysis Basis}

In Table 5.0A of the Final Report for the Wabash River Repowering Project, Global Energy reported downtime and an availability analysis of each plant system for the final year of the Demonstration Period. $^{2}$ During this March 1, 1998 through February 28, 1999 period, the plant was operating on coal for $62.37 \%$ of the time. There were three scheduled outages for $11.67 \%$ of the time (three periods totaling 42 days), and non-scheduled outages accounted for the remaining $25.96 \%$ of the time (95 days). After some adjustments, the EPRI recommended procedure was used to calculate availability estimates for each case. ${ }^{6}$

Recent data presented at the 2002 Gasification Technologies Council conference by Clifton Keeler show further reliability improvements in the on-stream performance of the Wabash River Repowering Project. ${ }^{7}$ However, the following availability and financial analyses are based on the data reported in the final repowering project report. Thus, the following financial analysis is somewhat conservative.

Since the objective of this availability study is to determine the projected annual revenue stream, this study does not differentiate between forced and scheduled outages. In other words, it is immaterial whether the plant is off line because of a forced outage as the result of an equipment malfunction or whether it is off line because of a scheduled outage for normal maintenance or refractory replacement. Consequently, the annual availabilities reported in this study will be lower than those from studies which do not consider scheduled outages.

\section{II.3.2 Use of Natural Gas}

In certain situations, sufficient amounts of syngas may not be available to fully load all available gas turbines. Under these conditions natural gas may used to supplement the

\footnotetext{
${ }^{6}$ Research Report AP-4216, Availability Analysis handbook for Coal gasification and Combustion Turbine-based Power Systems, Research Project 1800-1, Electric Power Research Institute, 3412 Hillview Avenue, Pala Alto, CA 94304, August 1985.

${ }^{7}$ Clifton G. Keeler, Operating Experience at the Wabash River Repowering Project, 2002 Gasification Technologies Council Conference, San Francisco, CA, October 28, 2002.
} 
available syngas to fire the combustion turbine(s) to maximize power production. When this situation occurs, the power output from the turbines is reduced. However, the internal power consumption also is reduced by that of the non-operating units. The net effect of this combination of events is that there is a reduction in export power.

The decision of whether or not to use backup natural gas to supplement power production should be a "real time" decision that considers the relative prices of natural gas and power, expected length of the syngas shortage, power demand, etc.

In addition, all plants use some natural gas during startup, for refractory conditioning, etc. This gas usage is considered to be an O\&M cost and not a feedstock cost.

The Subtask 2.2 Optimized Coke Gasification Power Plant with Liquids Coproduction uses purchased power to maintain Fischer-Tropsch liquids production during periods when the combustion turbine is unavailable.

\section{II.4 Commodity Pricing}

At the start of this project in early 2000, an economic and financial environment for the discounted cash flow evaluations was assumed based on reasonable future projections. This set of economic conditions was used for all the discounted cash flow financial analyses performed in this study. Table II.1 contains a shows most of these economic assumptions. The commodity prices are based on long term projections for the U. S. Gulf Coast (except the coal price which is a Mid-West price). In this price structure, the hydrogen and steam prices were set based on their cost of production from 2.60 \$/MMBtu natural gas. Also, an in-house combined cycle model predicts a required electricity price of about $35 \$ / \mathrm{MW}-\mathrm{hr}$ for a $12 \%$ after tax ROI with natural gas at $2.60 \$ / M M B t u$. The inflation rates generally are based on the Energy Information Administration's Annual Energy Outlook 2001.

However, since the time when these commodity prices were set, the economic scenario has changed. Natural gas prices have spiked to 9-10 \$/MMBtu, dropped to below 3.00 $\$ / \mathrm{MMBtu}$, and now are almost 6.00 $\$ / \mathrm{MMBtu}^{9}{ }^{9}$ Oil prices also have had wide fluctuations over the past few years as a result of the economic slowdown, OPEC actions, and the political situation in the Middle East. Now they are in the 25 to $30 \$ / \mathrm{bbl}$ range. Studies have shown that the F-T liquids can be more valuable than crude oil. The specific amount can range from only $2 \$ / \mathrm{bbl}$ up to $10 \$ / \mathrm{bbl}$ depending upon the refinery configuration, the crude oils being replaced, and the required refinery product mix. ${ }^{10}$

Interest rates in the United States are the lowest that have been in over 40 years. Electricity deregulation is occurring and its effect on the utility market is unknown. The Annual Energy Outlook 2001 shows a current industrial power price of about $40 \$ / \mathrm{kW}$-hr and an average residential power price of about $84 \$ / \mathrm{kW} / \mathrm{hr}$ with the average to all users being about 60 $\$ / \mathrm{kW}$-hr. Furthermore, over the next 20 years the Energy Information Administration predicts a $0.5 \%$ /year decrease in power prices (on a current dollar basis). This study inflated the cost of electricity at $1.7 \%$ /year which is $2.3 \%$ less than the general inflation rate.

\footnotetext{
${ }^{8}$ U. S. Department of Energy, Energy Information Administration, “Annual Energy Outlook 2001 with Projections to 2020", December 2000, www.eia.doe.gov/oiaf/aeo.

${ }^{9}$ Oil and Gas Journal, page 6, Sept 10, 2001, and Houston Chronicle, page 7D, June 15, 2003.

${ }^{10}$ Marano, J. J., Rogers, S., Choi, G. N., and Kramer, S. J., "Product Valuation of Fischer-Tropsch Derived Fuels," ACS National Meeting, Washington, D. C., August 21-6, 1994.
} 
On a constant dollar basis this is a $0.6 \%$ annual decrease. Thus, the economic projections used in the study may be slightly conservative.

Therefore, although this assumed economic and financial environment was reasonable when it was proposed, it should not be used to evaluate proposed projects. Each project should be evaluated using a project specific economic scenario that is appropriate for its situation.

\section{Table II.1 \\ Basic Economic Parameters}

\begin{tabular}{l}
$\frac{\text { Feeds }}{\text { Petroleum Coke, \$/ton }}$ \\
Coal \\
Flux, \$/ton \\
Natural Gas, HHV \\
Products \\
\hline Electric Power \\
Hydrogen \\
Fischer-Tropsch Liquids \\
Steam \\
Fuel Gas \\
Sulfur \\
Slag
\end{tabular}

Other Financial Parameters

General Inflation
Loan Amount
Loan Interest Rate
Loan Financing Fee
Owner's Contingency
Development Fee
Start-up Cost
Income Tax Rate

$\begin{array}{cc}\frac{\text { Price }}{0 \text { \$/ton }} & \text { Inflation, } \% / y r \\ 22.0 \text { \$/ton } & 0 \\ 5.0 \text { \$/ton } & 1.2 \\ 2.6 \text { \$/MMBtu } & 1.7 \\ & 3.9\end{array}$

Calculated*

1.7

1.3 \$/Mscf $\quad 3.1$

$30 \$ / \mathrm{bbl} \quad 3.1$

$5.6 \$$ tom $\quad 3.1$

$2.6 \$$ MMBtu $\quad 3.9$

$30.0 \$ /$ ton $\quad 0$

$0 \$$ ton $\quad 0$

* Electric power prices are calculated to yield a given return on investment. They are reported on a current day cost; i.e., the cost at the time when construction begins. 


\section{$\underline{\text { II.5 Financial Analysis }}$}

For all cases a financial analysis was performed using a discounted cash flow (DCF) model that was developed by Bechtel Technology and Consulting (now Nexant Inc.) for the DOE as part of the Integrated Gasification Combined Cycle (IGCC) Economic and Capital Budgeting Practices Task. ${ }^{11}$ This model calculates investment decision criteria, such as net present value (NPV) and return on investment (ROI), used by industrial end-users and project developers to evaluate the economic feasibility of IGCC projects.

In using this model, items that were excluded is the cost estimate, such as spares, owners cost, contingency and risk were included. Furthermore, since the cost estimates developed in this study are "overnight" cost estimates, the EPC spending pattern was adjusted to reflect forward escalation during construction.

\footnotetext{
${ }^{11}$ Nexant, Inc., "Financial Model User's Guide - IGCC Economic and Capital Budgeting Evaluation”, Report for the U. S. Department of Energy, Contract DE-AMO1-98FE64778, May 2000.
} 


\section{Task 1 Gasification Plants}

Task 1 has nine subtasks. Subtasks 1 through 7 developed non-optimized and optimized plant design for various coal and petroleum coke IGCC power and coproduction plants. The eleven plant designs developed in these subtasks are summarized in Table I.1. This section briefly describes and reviews each of these plant designs in numerical subtask order.

Subtask 1.8, Warm Gas Cleanup Review, reviewed syngas cleanup systems that operate at elevated temperatures that have the potential for reducing the cost of IGCC plants. The Selective Catalytic Oxidation of Hydrogen Sulfide (SCOHS) system, which is being developed by DOE/NETL has the potential to be a simple low cost process for IGCC plants. Appendix I of the Task 1 Topical Report contains the complete Subtask 1.8 Warm Gas Cleanup Review Report.

Subtask 1.9 documented the availability analysis procedures that were used in this study to calculate the average daily feed and product rates which were used in the financial analysis. Appendix $\mathrm{J}$ of the Task 1 Topical Report contains the complete Subtask 1.9 Availability Analysis Report.

\section{III.1 Wabash River Greenfield Plant}

The Subtask 1.1 Wabash River Greenfield Plant replicates the as-built Wabash River facility that was developed during the Wabash River Repowering Project and as was subsequently modified on a greenfield site. The primary objective for developing this plant design was to develop an accurate and documented cost basis starting from the actual Wabash River costs to use for the subsequent plant designs. In developing this case, new equipment was incorporated to replace the 1953 Westinghouse steam turbine, coal handling equipment, condensed and circulating water systems, and offsites. First-off-a-kind and project specific construction costs, such as site specific costs, were excluded.

The Subtask 1.1 Wabash River Greenfield Plant processes 2,259 tpd of dry Illinois No. 6 coal to make $269.3 \mathrm{MW}$ of export power, $57 \mathrm{tpd}$ of sulfur, and $356 \mathrm{tpd}$ of slag. The General Electric 7FA gas turbine produces $192 \mathrm{MW}$ of power, and the newer, more efficient steam turbine generates $118 \mathrm{MW}$. The plant consumes $40.7 \mathrm{MW}$ of power internally leaving 269.3 MW available for export. The plant has a heat rate of $8,912 \mathrm{Btu}(\mathrm{HHV}) / \mathrm{kW}-\mathrm{hr}$, or a $38.3 \%$ $\mathrm{HHV}$ thermal efficiency when the byproduct sulfur is not considered. As configured at the start of this study including all revisions and modifications that were made to improve performance, the plant would have an EPC cost of 452.6 MM mid-2000 dollars (or 1,681 $\$ / \mathrm{kW}){ }^{12}$ Figure III.1 is a simplified block train diagram of the Subtask 1.1 plant. ${ }^{13}$ Appendix A of the Task 1 Topical Report contains a detailed description of the Subtask 1.1 Wabash River Greenfield Plant. ${ }^{2}$

\footnotetext{
${ }^{12}$ All reported costs are mid-year 2000 “overnight" EPC costs which exclude contingency, taxes, licensing fees, and owners costs (such as land, operating and maintenance equipment, capital spares, operator training and commercial test runs. These excluded items are included in the subsequent discounted cash flow analysis. They are presented here to show the relative differences between cases. Current cost estimates should be developed for any proposed application.

${ }^{13}$ To facilitate comparison among the block train diagrams of the various plant designs developed in this and the subsequent subtasks, all the block train diagrams are grouped together at the end of this section.
} 
When this study was started, the Wabash River facility was not configured to use backup natural gas to fire the gas turbine when syngas was unavailable. However, the plant was modified to use backup natural gas during the summer of 2001.

\section{III.2 Petroleum Coke IGCC Coproduction Plant}

The Subtask 1.2 [Non-optimized] Petroleum Coke IGCC Coproduction Plant was developed from the Subtask 1.1 plant by making several changes that included:

- Changing the feedstock to petroleum coke

- Moving the plant location to be adjacent to a petroleum refinery on the U.S. Gulf Coast

- Enlarging the plant capacity to process about 5,400 tpd of dry coke in gasification two trains

- Adding coproduction of about $80 \mathrm{MMscfd}$ of hydrogen

- Adding coproduction of $980,000 \mathrm{lb} / \mathrm{hr}$ of $750^{\circ} \mathrm{F} / 700 \mathrm{psig}$ steam to the refinery

- Adding a spare gasification train to maintain hydrogen and steam reliability

- Adding the ability to use backup natural gas to maintain power reliability

- Using the refinery's fresh water intake system and waste water outfall systems

The Subtask 1.2 plant is an enlarged, three-train, non-optimized modification of the Subtask 1.1 Wabash River Greenfield Plant to process petroleum coke at a Gulf Coast location with the addition of the hydrogen and steam generation facilities. Gasifier performance was based on Wabash River experience with petroleum coke. This design was developed with three gasification trains (two operating and one spare) feeding two parallel General Electric 7FA combustion turbines. Figure III.2 is a simplified block train diagram of the Subtask 1.2 plant. These gas turbines are the same model as the one that is installed at Wabash River. In the event of an outage of one gasification train, the spare train can be put on-line to provide the design hydrogen and steam rates to the refinery without sacrificing export power production. The low Btu PSA tail (sweep) gas is sent to the refinery for fuel gas. From 5,249 tpd of dry petroleum coke and 107 tpd of flux, the Subtask 1.2 Petroleum Coke IGCC Coproduction Plant produces 79.4 MMscfd of $99 \%$ hydrogen, $980,000 \mathrm{Ib} / \mathrm{hr}$ of $750^{\circ} \mathrm{F} / 700$ psig steam, $363 \mathrm{MMBtu} / \mathrm{hr}(\mathrm{HHV})$ of fuel gas, $367 \mathrm{tpd}$ of sulfur, and $190 \mathrm{tpd}$ of slag $(15 \%$ water), and $395.8 \mathrm{MW}$ of export power. Condensate, amounting to about $70 \%$ of the exported steam, is returned from the refinery to the gasification plant. The Subtask 1.2 plant would be expected to cost about $999.2 \mathrm{MM}$ mid-2000 dollars. ${ }^{12}$ It is described in detail in Appendix B of the Task 1 Topical Report. ${ }^{2}$

\section{III.3 Optimized Petroleum Coke IGCC Coproduction Plant}

The Subtask 1.3 Optimized Petroleum Coke IGCC Coproduction Plant was developed from the Subtask 1.2 plant by making numerous changes as the result of the VIPs exercise. The major improvements that were made include:

- Replacement of the GE 7FA combustion turbines with the newer GE 7FA+e model which has a larger capacity (210 MW vs. $192 \mathrm{MW}$ ), higher thermal efficiency, and lower NOx and $\mathrm{CO}$ emissions

- Utilization of the low Btu PSA tail gas to make high-pressure steam for power production rather than exporting it to the refinery

- Removal of the post reactor residence vessel 
- Cleaning the syngas with hot gas cyclones followed by wet scrubbing rather than a using a dry char filter system similar to that a the Wabash River facility.

- Modifying the gasifier for full slurry quench operation from the recycle gas quench mode

- Removing replicated equipment unless economically justified

- Replacing the on-site coke storage silos with dome storage

- Increasing the main steam and reheat steam temperatures for increased steam turbine efficiency

- Redesigning the hydrogen plant to be more efficient with improved heat recovery.

From 5,399 tpd dry of petroleum coke and 110 tpd of flux, a Subtask 1.3 plant produces $80.0 \mathrm{MMscfd}$ of $99 \%$ hydrogen, $980,000 \mathrm{lb} / \mathrm{hr}$ of $750^{\circ} \mathrm{F} / 700 \mathrm{psig}$ steam, $372 \mathrm{tpd}$ of sulfur, $195 \mathrm{tpd}$ of slag (15\% water), and $460.7 \mathrm{MW}$ of export power.

Three variations of the Subtask 1.3 plant were developed with the differences in the designs being the amount of replication in the gasification block. These cases are

1. Subtask 1.3 Base Case which contains two gasification trains with each gasification train containing a spare gasification reactor vessel. A shutdown is required to switch gasification vessels. This is the same configuration as the Wabash River facility. This plant was expected to cost $764.0 \mathrm{MM}$ mid-2000 dollars. ${ }^{12}$

2. Subtask 1.3 Minimum Cost Case which removed the spare gasification vessels This plant was expected to cost $746.0 \mathrm{MM}$ mid-2000 dollars. ${ }^{12}$

3. Subtask 1.3 Spare Gasification Train Case which added a complete spare gasification train (from the slurry feed pumps through the wet scrubber) to the Subtask 1.3 Minimum Cost Case. This plant was expected to cost $812.6 \mathrm{MM}$ mid2000 dollars. $^{12}$

The purpose of developing and documenting these three design cases was to determine the effect of replicated equipment on availability and its cost benefit. Figure III.3 contains simplified block train diagrams of the three Subtask 1.3 plants. The Subtask 1.3 Spare Gasification Train Case had the highest return on investment. Appendix C of the Task 1 Topical Report describes these three Subtask 1.3 designs in more detail. ${ }^{2}$

\section{III.4 Next Optimized Petroleum Coke IGCC Coproduction Plant}

The Subtask 1.3 Next Plant was developed from the Subtask 1.3 Spare Gasification Train Case by changing the system for particulate removal from the syngas to a dry system from the previous dry/wet system. This completely dry system is a two-step process; first a cyclone removes over $90 \%$ of the solids and then dry char filters remove the remainder. This is a cheaper system that should have a higher availability than the cyclone/wet scrubber system. In this system, dry (rather than wet char) char is recycled to the gasifier which results in a more efficient system that, in addition, should have a higher availability. Furthermore, this design eliminates the need of a wet scrubber column in each gasification train allowing the use of only two wet scrubber columns. Figure III.4 is a simplified block train diagram of the Subtask 1.3 Next Plant.

From 5,417 tpd of dry petroleum coke and 111 tpd of flux, the Subtask 1.3 Next Plant produces $80.0 \mathrm{MMscfd}$ of $99 \%$ hydrogen, $980,000 \mathrm{lb} / \mathrm{hr}$ of $750^{\circ} \mathrm{F} / 700 \mathrm{psig}$ steam, $373 \mathrm{tpd}$ of sulfur, 195 tpd of slag (15\% water), and $474 \mathrm{MW}$ of export power. It has an expected EPC 
cost of about 999.2 MM mid-2000 dollars. ${ }^{12}$ Appendix D of the Task 1 Topical Report describes the Subtask 1.3 Next Plant is more detail. ${ }^{2}$

\section{III.5 Advanced Coal IGCC Power Plant}

The Subtask 1.4 Advanced Coal IGCC Power Plant was developed after the Subtask 1.3 plants, but before the Subtask 1.3 Next Plant. The plant will be situated at a generic Midwest location. It includes most of the design improvements of the Subtask 1.3 plants plus some others that were developed during the VIPs sessions that are applicable only to coal. Furthermore, since this plant is expected to be implemented around 2010, it includes some features that still are in the development stage and require additional testing. Such items included:

- Removal of the slurry feed heaters

- Redesigned the gasifier for higher pressure operation

- Utilization of slurry feed vaporization in the second stage of the gasifier

- Improved burner design

- Application of a cyclone and an advanced dry char filter system to remove particulates from the syngas

- Utilization of a state-of-the-art "G/H class" advanced gas turbine

- Utilization of full air/nitrogen integration between the air separation unit and the gas turbine to balance the flows in the turbine

- Adding a zero process water discharge system.

From 3,007 tpd of dry Illinois No. 6 coal, the Subtask 1.4 Advanced Optimized Coal IGCC Power Plant produces $416.5 \mathrm{MW}$ of export power and $77 \mathrm{tpd}$ of sulfur. The plant has a heat rate of $7,617 \mathrm{Btu}(\mathrm{HHV}) / \mathrm{kW}-\mathrm{hr}$, or a $44.5 \% \mathrm{HHV}$ thermal efficiency when the byproduct sulfur is not considered. It has an expected EPC cost of about $464.7 \mathrm{MM}$ mid-2000 dollars (or $1,116 \$ / \mathrm{kW}$ ).12 Figure III.5 is a simplified block train diagram of the Subtask 1.4 plant. Appendix $\mathrm{E}$ of the Task 1 Topical Report describes the Subtask 1.4 plant is more detail. ${ }^{2}$

\section{III.6 Single Train Coal and Coke IGCC Power Plants}

The Subtask 1.5A Single Train Coal IGCC Power Plant and the Subtask 1.5B Single Train Coke Power Plant were developed from the Subtask 1.3 Base Case to highlight the similarities and differences between them and to develop the EPC cost of a single train IGCC power plant using the best available current technology. Both plants are located on the U.S. Gulf Coast.

The coal and coke IGCC power plants have very similar designs except for the following differences that are a result of either the difference in feedstock properties or a result of the coke plant utilizing some of the refinery facilities.

- The coal plant requires feed handling and storage facilities which are not needed in the coke plant because the adjacent refinery delivers coke by conveyor directly to the active coke storage pile.

- The coal plant includes river water intake facilities whereas the coke plant uses those of the adjacent refinery.

- The coal plant includes a waste water outfall system whereas the coke plant uses the adjacent refinery's outfall system. 
- The post reactor residence vessel has been eliminated in the coke plant.

- The coke plant requires the use of flux and has additional flux receiving, storage and delivery facilities.

- The coal plant produces more slag, and consequently, has larger slag handling facilities.

- The sulfur removal and sulfur recovery facilities are larger for the coke plant because the sulfur content of the coke is higher than that of the coal.

- The water discharge rate from the syngas scrubbing column is larger for the coal plant because the chloride content of the coal is higher than that of the coke.

- The gasification area of the coal plant requires more intermediate pressure steam than it produces, and consequently, some is withdrawn from the combined cycle section for use in the gasification area. However, the gasification area of the coke plant produces excess intermediate pressure steam which is sent to the combined cycle section for power production.

Figure III.6 contains a simplified block train diagram of either the Subtask $1.5 \mathrm{~A}$ coal or Subtask 1.5B coke single-train IGCC power plant.

From 2,355 tpd of dry Illinois No. 6 coal, the Subtask 1.5A Single Train Coal IGCC Power Plant produces $284.6 \mathrm{MW}$ of export power, $60 \mathrm{tpd}$ of sulfur, and $364 \mathrm{tpd}$ of slag (15\% water). The plant has a heat rate of $8,717 \mathrm{Btu}(\mathrm{HHV}) / \mathrm{kW}$-hr, or a $39.1 \% \mathrm{HHV}$ thermal efficiency when the byproduct sulfur is not considered. It has an expected EPC cost of about $375 \mathrm{MM}$ mid-2000 dollars (or $1,318 \$ / \mathrm{kW}$ ). ${ }^{12}$

From 1,977 tpd of delayed petroleum coke and 40 tpd of flux, the Subtask 1.5B Single Train Petroleum Coke IGCC Power Plant produces 291.3 MW of export power, 166 tpd of sulfur, and $71 \mathrm{tpd}$ of slag (15\% water). The plant has a heat rate of $8,397 \mathrm{Btu}(\mathrm{HHV}) / \mathrm{kW}-\mathrm{hr}$, or a $40.6 \% \mathrm{HHV}$ thermal efficiency when the byproduct sulfur is not considered. It has an expected EPC cost of about $367 \mathrm{MM}$ mid-2000 dollars (or 1,260 \$/kW). ${ }^{12}$

Appendix F of the Task 1 Topical Report describes the Subtask 1.5 Plants in more detail. ${ }^{2}$

\section{III.7 Nominal 1,000 MW Coal IGCC Power Plant}

The Subtask 1.6 Nominal 1,000 MW Coal IGCC Power Plant was developed from the Subtask 1.3 Next Plant to provide a current day design and cost estimate for a multi-train coal power plant. The plant is located at a generic Midwest location. Modifications were made, as required to make this a stand-alone facility. The Subtask 1.6 plant contains three air separation units, two slurry preparation trains, four gasification trains, two syngas cleanup trains, two sulfur recovery plants, four combustion turbines and associated HRSGs, and two steam turbines. Figure III.7 contains a simplified block train diagram of the Subtask 1.6 Nominal 1,000 MW Coal IGCC Power Plant.

From 9,844 tpd of dry Illinois No. 6 coal, the Subtask 1.6 Nominal 1,000 MW Coal IGCC Power Plant produces 1,154.6 MW of export power, 237 tpd of sulfur, and 1,423 tpd of slag (15\% water). The plant has a heat rate of $8,526 \mathrm{Btu}(\mathrm{HHV}) / \mathrm{kW}-\mathrm{hr}$, or a $40.0 \% \mathrm{HHV}$ thermal efficiency when the byproduct sulfur is not considered. It has an expected EPC cost of about 1,231 MM mid-2000 dollars (or 1,066 \$/kW). ${ }^{12}$

Appendix G of the Task 1 Topical Report describes the Subtask 1.6 Plant in more detail. ${ }^{2}$ 


\section{III.8 Coal to Hydrogen Plant}

The Subtask 1.6 Coal to Hydrogen Plant was developed to obtain a design and EPC cost estimate for an IGCC coal to hydrogen plant, which incorporates the VIPs results from Subtasks 1.4 and 1.4, where appropriate, at the same coal capacity as Subtask 1.4. The plant is located at a generic Midwest location.

The gasifier is Global Energy's two-stage gasifier which employs full slurry quench to control the second stage outlet temperature. The full slurry quench gasifier design of Subtask 1.3 was selected to maximize the hydrogen and $\mathrm{CO}$ (for subsequent conversion to hydrogen) production and minimize the methane make. The plant contains a spare gasifier vessel that can be placed in service to minimize the downtime whenever refractory replacement is required. Particulates are removed from the syngas in a two-step system. First, a hot cyclone removes over $90 \%$ of the particulates, and the remainder is removed by an advanced dry char filtration system.

A Rectisol system is used for acid gas removal from the syngas because it provides better sulfur removal than an amine system so that a "sweet" shift process can be used to produce hydrogen from the $\mathrm{CO}$. The "sweet" $\mathrm{CO}$ shift system allows higher $\mathrm{CO}$ conversions than the "sour" shift process. Secondly, the Rectisol system also can be used to remove the bulk of the $\mathrm{CO}_{2}$ from the shifted syngas for possible sale or sequestration, and it allows the downstream PSA unit to produce a $99.0 \%$ pure hydrogen stream containing only trace amounts of unconverted CO. However, a Rectisol system is more expensive and auxiliary power intensive than the amine systems that are used for the other subtasks.

The hydrogen production area consists of two parallel trains. Each train contains three CO shift reactors in series with cooling between them. The first two reactors are high temperature shift reactors that are sized to control the maximum outlet temperature. The third reactor is a low temperature reactor for maximum conversion. CO conversion is over $99 \%$. After the bulk of the $\mathrm{CO}_{2}$ has been removed by the second stage of the Rectisol unit, two parallel PSA units purify the hydrogen. Hydrogen recovery from the shifted syngas is $90 \%$ to the $99.0 \%$ pure hydrogen product. PSA sweep (off) gas is used to generate steam for power production in the steam turbine. Figure III.8 contains a simplified block train diagram of the Subtask 1.7 Coal to Hydrogen Plant.

From 3,007 tpd of dry Illinois No. 6 coal and 18.4 MW of import power, the Subtask 1.7 Coal to Hydrogen Plant produces 141.2 MMscfd of hydrogen, 76 tpd of sulfur and 474 tpd of slag (15\% water). The plant has an expected EPC cost of $530 \mathrm{MM}$ mid-2000 dollars. ${ }^{12}$ Appendix $\mathrm{H}$ of the Task 1 Topical Report describes the Subtask 1.7 plant in detail. $^{2}$ 
Figure III.1

\section{Subtask 1.1 Wabash River Greenfield Plant}

\section{Simplified Block Train Diagram}

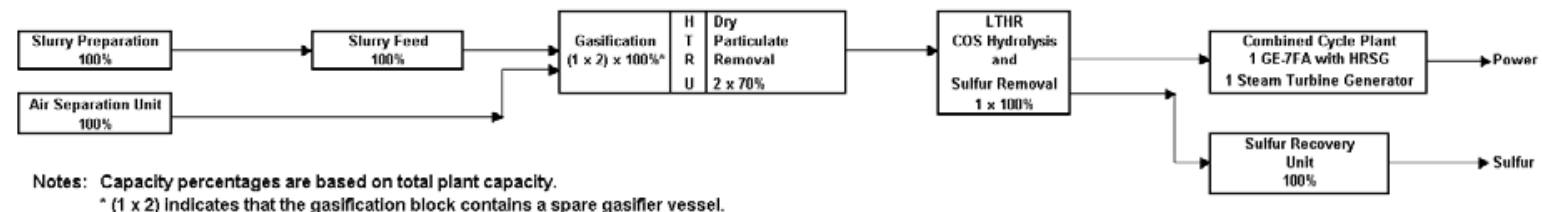

Figure III.2

Subtask 1.2 Petroleum Coke IGCC Coporoduction Plant

Simplified Block Train Diagram

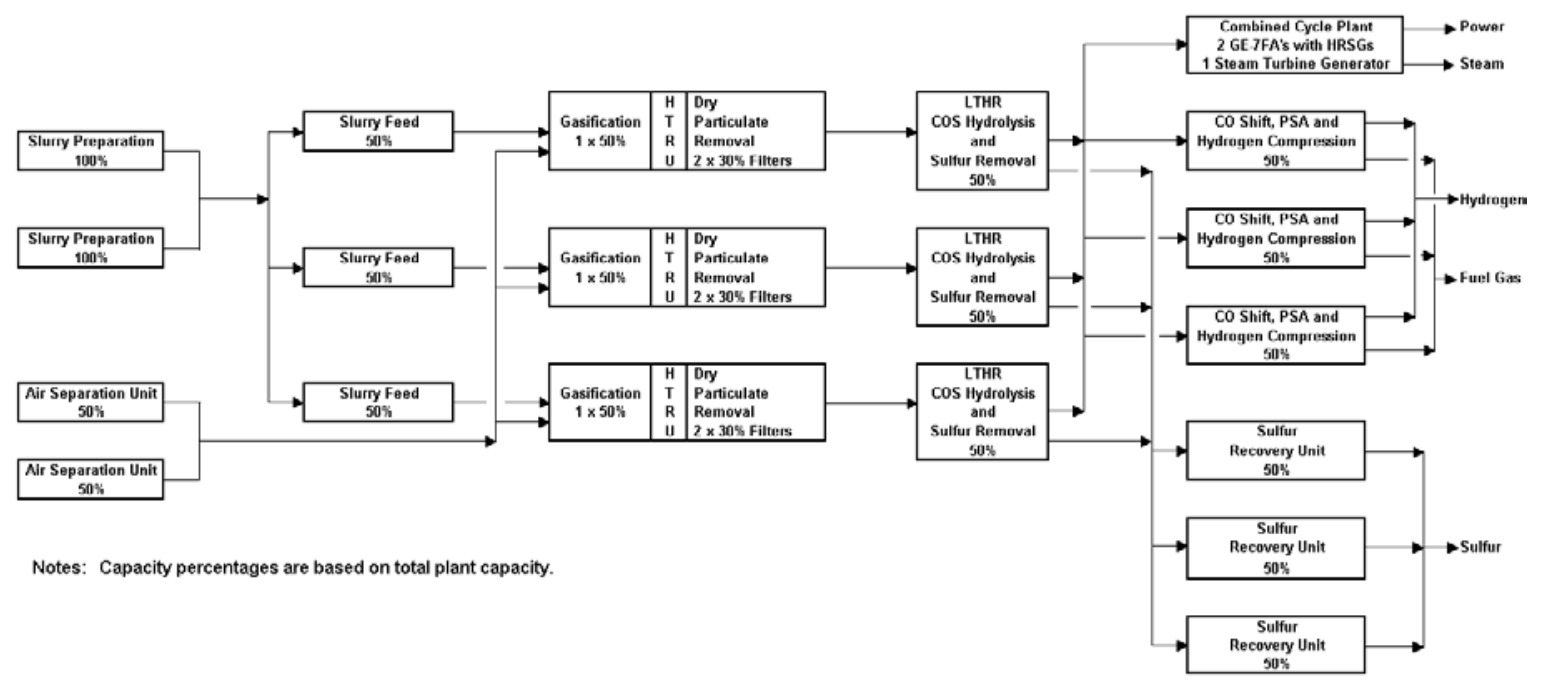

Figure III.3A

\section{Simplified Block Train Diagram}

\section{Subtask 1.3 Optimized Petroleum Coke IGCC Coporoduction Plant - Base Case}

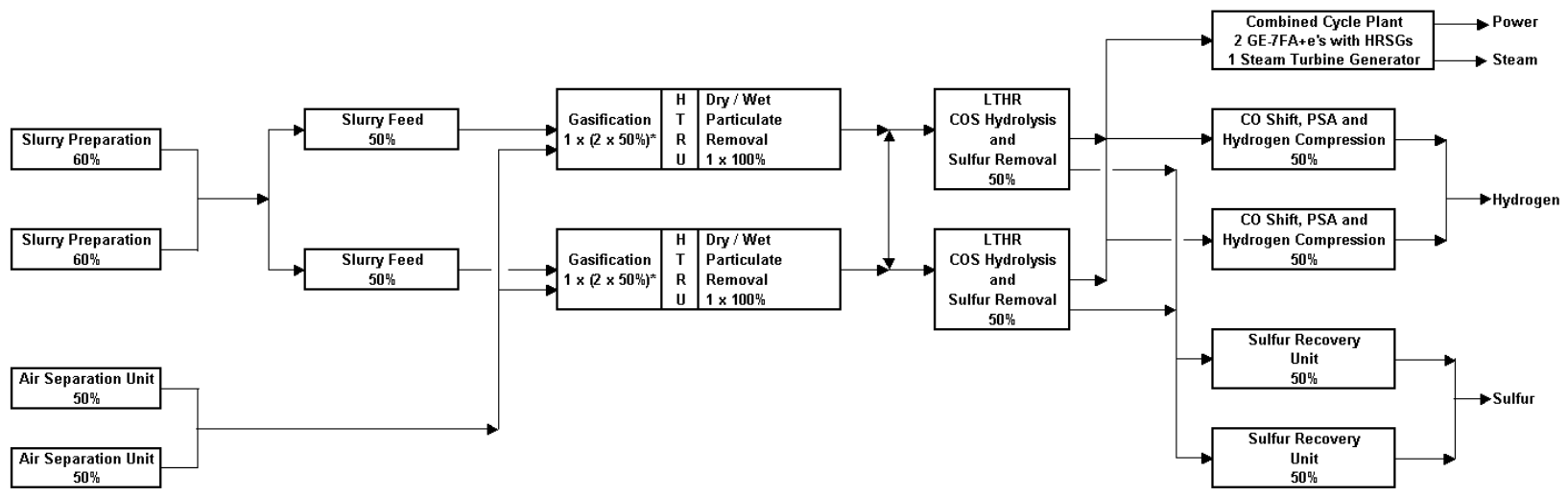

Notes: Capacity percentages are based on total plant capacity.

${ }^{*}(1 \times 2)$ indicates that the gasification block contains a spare gasifier vessel. 
Figure III.3B

Subtask 1.3 Optimized Petroleum Coke IGCC Coporoduction Plant - Minimum Cost Case Simplified Block Train Diagram

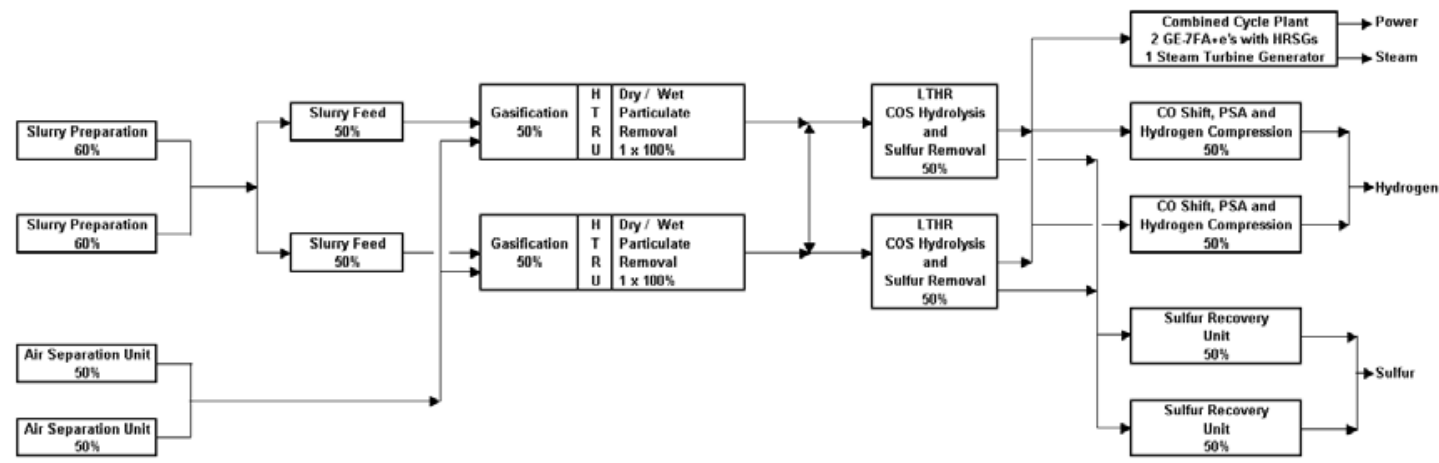

Notes: Capacity percentages are based on total plant capacity.

Figure III.3C

Subtask 1.3 Optimized Petroleum Coke IGCC Coporoduction Plant - Spare Train Case Simplified Block Train Diagram

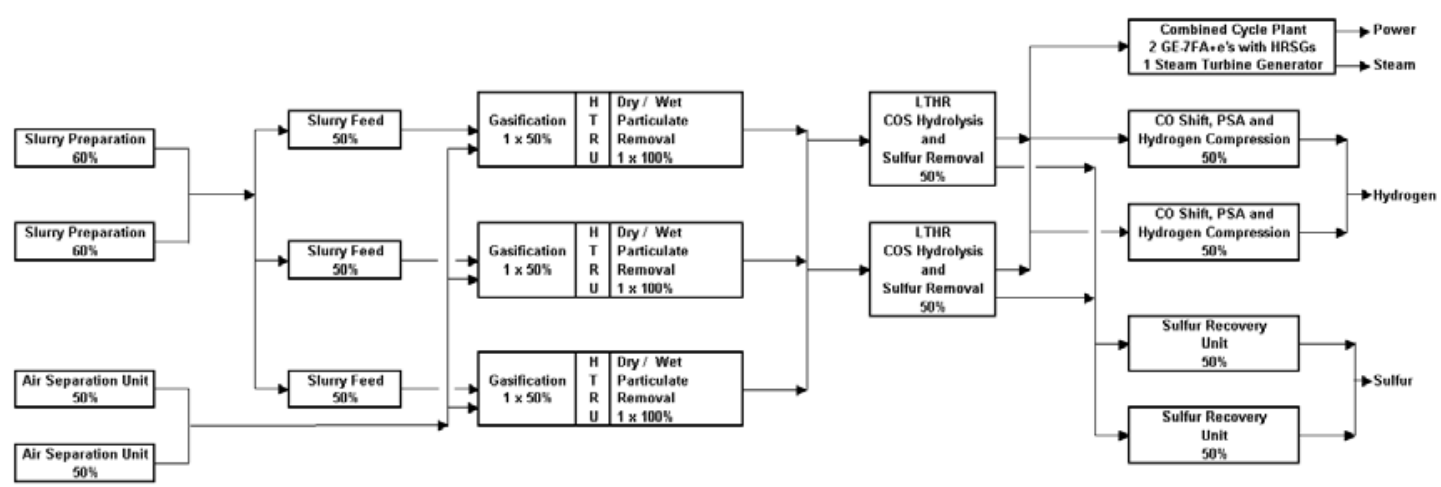

Notes: Capacity percentages are based on total plant capacity.

Figure III.4

Subtask 1.3 Next Optimized Petroleum Coke IGCC Coproduction Plant Simplified Block Train Diagram

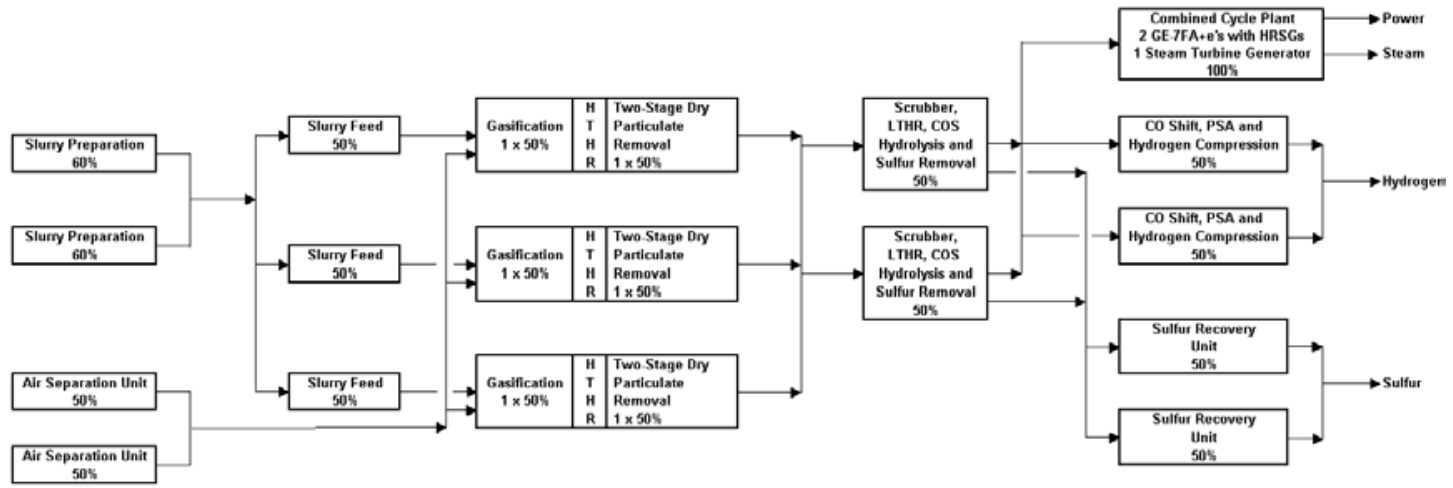

Notes: Capacity percentages are based on total plant capacity. 
Figure III.5

Subtask 1.4 Advanced Coal IGCC Power Plant Simplified Block Train Diagram

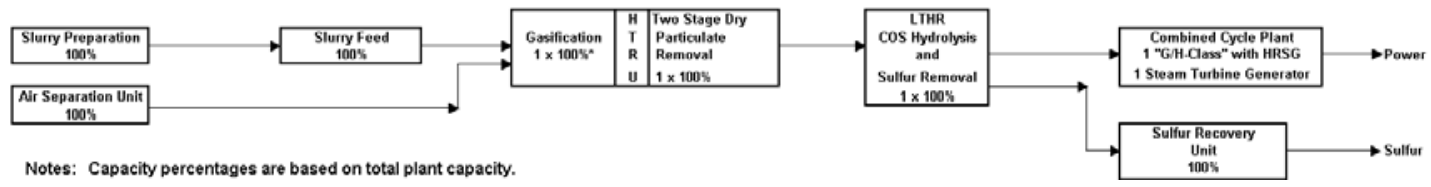

Figure III.6

Subtask 1.5 Single-Train Coal or Coke IGCC Power Plant

Simplified Block Train Diagram

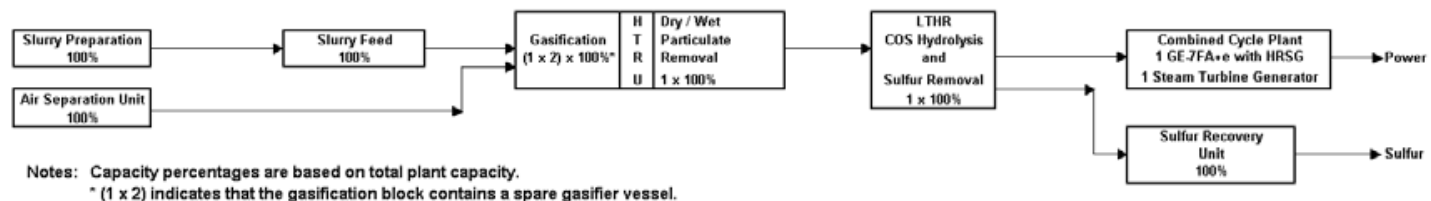

$(1 \times 2)$ indicates that the gasification block contains a spare gasifier vessel.

Figure III.7

Subtask 1.6 Nominal 1,000 MW Coal IGCC Power Plant

Simplified Block Train Diagram

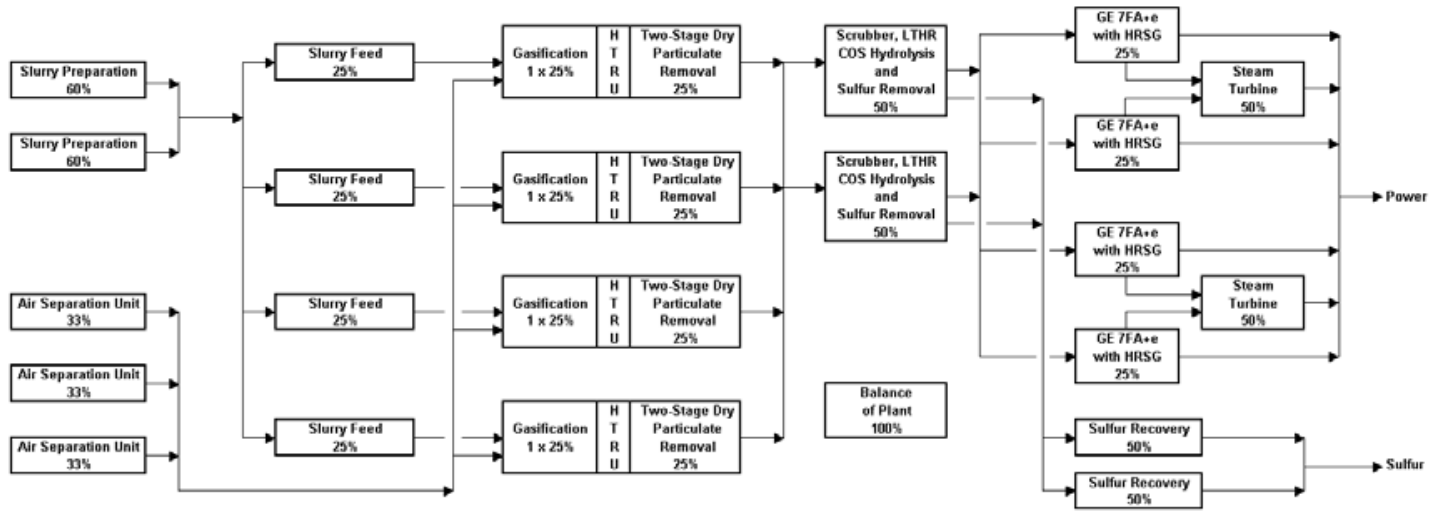

Note: Capacity percentages are based on total plant capacity.

Figure III.8

Subtask 1.7 Coal to Hydrogen Plant

Simplified Block Train Diagram

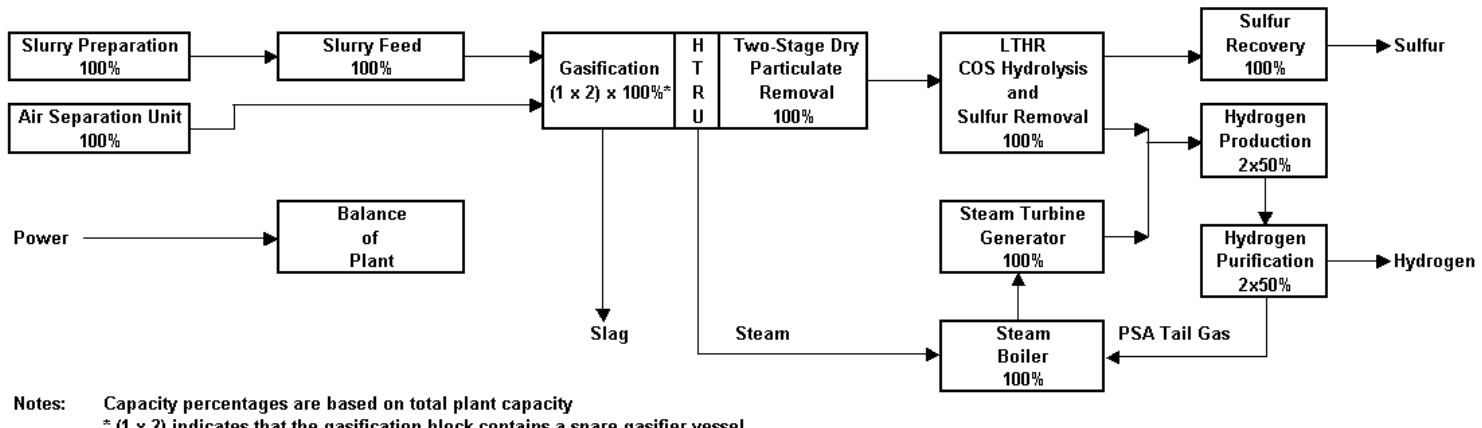

* $(1 \times 2)$ indicates that the gasification block contains a spare gasifier vessel. 


\section{Task 2 Gasification Coproduction Plants}

Task 2 has three subtasks that developed designs for IGCC coproduction plants that coproduced Fischer-Tropsch liquids in addition to power. The Subtask 2.1 and 2.2 plants are fueled by petroleum coke, and the Subtask 2.3 plant is fueled by Illinois No. 6 coal. The three Task 2 subtask plant designs, as well as some related Task 1 subtask designs, are summarized in Table I.2. This section briefly describes and reviews each of these plant designs in numerical subtask order.

\section{IV.1 Non-optimized Coke Gasification Power Plant with Liquids Coproduction}

The Subtask 2.1 [Non-optimized] Coke Gasification Power Plant with Liquids Coproduction was developed from the Subtask 1.3 Next Optimized Petroleum Coke IGCC Coproduction Plant by eliminating export steam and hydrogen production facilities and replacing them with a once-through Fischer-Tropsch hydrocarbon synthesis plant. A once-through system eliminates the cost of the expensive recycle system which requires recycle gas purification facilities in addition to the recycle compressor. The energy that was used to produce the export steam now is used to generate additional power.

Figure IV.1 is a simplified block train diagram of the Subtask 2.1 Coke Gasification Power Plant with Liquids Coproduction. The syngas generation and clean up sections of the plant essentially are a two train facility, but it contains a complete spare gasification train. There also are two sulfur recovery trains and two sulfur production trains that are sized so that they only have sufficient capacity to process the output from two gasifiers simultaneously operating at design capacity. The combined cycle power block contains two General Electric 7FAe+ combustion turbines, each one with a dedicated HRSG, and a single steam turbine generator. The F-T hydrocarbon synthesis section is a single-train facility.

From 5,376 tpd of dry petroleum coke and 110 tpd of flux, the Subtask 2.1 [Non-optimized] Coke Gasification Power Plant with Liquids Coproduction produces 4,124 bpd of F-T liquid fuel precursors, $371 \mathrm{tpd}$ of sulfur, $194 \mathrm{tpd}$ of slag (15\% water), and $617 \mathrm{MW}$ of export power. Compared to the Subtask 1.3 Next Plant, the Subtask 2.1 plant produces substantially more power (617MW vs. $474 \mathrm{MW}$ ) because the plant does not export any steam. It has an expected EPC cost of about 818 MM mid-2000 dollars. ${ }^{12}$ Appendix A of the Task 2 Topical Report describes the Subtask 2.1 plant in more detail. ${ }^{3}$

On a higher heating value (HHV) basis, the plant has a thermal efficiency $47.9 \%$ when the heating value of the byproduct sulfur is included and $46.0 \%$ when the byproduct sulfur is not included. These thermal efficiencies are higher than those that would be obtained from a coke IGCC power plant of a similar design because it includes the heating value of the liquid fuel that is produced. Since the second law of thermodynamics states this liquid fuel cannot be used at a $100 \%$ thermal efficiency, the thermal efficiency of the plant will be somewhat lower when the final disposition of the liquid fuel is considered.

The Fischer-Tropsch Hydrocarbon Synthesis Area was developed using the ASPEN Plus process flowsheet reactor model that was developed for the Baseline Design/Economics for 
Advanced Fischer-Tropsch Technology study ${ }^{14}$ This model also simulated the final syngas cleanup before the slurry-bed reactor, the F-T slurry-bed reactor system, and the cooling, separation, and recovery of the liquid product. About $36 \%$ of the syngas produced by the gasification block goes through the F-T area while the remaining $64 \%$ is sent directly to the power block.

The residual sulfur in the syngas going to the F-T hydrocarbon synthesis area is reduced to less than $0.1 \mathrm{ppm}$ of sulfur. This is done by converting the small amounts of carbonyl sulfide (COS) and trace amounts of other light organic sulfur compounds to hydrogen sulfide $\left(\mathrm{H}_{2} \mathrm{~S}\right)$, and removing the $\mathrm{H}_{2} \mathrm{~S}$ by reaction with solid zinc oxide $(\mathrm{ZnO})$ to produce solid zinc sulfide $(\mathrm{ZnS})$ and water. The $\mathrm{ZnO}$ is permanently consumed, and the $\mathrm{ZnS} / \mathrm{ZnO}$ mixture eventually is discarded. The hydrolysis catalyst is Süd-Chemie G-41P RS, and the ZnO sorbent is Süd-Chemie G-72E.

The Fischer-Tropsch slurry-bed reactor converts the sulfur-free syngas primarily into olefinic and paraffinic hydrocarbons over an iron-based catalyst by the reactions

$$
\begin{aligned}
\mathrm{nCO}+2 \mathrm{nH}_{2} & \rightarrow \mathrm{C}_{\mathrm{n}} \mathrm{H}_{2 \mathrm{n}}+\mathrm{nH}_{2} \mathrm{O} \text { and } \\
\mathrm{C}_{\mathrm{n}} \mathrm{H}_{2 \mathrm{n}}+\mathrm{H}_{2} & \rightarrow \mathrm{C}_{n} \mathrm{H}_{2 \mathrm{n}+2}
\end{aligned}
$$

The catalyst also promotes the water-gas shift reaction

$$
\mathrm{CO}+\mathrm{H}_{2} \mathrm{O} \rightarrow \mathrm{CO}_{2}+\mathrm{H}_{2}
$$

Constant catalyst activity is maintained by the continual addition of fresh catalyst and continual removal of used catalyst from the slurry-bed reactor. The reactor temperature is controlled by the generation of $440^{\circ} \mathrm{F} / 375$ psia in tubes within the reactor. Most of this steam is sent to the combined cycle power block where it is superheated in the HRSG and used for power production.

The lighter hydrocarbon products leave the slurry-bed reactor in the vapor phase, are cooled and the condensed liquid collected. The unconverted syngas ( $\mathrm{CO}$ and $\left.\mathrm{H}_{2}\right)$, carbon dioxide, methane, and the $\mathrm{C} 2$ and heavier material in the vapor are compressed and sent to the power block where it becomes fuel for the combustion turbine. The heavier hydrocarbons are removed as liquids from the reactor, separated from the suspended catalyst, cooled, and combined with the lighter liquid products to form the liquid fuel precursors product.

\section{IV.2 Optimized Coke Gasification Power Plant with Liquids Coproduction}

The Subtask 2.2 Optimized Coke Gasification Power Plant with Liquids Coproduction was developed from the Subtask 2.1 non-optimized plant by maximizing the F-T liquids production at the expense of the power production. The F-T section of the plant was enlarged so that almost all of the syngas now passes through the F-T slurry bed reactor. The power block now contains only one gas turbine and one steam turbine. Figure IV.2 is a simplified block train diagram of the Subtask 2.2 Optimized Coke Gasification Power Plant with Liquids Coproduction.

\footnotetext{
${ }^{14}$ Topical Report - Volume I, "Process Design - Illinois No. 6 Coal Case with Conventional Refining, , Baseline Design/Economics for Advanced Fischer-Tropsch Technology, U. S. Department of Energy, Contract Number DE-AC2291PC90027, October 1994
} 
From 5,417 tpd of dry petroleum coke and 111 tpd of flux, the Subtask 2.2 Optimized Coke Gasification Power Plant with Liquids Coproduction produces 10,450 bpd of F-T liquid fuel precursors, $373 \mathrm{tpd}$ of sulfur, $195 \mathrm{tpd}$ of slag (15\% water), and $366.9 \mathrm{MW}$ of export power. It has an expected EPC cost of about 753 MM mid-2000 dollars. ${ }^{12}$ Appendix B of the Task 2 Topical Report describes the Subtask 2.2 plant in more detail. ${ }^{3}$

On a higher heating value (HHV) basis, the plant has a thermal efficiency $56.7 \%$ when the heating value of the byproduct sulfur is included and $54.9 \%$ when the byproduct sulfur is not included. These thermal efficiencies are higher than those of the Subtask 2.1 plant because the liquid fuel is a higher percentage of the plant's output.

Residual sulfur now is removed from all the syngas by adsorption on impregnated activated carbon since now about $92 \%$ of the syngas goes to the F-T hydrocarbon synthesis reactor with the remaining $8 \%$ going to the gas turbine. The activated carbon is regenerable with medium-pressure steam. After its useful life, the deactivated carbon is sent to the gasifier for destruction and conversion to syngas and slag. The metal activator is entrained in the slag, which is a non-hazardous waste.

The F-T hydrocarbon synthesis section of the Subtask 2.2 plant is essentially the same as that of Subtask 2.1 with the following changes.

- Low-pressure steam from the combined cycle plant is used to preheat the syngas going to the F-T reactor.

- A second vapor/liquid separator was added to the F-T reactor vapor cooling loop to remove liquid water to prevent freezing in the downstream refrigerated cooler.

- The liquid product recovery from the vapor stream leaving the F-T reactor was improved by adding a refrigerated condenser at $40^{\circ} \mathrm{F}$ following the cooling water condenser.

- High-pressure steam from the combined cycle plant is used to heat the catalyst pretreater instead of a fired furnace burning natural gas.

- A spare F-T offgas/syngas compressor was added to improve the reliability of the fuel supply to the combustion turbine.

As a result of the increased F-T liquids recovery from the reactor vapor, the combined gas turbine fuel gas (F-T offgas and bypass syngas) has a lower heating value of about 164 Btu $(\mathrm{LHV}) / \mathrm{scf}$ unmoisturized. Based on previous information from General Electric, this fuel gas could be used in the GE7FA+e combustion turbine when moisturized to a lower heating value of $147 \mathrm{Btu} / \mathrm{scf}$ for NOx control, but it would require a higher inlet pressure. Thus, in the Subtask 2.2 design, the complete gas turbine fuel gas ( $\mathrm{F}-\mathrm{T}$ product gas and syngas bypassing the F-T area) is compressed to 475 psia. It is then sent to the gasification block where it is moisturized using low-level heat from syngas cooling and heated to $425^{\circ} \mathrm{F}$ with intermediate pressure steam from the gasification block before going to the combustion turbine.

\section{IV.3 Optimized Coal Gasification Power Plant with Liquids Coproduction}

The Subtask 2.3 Optimized Coal Gasification Power Plant with Liquids Coproduction was developed from the Subtask 1.6 Nominal 1,000 MW Coal IGCC Power Plant using the design approach adopted for the Subtask 2.2 optimized coke plant. The coal gasification 
capacity of the plant was kept the same as Subtask 1.6; i.e., that amount which could be processed in four gasification trains to allow direct comparison between these two cases. However, the F-T liquids production was maximized, and power production was reduced to only one power block train consisting of two GE 7FA+e combustion turbines, two HRSGs, and a single steam turbine. The unconverted syngas and light hydrocarbons from the F-T synthesis section is compressed and combined with the remaining $18 \%$ of syngas bypassing the F-T reactor to provide fuel for the two combustion turbines. Figure IV.3 is a simplified block train diagram of the Subtask 2.3 Optimized Coal Gasification Power Plant with Liquids Coproduction.

From 9,844 tpd of dry Illinois No. 6 coal, the Subtask 2.3 Optimized Coal Gasification Power Plant with Liquids Coproduction. Produces 12,377 bpd of F-T liquids, 237 tpd of sulfur, $1,423 \mathrm{tpd}$ of slag(15\% water), and $675.9 \mathrm{MW}$ of power. The plant has an EPC cost of 1,159 MM mid-2000 dollars. ${ }^{12}$ Appendix $\mathrm{C}$ of the Task 2 Topical Report describes the Subtask 2.3 plant in more detail. ${ }^{3}$

On a higher heating value (HHV) basis, the plant has a thermal efficiency $53.4 \%$ when the heating value of the byproduct sulfur is included and $52.6 \%$ when the byproduct sulfur is not included. These thermal efficiencies are higher than those of the Subtask 1.6 coal IGCC power plant because it includes the heating value of the liquid fuel that is produced.

Except for size, the F-T processing areas of the Subtask 2.3 Optimized Coal Gasification Power Plant with Liquids Coproduction essentially are the same as that of the Subtask 2.2 coke plant. However, this area contains two parallel trains instead of a single train.

Figure IV.1

\section{Subtask 2.1 Coke Gasification Power Plant with Liquids Coproduction}

\section{Simplified Block Train Diagram}

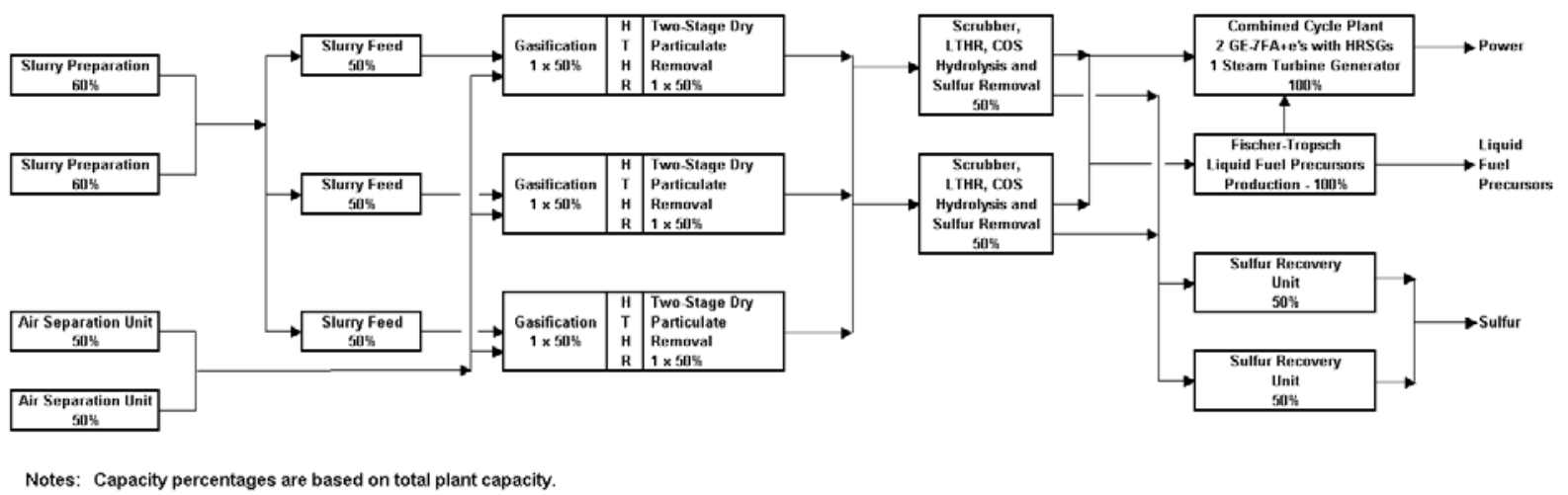


Figure IV.2

Subtask 2.2 Optimized Coke Gasification Power Plant with Liquids Coproduction Simplified Block Train Diagram

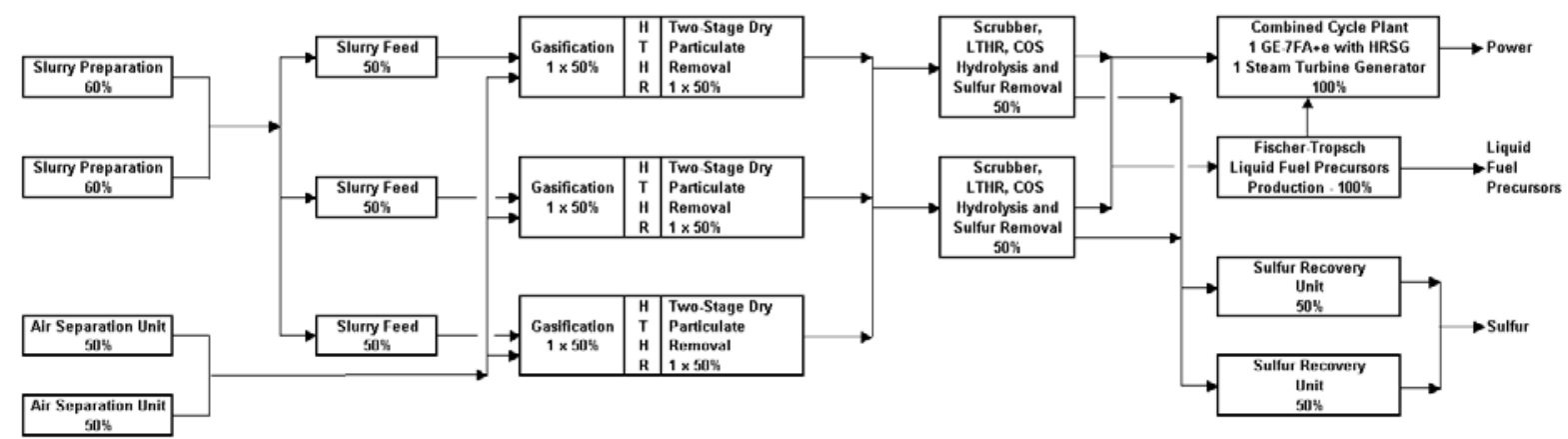

Notes: Capacity percentages are based on total plant capacity

Figure IV.3

Subtask 2.3 Optimized Coal Gasification Power Plant with Liquids Coproduction Simplified Block Train Diagram

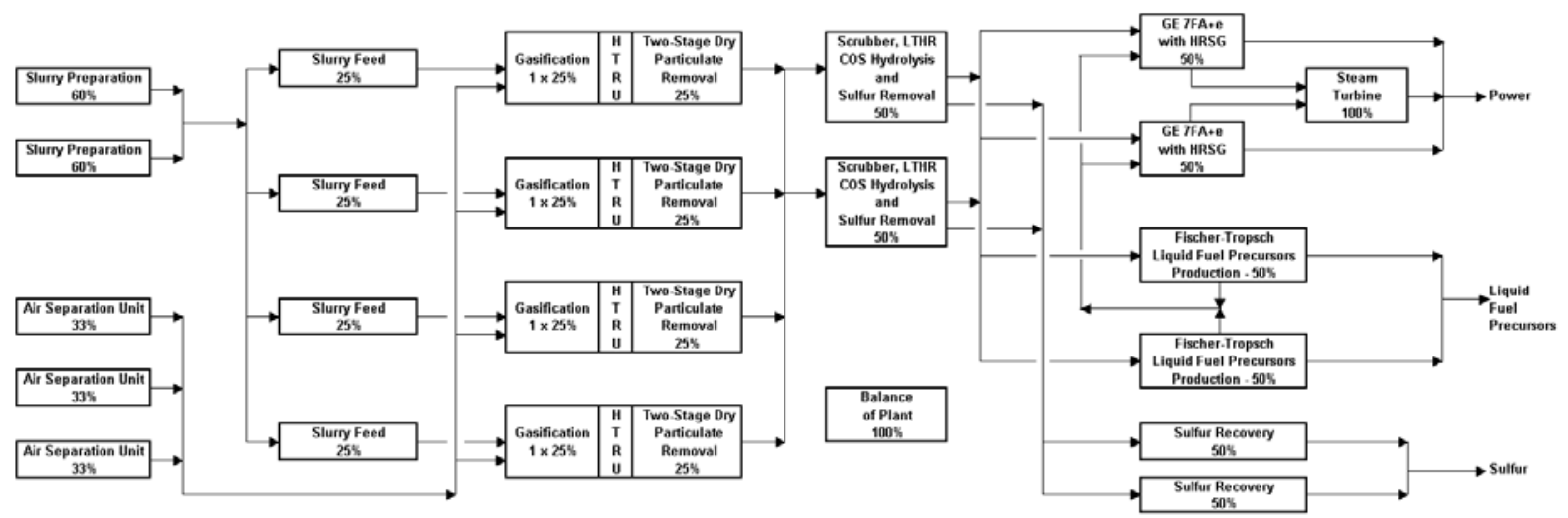

Note: Capacity percentages are based on total plant capacity. 


\section{Emissions}

The Wabash River facility, and the Tampa Electric Polk Power Station in Florida, are the first of a new class of coal-based electrical generation plants with superior environmental performance compared to other technologies such as pulverized coal and fluidized bed boilers. Wabash River has been operating since 1995 with emissions lower than coal-based power plants that are now being permitted for operation in 2005."15

This project started from the as-built Wabash River Repowering Project and developed improved or optimized designs that are even cleaner and less polluting than the Wabash River facility. Tables I.1 and I.2 show the emissions of SOx, NOx and CO in both Ib/hr, $\mathrm{lb} / \mathrm{MW}-\mathrm{hr}$, and Ib/MMBtu (HHV) of feed from all the designs developed in this study. In all the improved or optimized IGCC cases, the SOx and NOx emissions on a Ib/MMBtu basis are lower than the Subtask 1.1 Wabash River Greenfield Plant (which corresponds to the Wabash River Repowering Project) whether the plants were fueled by petroleum coke or coal or whether they co-produced hydrogen or F-T liquids. The same is true for the CO emissions by plant type. For all the IGCC power plants, the CO emissions in Ib/MMBtu are lower than those of the Subtask 1.1 Wabash River Greenfield Plant. Also the CO emissions from the optimized Subtask 1.3 plants are significantly lower than those of the non-optimized Subtask 1.2 plant. The $\mathrm{CO}$ emissions from the Subtask 1.7 Coal to Hydrogen Plant is an entirely different system (without a gas turbine), and because of this, it has higher $\mathrm{CO}$ emissions.

The SOx emissions are reduced from those of the Wabash River Greenfield Plant by more efficient scrubbing of the syngas in the amine Acid Gas Removal Unit and by better recovery of the sulfur from the purge gas streams. Four other plants clean the syngas to lower sulfur levels as required by downstream processing. The Subtask 1.7 Coal to Hydrogen Plant uses a more expensive Rectisol Acid Gas Removal Unit to clean the syngas to lower sulfur levels as required by the $\mathrm{CO}$ shift catalyst. The Subtask 2.1 Petroleum Coke IGCC Power Plant with Liquids Coproduction removes the sulfur from the syngas going to the F-T slurrybed reactor by a second COS hydrolysis step followed by reaction of the sulfur with $\mathrm{ZnO}$ to form solid ZnS. The Subtask 2.2 coke and Subtask 2.3 coal optimized IGCC power plants with liquids coproduction further clean all the syngas leaving the amine Acid Gas Removal Unit by passing it over impregnated activated carbon to remove sulfur.

In the improved and optimized designs, the $\mathrm{CO}$ and NOx emissions from the gas turbines were reduced by using the newer GE 7FA+e turbine instead of the older GE 7FA turbine that is installed at Wabash River. The higher $\mathrm{CO}$ emissions from the Subtask 1.2, Subtask 1.3, and Subtask 1.7 plants are caused by the larger incinerators that are need for the PSA purge gas. If required, these $\mathrm{CO}$ emissions can be reduced by the use of a catalytic afterburner at additional expense.

The lower NOx from the combustion turbines are the result of improved turbine design and the use of a diluent for NOx control. For most of the designs, water vapor (steam) is the diluent. The Subtask 1.4 Advanced Coal IGCC Power Plant uses nitrogen as the primary diluent. The Subtask 2.2 Optimized Petroleum Coke IGCC Power Plant with Liquids

\footnotetext{
${ }^{15}$ Testimony of Richard A. Olliver before a hearing of The Subcommittee on Energy and Air Quality, The Committee on Energy and Commerce of the U.S. House of Representatives, June 24, 2003, from www.gasification.org.
} 
Coproduction uses the $\mathrm{CO}_{2}$ produced in the F-T slurry-bed reactor as the primary diluent with steam as the supplementary diluent. Selective Catalytic Reduction (SCR) systems can be used to further reduce the NOx content of the exhaust gases where required by regulations. However, if the feed gases contain too much sulfur, these SCR catalyst can be poisoned by sulfate production. This sulfur problem does not exist in the Subtask 1.7, Subtask 2.2 and Subtask 2.3 plants because these plants reduce the sulfur to very low level because of downstream processing requirements.

Essentially all the carbon that enters these plants in the feed eventually is converted to carbon dioxide except for the small amounts that are contained in the slag and leave as carbon monoxide. In all the Task 1 plants this occurs in the facility itself. In the Task 2 plants that produce a carbon-containing product, the F-T liquids, this occurs where and when the fuel is used. Thus, in effect, we are transferring the source of the $\mathrm{CO}_{2}$ away from the gasification plant.

One way to minimize the $\mathrm{CO}_{2}$ production is to increase the thermal efficiency of the power plants so that less carbon is consumed per unit of power produced. All the power only plants have higher thermal efficiencies than the Wabash River Greenfield Plant, and therefore, they emit less $\mathrm{CO}_{2}$ per unit of power produced.

In a gasification facility, heavy metals are very low because they are encapsulated in the slag. Other metals, such as mercury and selenium, are volatile and are detected in the syngas. Compared to a conventional combustion plant, metals removal should be easier because the cleanup can be done on the syngas at a higher pressure in a reducing environment rather than in the lower pressure, oxidizing environment of the effluent. Thus, the potential exists for effectively complete removal from the syngas by selective adsorbents, but additional research and development efforts are needed.

Mercury removal was not considered in any of the plant designs developed in this study. "Eastman Chemical also uses sulfur-impregnated carbon in its bed and has experienced removals of 90 to 95 percent." 16 "A plant like the Wabash River facility could be upgraded to $80 \%$ or better mercury removal by the addition of a single carbon bed vessel, at a cost of less than $\$ 1$ million dollars." 17 In a similar manner, carbon adsorption beds could be added to each of the designs developed in this study for minimal additional cost of less than $1 \mathrm{MM} \$$ per gasification train.

Slag, the major solid byproduct of the gasification process, is a vitrified black sand like material that can be marketed as construction material. "There are no solid wastes from the coal gasification process [similar to those produced by a pulverized coal process] - no scrubber sludge, fly ash or bottom ash." ${ }^{16}$ Small amounts of used catalysts or adsorbents, such as the $\mathrm{ZnO} / \mathrm{ZnS}$ mixture in Subtask 2.1, still require disposal.

\footnotetext{
${ }^{16}$ Rutkowski, M. D., Klett, M. G. and R. C. Maxwell, "The Cost of Mercury Removal in an IGCC Plant," Gasification Technologies 2002, San Francisco, CA, Oct. 27-30, 2002.

17 Testimony of Phil Amick before a hearing of The Subcommittee on Energy and Air Quality, The Committee on Energy and Commerce of the U.S. House of Representatives, June 24, 2003, as attached to the testimony of Richard A. Oliver in the previous reference from www.gasification.org.
} 
The waste water from the gasification plants is cleaned up to meet the requirements for water discharges. However, if desired and at additional expense, a reverse osmosis system can be added to treat the waste water from the gasification system to obtain a zero discharge system as was done in the Subtask 1.4 Advanced Coal IGCC Power Plant. 


\section{Financial Results}

\section{VI.1 Introduction}

This chapter contains a brief summary of the availability and financial analyses that were performed for the various cases. Availability analyses were performed as described in Section II. 3 of this report and Appendix $\mathrm{J}$ of the Task 1 Topical report. Discounted financial analyses were performed as described in Section II.5 using the price structure in Section II.4.

Comparisons are made between cases, as appropriate; i.e., a comparison between a coal IGCC power plant located in the Midwest should not be compared to a coke petroleum coke coproduction plant located on the U. S. Gulf Coast that co-produces steam and hydrogen. Thus, this rest of chapter is divided into various subsections that compare similar plants. More extensive financial analyses are contained in the Task 1 and Task 2 Topical Reports and the appendices for each subtask. ${ }^{2,3}$

\section{VI.2 Petroleum Coke IGCC Coproduction Plants}

There are five variations of the Subtask 1.2 and Subtask 1.3 Petroleum Coke IGCC Coproduction Plants as described in Sections III.2 through III.4 and shown in Figures III.2 through III.4. Table VI.1 and Figure VI.1 show the design and calculated daily average flow rates for the Subtask 1.2 and the four Subtask 1.3 plants. These results show that the Subtask 1.3 Next Plant has the highest availabilities and the highest daily average product rates.

The "overnight" mid-year 2000 EPC costs for the Subtask 1.2 and 1.3 petroleum coke IGCC coproduction plants also are shown in Table VI.1. The Subtask 1.2 plant cost is $993.2 \mathrm{MM} \$$. The four Subtask 1.3 plant costs range from 812.6 MM\$ to 746.0 MM\$. As compared to the cost of the four non-optimized Subtask 1.2 case, the saving varies from $180.6 \mathrm{MM} \$$ to 247.2 MM\$. These savings are the result of the Value Improving Practices and optimization efforts.

Using a discounted cash flow economic model that was developed by Nexant, Inc. for the Department of Energy, the required power selling prices that were required to produce a $12 \%$ after tax ROI were calculated. ${ }^{18}$ The bottom row of Table IV.1 shows the results. In all cases, backup natural gas is used to fire the combustion turbines whenever sufficient syngas is unavailable in order to provide export power.

The Subtask 1.2 plant requires a power selling price of $43.4 \$ / \mathrm{MW}-\mathrm{hr}$. The required power selling prices for the Subtask 1.3 plants varies between 32.5 \$/MW-hr for the Spare Train Case to 36.5 \$/MW-hr for the Minimum Cost Case. The Minimum Cost Case has the highest power selling price showing that elimination of the spare gasification vessels is not advantageous. For the best Subtask 1.3 case, the Spare Train Case, the required selling price was reduced by almost $11 \$ / \mathrm{MW}-\mathrm{hr}$ as a result of this study. Furthermore, examination of the first three Subtask 1.3 cases shows that the extra cost of the spare train

\footnotetext{
${ }^{18}$ Nexant Inc., "Financial Model Users Guide - IGCC Economic and Capital Budgeting Evaluation", Report for the U. S. Department of Energy, Contract No. DE-AM01-98FE64778, May 2000.
} 
to increase the average daily plant capacity is beneficial since it reduces the required power selling price for a $12 \% \mathrm{ROI}$ by about $2 \$ / \mathrm{MW}$-hr over the Base Case. See Appendix C for a more complete availability and financial analysis of the Subtask 1.3 plants.

As shown in Table VI.1, the further optimization made in the Subtask 1.3 Next Plant case reduced its cost to $787.2 \mathrm{MM} \$$, or about $25 \mathrm{MM} \$$ less than that of the Subtask 1.3 Spare Train Case. As a result, the required power selling price for a $12 \%$ ROI dropped to 30.0 $\$ / \mathrm{MW}$-hr. This is a $30 \%$ reduction in the electricity price compared to the non-optimized Subtask 1.2 plant.

An advanced natural gas combined cycle plant starting up in 2005 is expected to have a heat rate of 6,639 HHV Btu/kw-hr (6,035 LHV Btu/kW-hr). ${ }^{8}$ With 2.60 \$/MMBtu HHV natural gas, this gas-fired power plant will require an export power price of $33.0 \$ / \mathrm{MW}$-hr to generate a $12 \%$ ROI. Thus, the Subtask 1.3 Next plant is competitive with a new natural gas combined cycle plant that will be starting up at about the same time.

Currently, the United States is in a period of low inflation and very low interest rates. With an $8 \%$ loan interest rate and the same $3 \%$ upfront financing fee, the required power selling price for the Next Plant drops to $28.6 \$ / \mathrm{MW}$-hr which is competitive with current power prices. As natural gas prices rise above the 2.60 \$/MMBtu price assumed in this economic analysis, petroleum coke gasification plants should become even more competitive.

Figure IV.2 shows the effect of the power selling price on the return on investment for the Subtask 1.2, Subtask 1.3, and Subtask 1.3 Next Plant cases. At a 30.0 \$/MW-hr the Subtask 1.3 Next Plant will produce a $12 \% \mathrm{ROI}$, which is over 2 points better than the Subtask 1.3 Spare Train Case and over 9 points better than the Subtask 1.2 plant. As the power selling price increases, the ROls increase significantly. At a $35 \$ / \mathrm{MW}$-hr power selling price the Subtask 1.3 Next Plant has a $16.7 \%$ ROI, and at a $40 \$ / M W-h r$, it has a ROI of $21.1 \%$. With a $10 \%$ loan interest rate and a $30 \$ / \mathrm{MW}$-hr power selling price, the ROIs for the Subtask 1.3 Next Plant and the Subtask 1.3 Spare Train case increase to $15.7 \%$ and $13.4 \%$, respectively. 
Table VI.1

\section{Comparison of the Subtask 1.2 and Subtask 1.3 Petroleum Coke IGCC Coproduction Plants}

\begin{tabular}{|c|c|c|c|c|c|c|c|c|}
\hline \multirow{4}{*}{ Case } & \multicolumn{2}{|c|}{ Subtask 1.2} & \multicolumn{4}{|c|}{ Subtask 1.3} & \multicolumn{2}{|c|}{$\begin{array}{c}\text { Subtask } 1.3 \\
\text { Next Plant }\end{array}$} \\
\hline & \multirow[b]{2}{*}{ Design } & \multirow[b]{2}{*}{$\begin{array}{r}\text { Daily } \\
\text { Average }\end{array}$} & \multirow[b]{2}{*}{ Design } & \multicolumn{3}{|c|}{ Daily Average } & \multirow{3}{*}{$\underline{\text { Design }}$} & \multirow[b]{2}{*}{$\begin{array}{r}\text { Daily } \\
\text { Average }\end{array}$} \\
\hline & & & & $\begin{array}{l}\text { Base } \\
\text { Case } \\
\end{array}$ & $\begin{array}{l}\text { Minimum } \\
\text { Cost Case }\end{array}$ & $\begin{array}{r}\text { Spare } \\
\text { Train } \\
\end{array}$ & & \\
\hline & & & & & & & & \\
\hline Power, MW & 395.8 & 374.3 & 460.7 & 430.0 & 425.4 & 436.4 & 474.0 & 448.4 \\
\hline Hydrogen, MMscfd & 79.4 & 78.8 & 80.0 & 77.5 & 76.5 & 78.7 & 80.0 & 78.8 \\
\hline Steam, Mlb/hr & 980.0 & 972.2 & 980.0 & 958.6 & 946.2 & 974.1 & 980.0 & 974.6 \\
\hline Sulfur, TPD & 367.0 & 324.1 & 371.8 & 296.8 & 273.6 & 331.5 & 373.4 & 333.8 \\
\hline Slag, TPD & 190.0 & 167.8 & 194.5 & 155.3 & 143.1 & 173.4 & 195.1 & 174.4 \\
\hline Fuel Gas, MMscfd & 99.6 & 98.8 & 0 & 0 & 0 & 0 & 0 & 0 \\
\hline \multicolumn{9}{|l|}{ Input Rates } \\
\hline Coke, TPD & 5,249 & 4,635 & 5,399 & 4,310 & 3,973 & 4,814 & 5,417 & 4,842 \\
\hline Flux, TPD & 107 & 94.5 & 110.2 & 88.0 & 81.1 & 98.3 & 110.6 & 98.9 \\
\hline Natural Gas, MMBtu/d & 0 & 10,099 & 0 & 20,000 & 26,977 & 9,303 & 0 & 9,059 \\
\hline \multicolumn{9}{|l|}{ EPC Cost (see note), } \\
\hline MM\$ (mid-year 2000) & & 993.2 & & 764.0 & 746.0 & 812.6 & & 787.2 \\
\hline \multicolumn{9}{|c|}{ Required Power Selling Price } \\
\hline For a $12 \%$ after-tax ROI, $\$$ & MW-hr & 43.36 & & 34.45 & 36.49 & 32.48 & & 30.02 \\
\hline
\end{tabular}


Figure VI.1

Design and Daily Average Coke Consumptions for the Subtask 1.2 and Subtask 1.3 Petroleum Coke IGCC Coproduction Plants

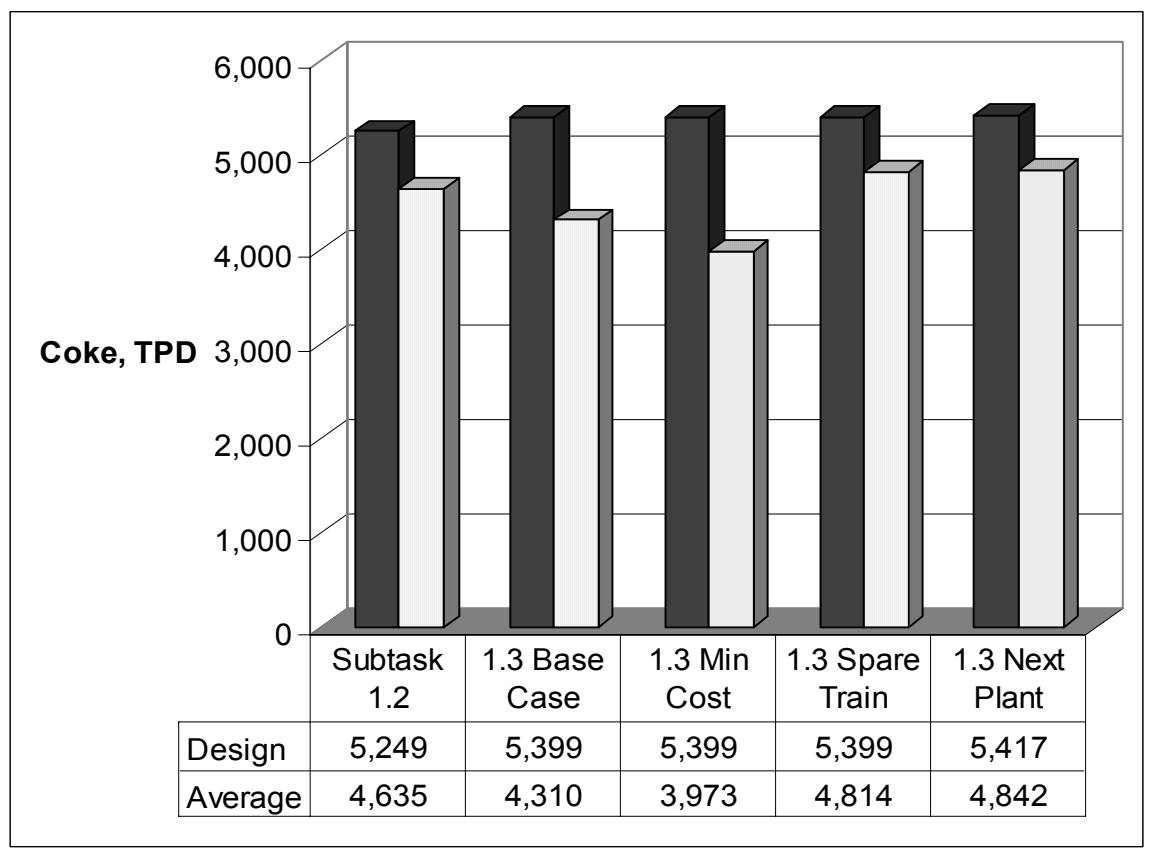

Figure VI.2

Return on Investment vs. Power Selling Price for the Subtask 1.2 and 1.3 Petroleum Coke IGCC Coproduction Plants

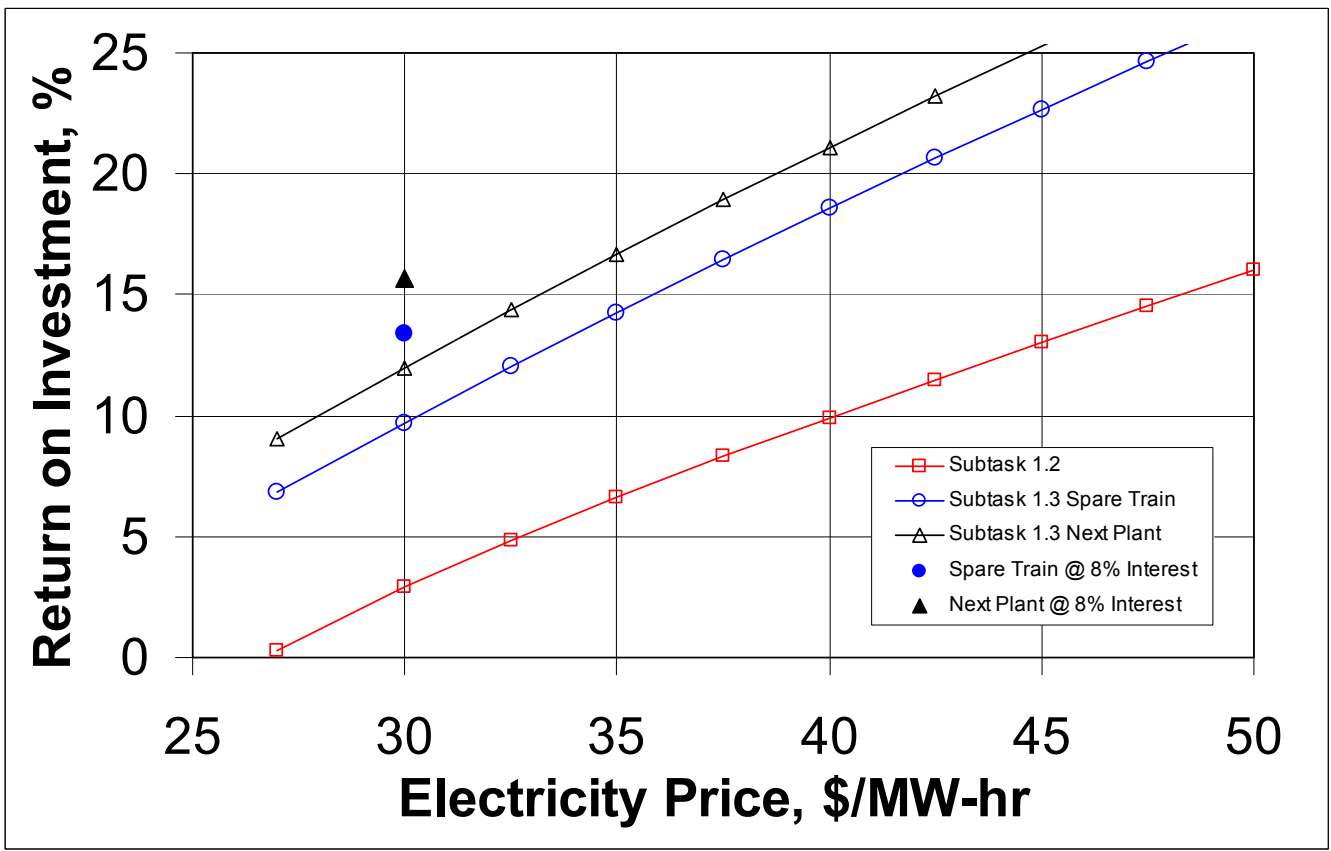




\section{Vl.3 Coal and Petroleum Coke IGCC Power Plants}

This study investigated four coal-fueled IGCC plants to compare the relative performance, merits, and costs of the optimized coal IGCC cases on a common basis as measured by net return on investment (ROI), and the cost of electricity. The four plants discussed in this section are:

1. The Subtask 1.1 Wabash River Greenfield Plant,

2. The future Subtask 1.4 Advanced Coal IGCC Power Plant,

3. The Subtask 1.5A Coal IGCC Power Plant,

4. The Subtask 1.6 Nominal 1,000 MW Coal IGCC Power Plant,

The first three of the above plants are single-train coal fueled IGCC power plants. The Subtask 1.6 1,000 MW plant essentially is a four-train power plant. In addition, Subtask 1.5 includes the design of the Subtask 1.5B coke fueled single-train IGCC power plant for comparison with the Subtask 1.5A coal fueled plant.

These cases were considered because they are the likely coal-fueled IGCC plant configurations that may be the first generation of clean-power-from-coal plants. The results of these case studies will allow future coal-fueled power plant owners to investigate various gasification plant options and also to identify future R\&D needs which will further reduce the cost of electricity.

Table VI.2 compares the performance of the four coal fired power plants with and without backup natural gas. Backup natural gas is not considered for the Subtask 1.1 Wabash River Greenfield Plant because at the time this study was started, the Wabash River Repowering Project did not have that capability. Figure VI.3 shows the Return on Investment (ROI) versus the power selling price four power plants. The Subtask 1.1 plant is in the lower right hand corner of the figure. Plant performance improves by moving to the left (to lower power prices) in the figure. This figure shows the significant improvement that has been made as the result of this study.

As expected the Subtask 1.4 Advanced Coal IGCC Power Plant has the best performance since it includes some features that are still in the development stage and require further testing. This plant uses an advanced " $\mathrm{G} / \mathrm{H}$ class" combustion that is not yet available. Without backup natural gas, for the plant to generate a $12 \% \mathrm{ROI}$, it has a required power selling price of $42.8 \$ / \mathrm{MW}-\mathrm{hr}$. With 2.60 \$/MM Btu natural gas, the required power selling price drops to $39.8 \$ / \mathrm{MW}-\mathrm{hr}$.

The Subtask 1,000 MW Coal IGCC Power Plant essentially is a four-train plant. This plant contains all of the applicable results from the VPIs optimization process that could be implemented in a new plant being designed at this time. Furthermore, it takes advantage of the economy of scale for much of the plant facilities outside of the gasification block. Without backup natural gas, for the plant to generate a $12 \% \mathrm{ROI}$, it has a required power selling price of $43.9 \$ / \mathrm{MW}-\mathrm{hr}$. With $2.60 \$ / \mathrm{MMBtu}$ natural gas, the required power selling price drops to $40.6 \$ / M W-h r$.

The performance of the single-train Subtask 1.5A coal IGCC Power Plant is worse than the Subtask 1.6 plant for two reasons; first, it is a single train plant, and secondly, it does not contain all the improvements that were included in the Subtask 1.6 plant because it was developed before the VIPs processes was completed. However, it is significantly better 
than the Subtask 1.1 Wabash River Greenfield Plant. Without backup natural gas, the Subtask 1.5A plant requires a power selling price of $53.9 \$ / \mathrm{MW}-\mathrm{hr}$ to generate a $12 \% \mathrm{ROI}$. With 2.60 \$/MM Btu natural gas, the required power selling price drops to 48.8 \$/MW-hr.

The Subtask 1.1 Wabash River Greenfield plant replicates the Wabash River Repowering Project. Without backup natural gas, for the plant to generate a $12 \% \mathrm{ROI}$, it has a required power selling price of 67.5 \$/MW-hr.

Figure VI.4 shows the effect of syngas availability on the required power selling price to produce a $12 \% \mathrm{ROI}$ for the Subtask 1.6 Nominal 1,000 MW Coal IGCC Power Plant with and without backup natural gas. The abscissa is the single train syngas availability; i.e., that percentage of the time that one syngas train will be delivering syngas at the design rate. This improved availability can be the result of "learning curve" improvements or design changes that are yet to be developed. As the syngas availability improves, the amount of backup natural gas is reduced until it disappears at the unattainable $100 \%$ syngas availability. This figure shows the importance of improving the syngas availability from gasification plants. Any reduction in the required power selling price below the actual selling price becomes increased profit.

For the case without natural gas backup, increasing the syngas availability from $75.74 \%$ to $80 \%$ reduces the required power selling price for a $12 \%$ ROI by about $2.00 \$ / \mathrm{MW}$-hr from 44.37 to $42.37 \$ / M W-h r$. With natural gas backup, the reduction is not as great, about 0.92 $\$ / \mathrm{MW}$-hr from 40.23 to 39.31 \$MW-hr. At the unattainable $100 \%$ syngas availability, no backup natural gas is required, and Subtask 1.6 requires a power selling price of about 35.3 $\$ / M W-h r$ for a $12 \%$ ROI. Without backup natural gas, at the unattainable $100 \%$ syngas availability, it is the same as the case with backup natural gas since, at this point, no backup natural gas is required. 


\section{Table VI.2}

Design and Daily Average Feed and Product Rates for the Subtask 1.1, 1.4, 1.5A and 1.6 Coal IGCC Power Plants

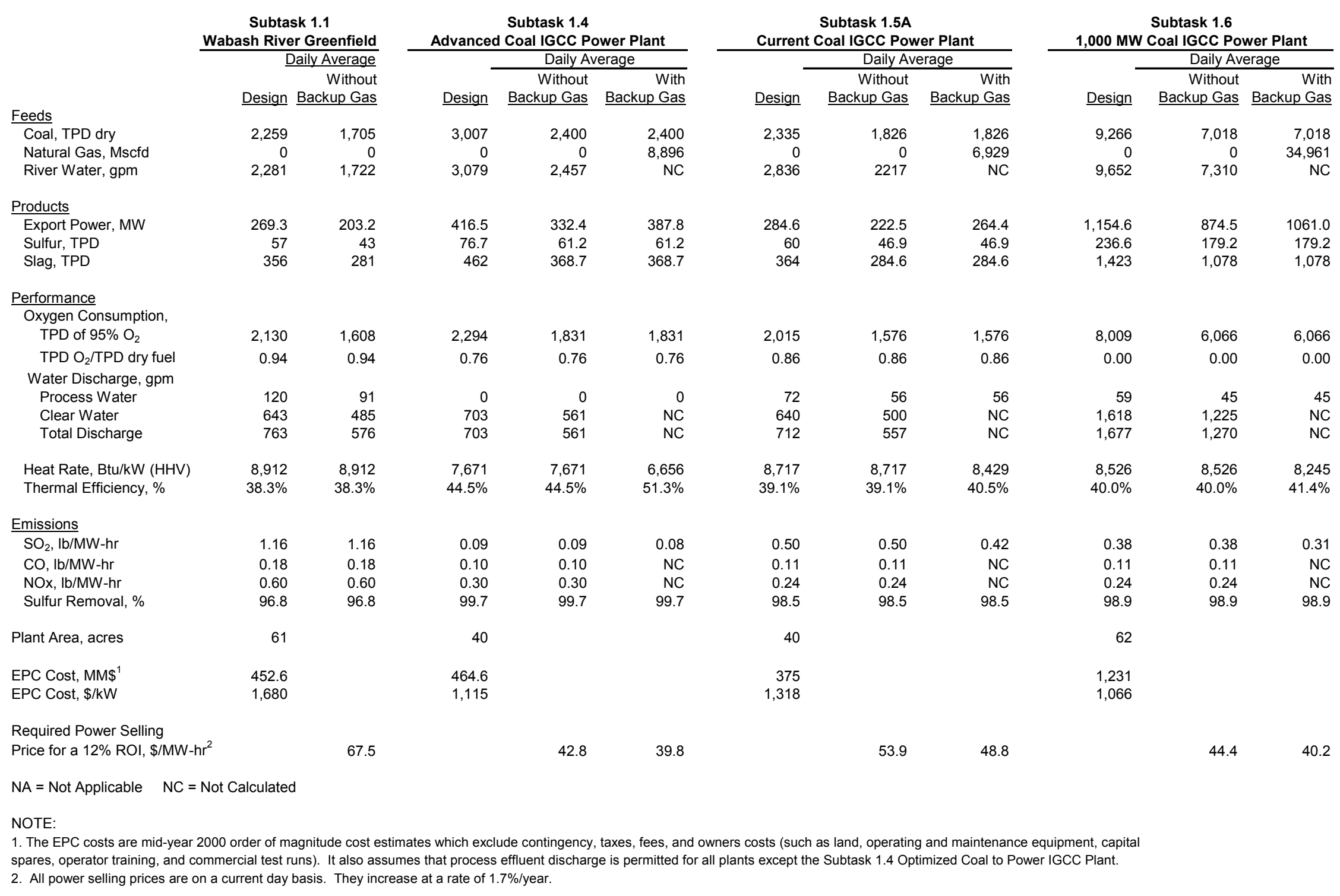




\section{Table VI.3}

\section{Design and Daily Average Feed and Product Rates for the Subtask 1.5A Coal and Subtask 1.5B Coke IGCC Power Plants}

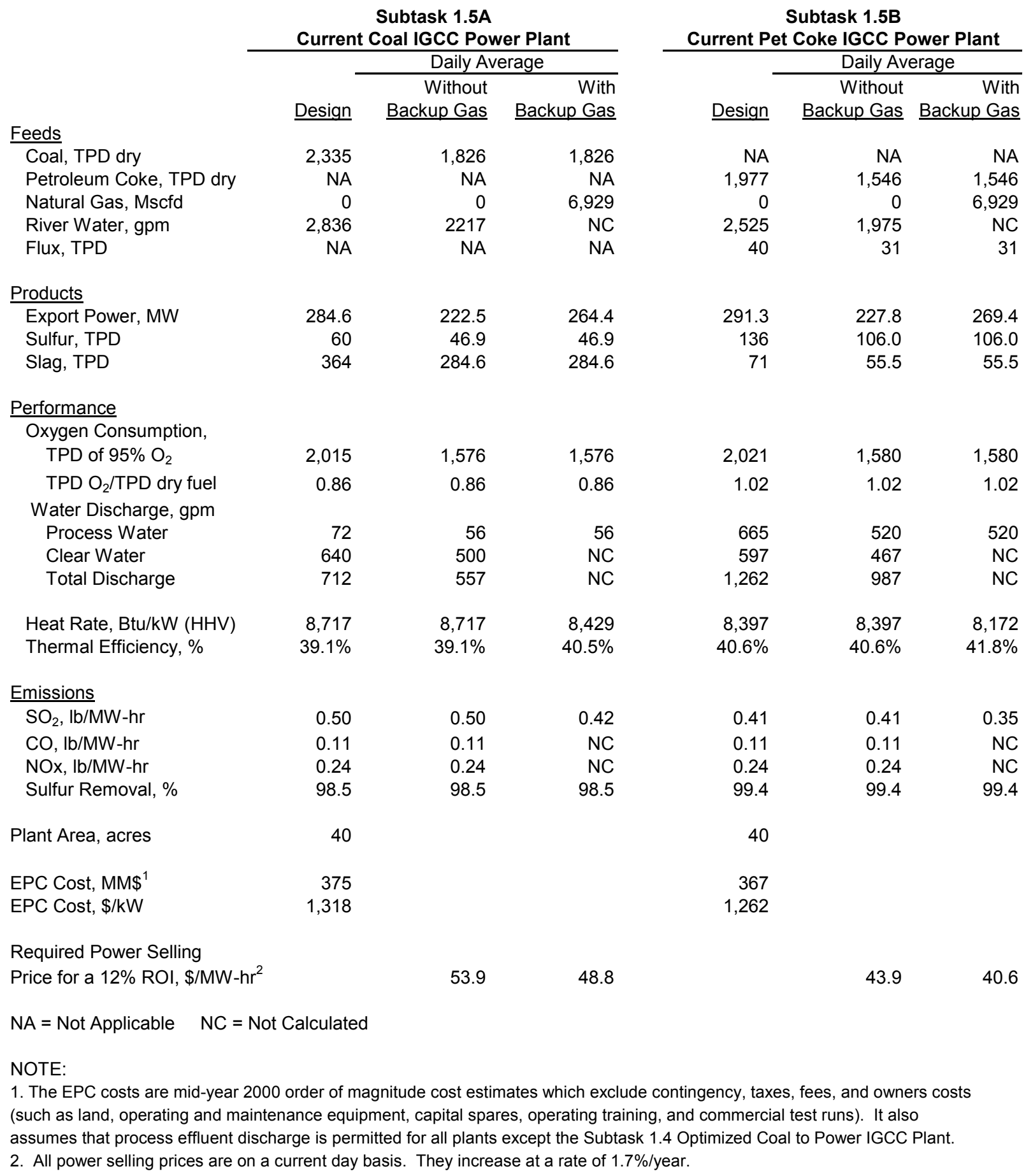


Figure VI.3

Return on Investment vs. Power Selling Price for the Subtask 1.1, 1.4, 1.5A and 1.6 Coal IGCC Power Plants

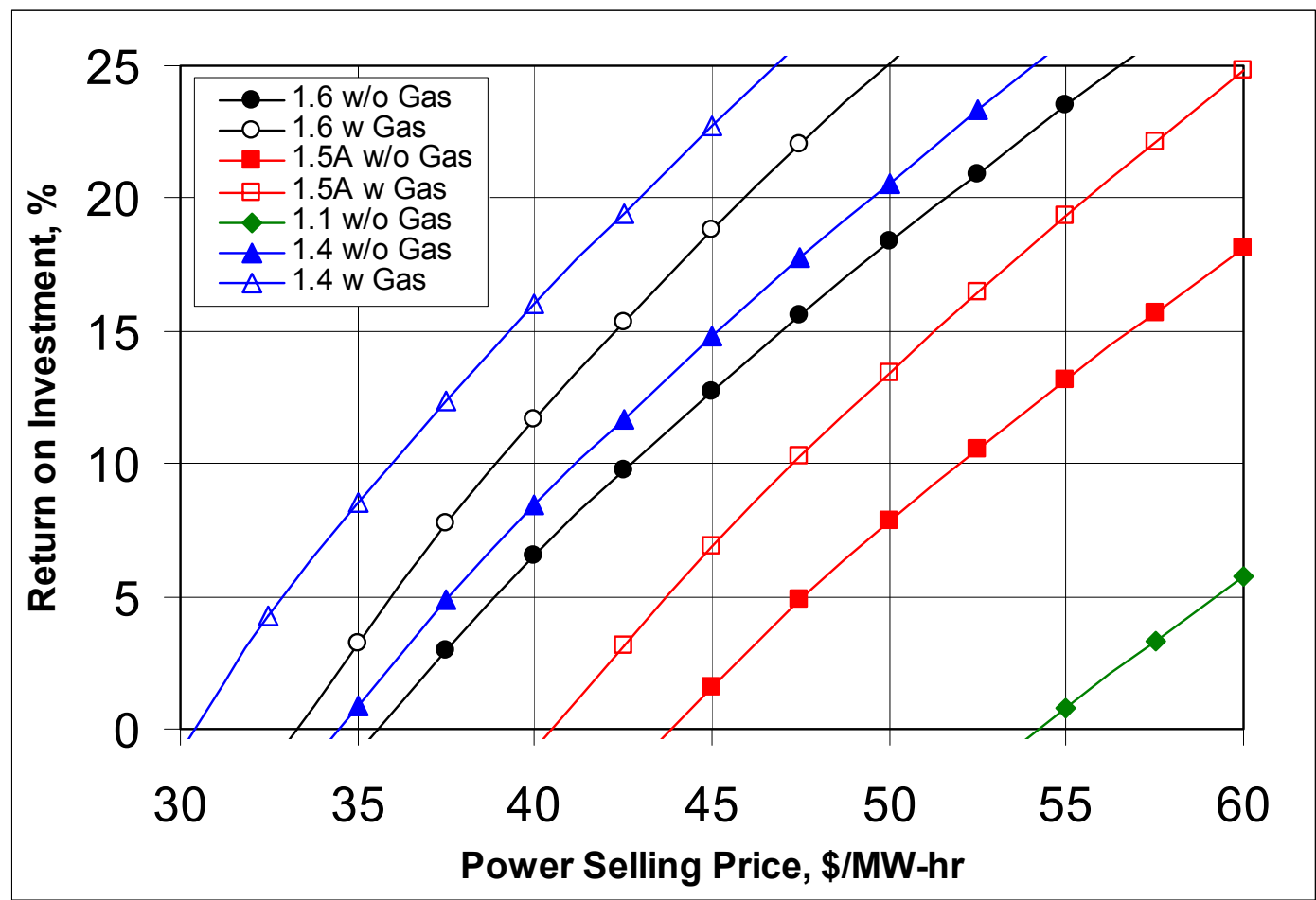

Figure VI.4

Effect of Syngas Availability on the Required Power Selling Price for a $12 \%$ Return on Investment For the Subtask 1.6 Coal IGCC Power Plant

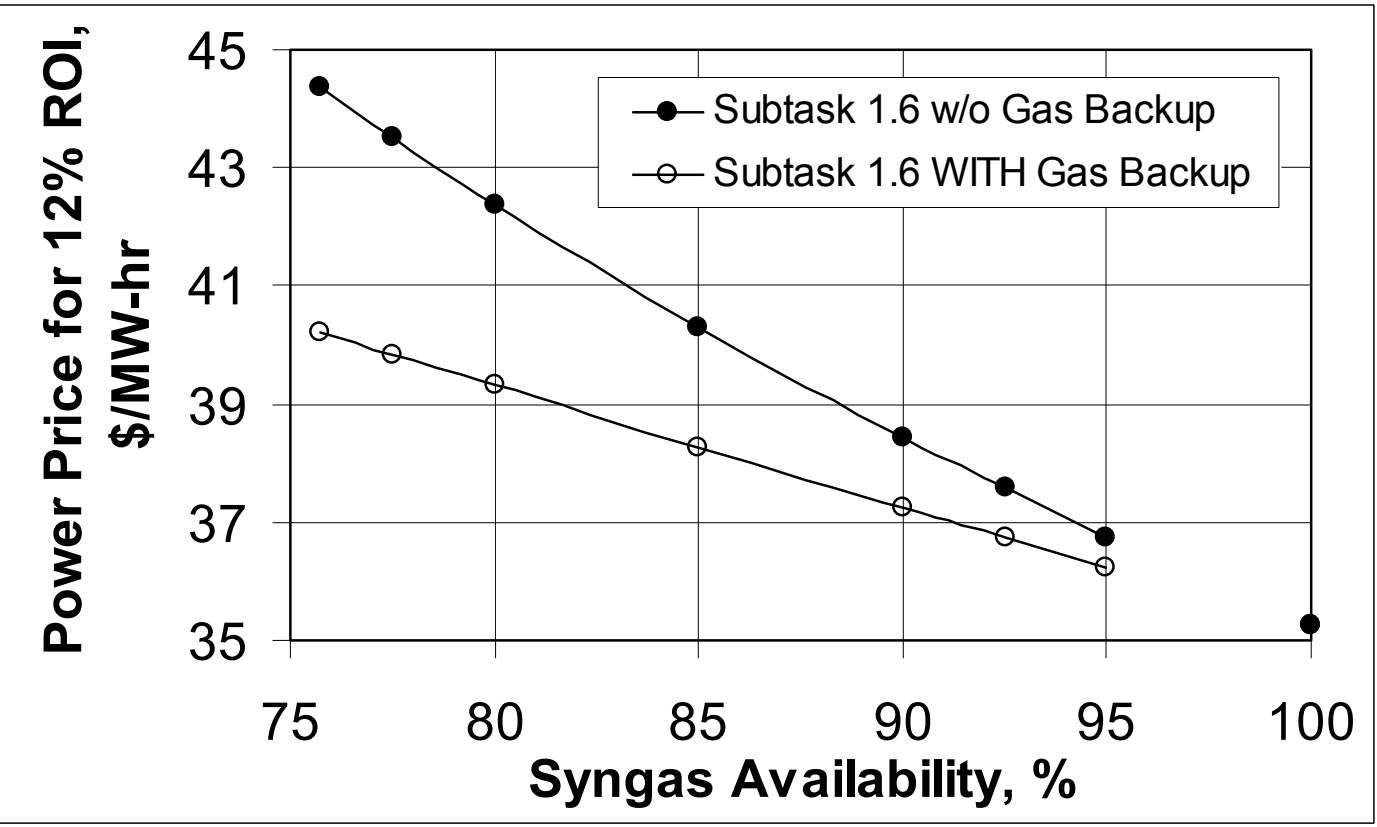




\section{VI.4 Coal to Hydrogen Plant}

The Subtask 1.7 Coal to Hydrogen Plant was developed to obtain a design and cost estimate for a facility, which incorporates the VIPs results from Subtasks 1.3 and 1.4, where appropriate, at the same capacity as Subtask 1.4. This plant produces $99.0 \%$ hydrogen delivered at 1,000 psig which is sulfur and $\mathrm{CO}_{2}$ free and contains less than $10 \mathrm{ppm}$ by volume of $\mathrm{CO}$.

Figure VI.5 shows the effect of the hydrogen selling price on the return on Investment for the plant with an $8 \%$ and $10 \%$ loan interest rate for an $80 \%$ loan. With a $10 \%$ loan interest rate, the plant requires a hydrogen selling price of $2.79 \$ / M s c f$ to generate a $12 \% \mathrm{ROI}$, and with an $8 \%$ loan interest rate, the required hydrogen selling price is $2.59 \$ / M s c f$.

After commissioning all plants undergo a "learning curve" during which problem areas are corrected, inadequate equipment is replaced, and design improvements are made. Consequently, performance improves as measured by increased capacity and/or improved on-stream factors. Figure VI.6 shows the effect of hydrogen availability on the required hydrogen selling price for a $12 \%$ return on investment for both $8 \%$ and $10 \%$ loan interest rates. Increasing the hydrogen availability from $81.3 \%$ to $85 \%$ reduces the required hydrogen selling price by about $0.10 \$ / M s c f$ in each case. Again, this figure shows the economic importance of increasing the product availability on the performance of the gasification plant.

Figure IV.5

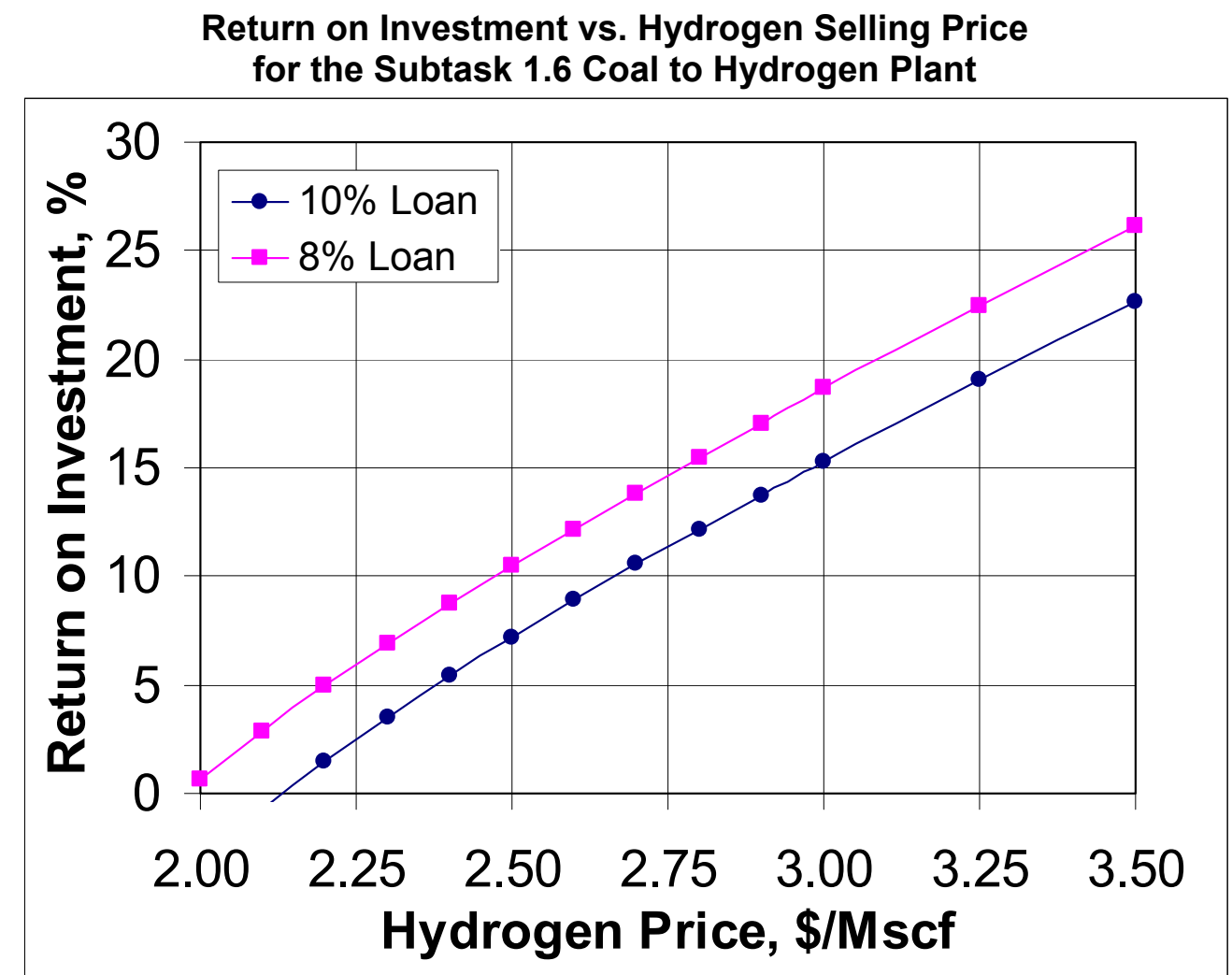


Figure IV.6

Effect of Hydrogen Availability on the Required Hydrogen Selling Price for a 12\% Return on Investment for the Subtask 1.6 Plant

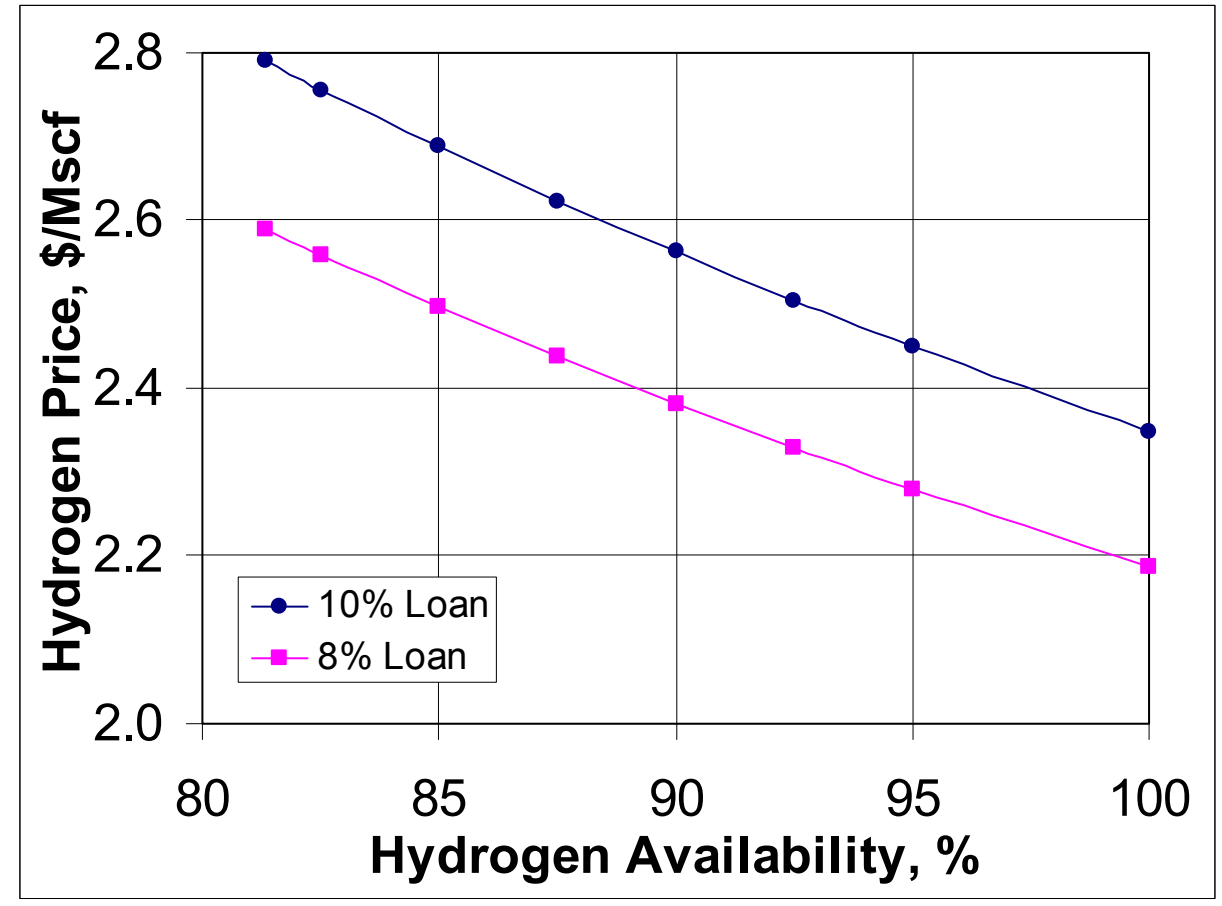

\section{VI.5 Petroleum Coke IGCC Power Plants with Liquids Coproduction}

Subtask 2.1 developed a design for a non-optimized petroleum coke IGCC power plant that co-produces liquid fuel precursors by the Fischer-Tropsch reaction starting from the Subtask 1.3 Next Optimized Petroleum Coke IGCC Coproduction Plant. Subtask 2.1 developed an optimized design for a petroleum coke IGCC power plant that co-produces liquid fuel precursors by maximizing the liquids production at the expense of power production.

Figure VI.7 shows the return on investment for the Subtask 1.3 Next Plant, Subtask 2.1 and Subtask 2.2 IGCC coproduction plants as a function of the power selling price using the basic economic parameters given in Table II.1 with a $10 \%$ loan interest rate. At a 27.0 \$/MW-hr export power price, the Subtask 2.2 Maximum F-T Liquids Case has an $18.24 \%$ ROI, the Subtask 2.1 Base Case has a 9.50\% ROI, and the Subtask 1.3 Next Plant has a $9.05 \%$ ROI.

The ROI for the Subtask 2.1 plant has a greater slope versus power price than that of the Subtask 2.2 plant because the revenue generated from the power sales is a significantly larger portion of the total plant revenue. As such, any change in the power price will have a larger influence on the ROI. Thus, at power prices above 45 \$/MW-hr, the Subtask 2.1 nonoptimized plant has a higher ROI than the Subtask 2.2 optimized plant because it produces more higher value export power and less liquid fuel precursors which are valued at $30 \$ / \mathrm{bbl}$. 
Table VI.4 shows the Return on Investments and Required Product Selling Prices for the Subtask 2.1 [Non-optimized] and Subtask 2.2 Optimized Coke Gasification Power Plants with Liquids Coproduction and the Subtask 1.3 Next Optimized Petroleum Coke IGCC Coproduction Plant with a natural gas price of $2.60 \$ / \mathrm{MW}-\mathrm{hr}$. At the basic economic conditions shown in Table II.1 (at a 10\% loan interest rate), the Subtask 2.2 optimized plant with backup power purchase at $27 \$ / \mathrm{MW}$-hr has a $18.2 \%$ ROI. This is over $8 \%$ greater than the ROI for either the Subtask 2.1 non-optimized plant or the Subtask 1.3 Next Optimized Petroleum Coke IGCC Coproduction Plant. The Subtask 2.2 optimized plant also requires a lower power selling price for a $12 \%$ ROI than either of the two other plants and a lower liquids selling price than the Subtask 2.1 non-optimized plant.

With an $8 \%$ loan interest rate, all three cases have higher ROls by about 3.5\%. However, their relative ranking remains the same. The Subtask 2.2 optimized coproduction plant with backup power purchase still has the best ROI followed by the Subtask 2.1 and the Subtask 1.3 Next Plant. The relative ranking of the required selling prices of power and F-T liquids for the four cases also are the same.

It is difficult to predict the future value of either power, natural gas and/or the F-T liquid fuel precursors. The liquid fuel precursors price is related to the crude oil price which also can be highly variable both because of market forces and the influence of international politics. Various studies have been made which attempt to relate the value of the F-T liquids to that of crude oil by replacing crude oil in the refinery feed stream with the F-T liquids. The resulting values for the F-T liquids generally are above the crude oil values, but the specific amount can range from $2 \$ / \mathrm{bbl}$ up to $10 \$ / \mathrm{bbl}$ depending upon the refinery configuration, the specific crude oils being replaced, and the required refinery product mix. ${ }^{19}$

Figure VI.8 shows the effect of the liquids selling price on the return on investment versus the power selling price for the Subtask 2.2 Optimized Coke Gasification Power Plant with Liquids Coproduction. The solid $30 \$ / \mathrm{bbl}$ line is the same line as shown on Figure IV.7 for the Subtask 2.2 plant. The dashed line is the corresponding $30 \$ / \mathrm{bbl}$ line for the Subtask 2.1 non-optimized plant as shown in Figure IV.7.

After commissioning all plants undergo a shakedown periods during which problem areas are corrected, inadequate equipment is repaired or replaced, and design improvements are made. Also as multiple plants start up and operate, the technology goes through a "learning curve" and improvements are incorporated into the next generation of plants. Consequently, performance is likely to improve as measured by increased capacity and/or improved onstream factors. Figure VI.9 shows the effect of improved syngas availability on the return on investment for the Subtask 1.3 Next Plant, 2.1 and 2.2 IGCC coproduction plants. The abscissa is equivalent syngas availability; i.e., the total syngas availability from the three gasification trains expressed as a percentage of the time that two gasification trains will be producing syngas at the design rate. Again, this figure shows the importance of designing gasification plants with high syngas availabilities.

For the Subtask 2.2 optimized plant, as the syngas availability improves, the amount of backup power that has to be purchased is reduced until it completely disappears at the

\footnotetext{
${ }^{19}$ Marano, J. J., Rogers, S., Choi, G. N., and Kramer, S. J., "Product Valuation of Fischer-Tropsch Derived Fuels," ACS National Meeting, Washington, D. C., August 21-6, 1994.
} 
unattainable $100 \%$ syngas availability. For the Subtask 2.1 non-optimized plant, the amount of purchased natural gas decreases in a similar manner as the syngas availability improves. However, even at $100 \%$ syngas availability, a small amount of natural gas is required for furnace fuel in the F-T area. At the expected $86.85 \%$ syngas availability, the Subtask 2.2 plant has an ROI of $18.24 \%$, the Subtask 2.1 plant has a ROI of $9.50 \%$, and the Subtask 1.3 Next Plant has a ROI of $9.05 \%$. At $90 \%$ syngas availability, the ROI of the Subtask 2.2 plant increases to about $19.4 \%$, that of the Subtask 2.1 plant increases to about $10.8 \%$, and that of the Subtask 1.3 Next Plant increases to $10.1 \%$. At the unattainable syngas availability of $100 \%$, the Subtask 2.2 optimized plant will have an expected ROI of $23.1 \%$, the Subtask 2.1 non-optimized plant will have an expected ROI of $14.9 \%$, and the Subtask 1.3 Next Plant will have an expected $13.4 \%$ ROI.

\section{Table VI.4}

\section{Return on Investment and Required Product Selling Price for the Subtask 1.3 Next Plant, Subtask 2.1 and Subtask 2.2 Coproduction Plants (with a Natural Gas Price of 2.60 \$/MMBtu)}

\begin{tabular}{|c|c|c|c|}
\hline & $\begin{array}{r}\text { Subtask } 1.3 \\
\text { Next Plant w } \\
\text { Gas Purchase } \\
\end{array}$ & $\begin{array}{c}\text { Subtask } 2.1 \\
\text { Non-optimized w } \\
\text { Gas Purchase }\end{array}$ & $\begin{array}{r}\text { Subtask } 2.2 \\
\text { Optimized w } \\
\text { Power Purchas } \\
\end{array}$ \\
\hline \multicolumn{4}{|l|}{ With a $10 \%$ Loan Interest Rate } \\
\hline $\begin{array}{l}\text { Return on Investment with } 27 \$ / M W-h r \\
\text { Power and } 30 \text { \$bbl Liquids }\end{array}$ & $9.05 \%$ & $9.50 \%$ & $18.24 \%$ \\
\hline $\begin{array}{l}\text { Required Selling Price for a } 12 \% \text { ROI of } \\
\text { Power with } 30 \$ / \text { bbl Liquids, } \$ / M W \text {-hr }\end{array}$ & 30.02 & 29.04 & 17.71 \\
\hline Liquds with 27 \$/MW-hr Power, \$/bbl & NA & 36.22 & 23.65 \\
\hline \multicolumn{4}{|l|}{ With a $8 \%$ Loan Interest Rate } \\
\hline $\begin{array}{l}\text { Return on Investment with } 27 \$ / M W-h r \\
\text { Power and } 30 \$ / b b l \text { Liquids }\end{array}$ & $12.70 \%$ & $13.24 \%$ & $21.81 \%$ \\
\hline $\begin{array}{l}\text { Required Selling Price for a } 12 \% \text { ROI of } \\
\text { Power with } 30 \$ / b b l \text { Liquids, } \$ / M W-h r\end{array}$ & 26.32 & 26.04 & 12.81 \\
\hline Liquds with 27 \$/MW-hr Power, \$/bbl & NA & 27.05 & 20.30 \\
\hline
\end{tabular}


Figure VI.7

Return on Investment vs. Power Price for the

Subtask 2.1 [Non-optimized] and Subtask 2.2 Optimized

Coke Gasification Power Plants with Liquids Coproduction and the Subtask 1.3 Next Optimized Petroleum Coke IGCC Coproduction Plant

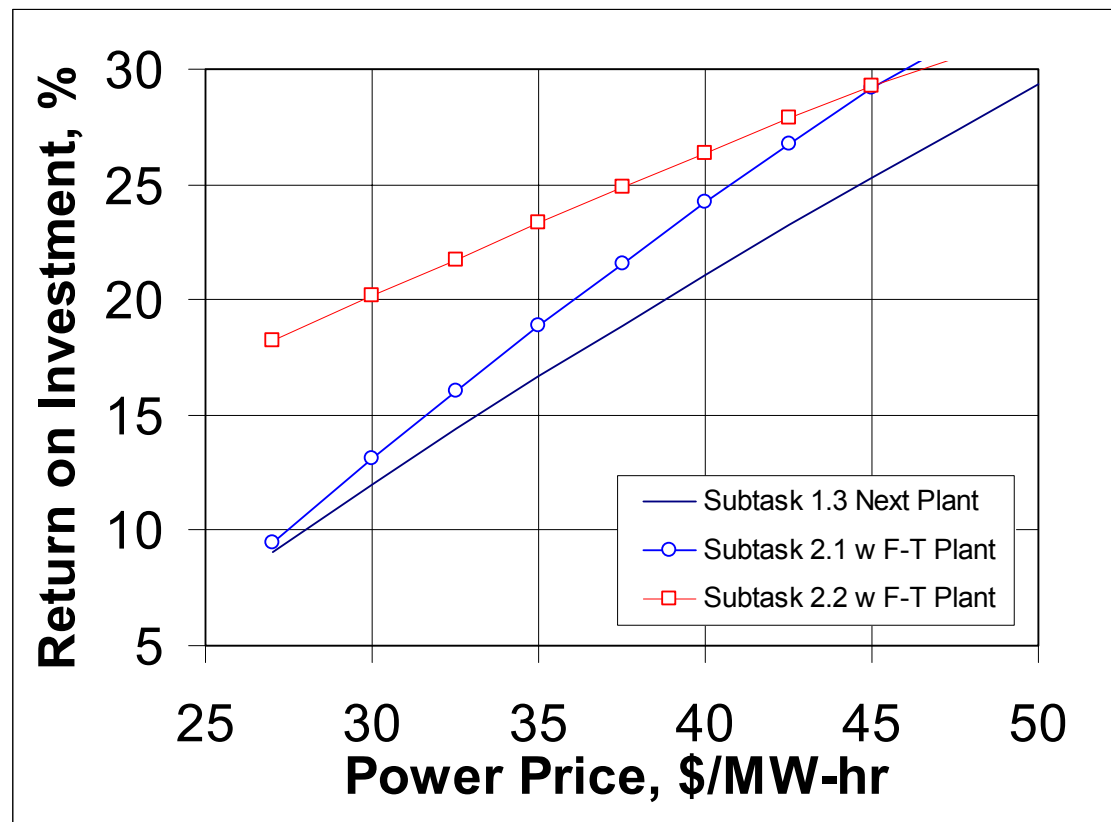

Figure IV.8

Return on Investment vs. Power Price Showing the Effect of the Liquids Price for the Subtask 2.2 Optimized Coke Gasification Power Plant with Liquids Coproduction

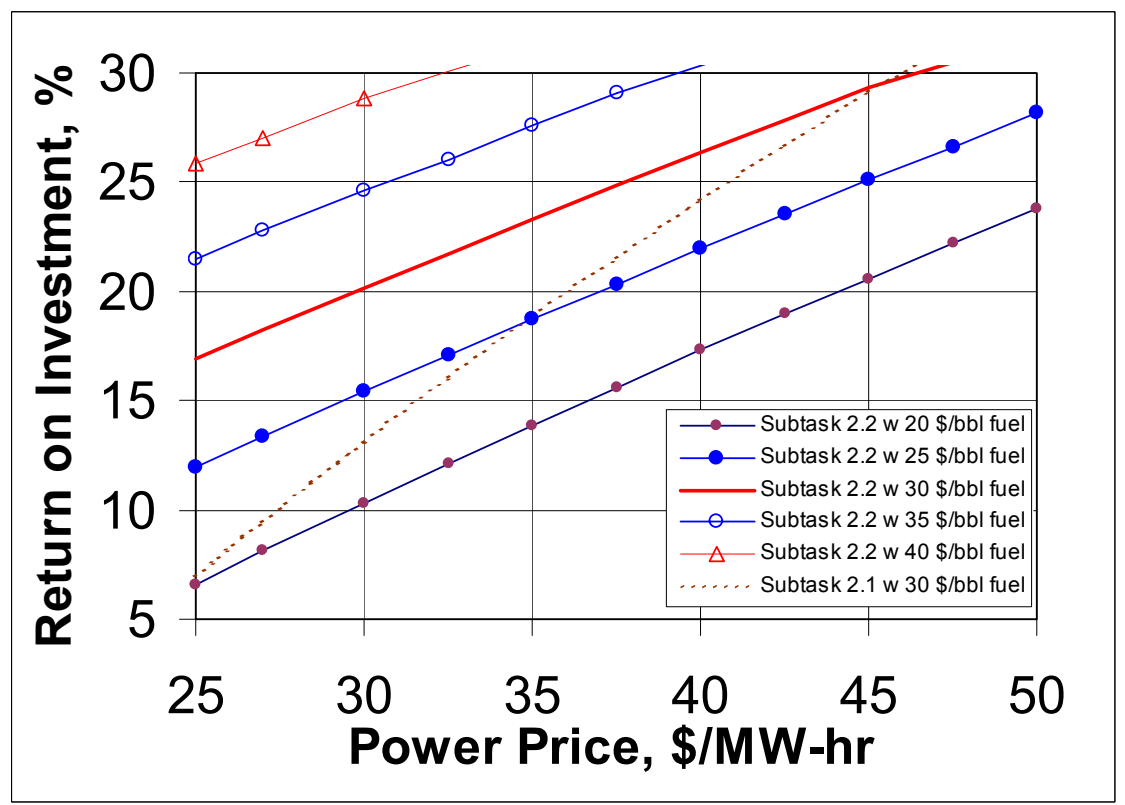


Figure VI.9

\section{Return on Investment vs. Syngas Availability for the \\ Subtask 2.1 [Non-optimized] and Subtask 2.2 Optimized Coke Gasification Power Plants with Liquids Coproduction and the Subtask 1.3 Next Optimized Petroleum Coke IGCC Coproduction Plant}

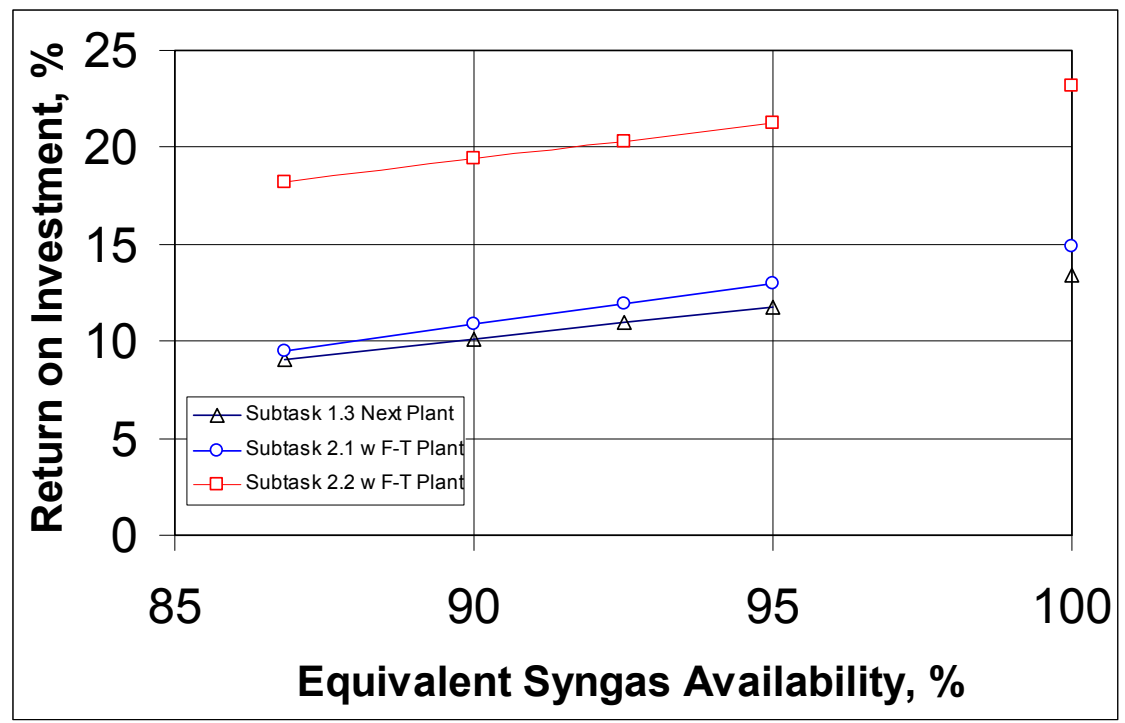

\section{VI.6 Coal IGCC Power Plant with Liquids Coproduction}

The Subtask 2.3 Optimized Coal Gasification Power Plant with Liquids Coproduction was developed from the Subtask 1.6 Nominal 1,000 MW IGCC plant using the design approach adopted for the Subtask 2.2 Optimized Coke Gasification Power Plant with Liquids Coproduction. The coal gasification capacity of the plant was kept the same as Subtask 1.6; i.e., that amount which could be processed in four gasification trains, to allow direct comparison between these two cases. Power production was reduced to only one power block train consisting of two combustion turbines, two HRSGs, and a single steam turbine.

Figure VI.10 shows the return on investment as a function of the export power price for the Subtask 2.3 Optimized Coal Gasification Power Plant with Liquids Coproduction under both operating scenarios and compares them with the Subtask 1.6 Nominal 1,000 MW Coal IGCC Power Plant with 2.60 \$/MMBtu natural gas at a $10 \%$ loan interest rate. This figure shows that generally the operating scenarios that use backup natural gas have higher Return on Investments (ROIs) than the cases without backup natural gas. Below a power selling price of about $38 \$ / \mathrm{MW}-\mathrm{hr}$, the Subtask 2.3 plant with the F-T liquids at $30 \$ / \mathrm{bbl}$ has a higher ROI than the Subtask 1.6 power plant. Above this power selling price, the Subtask 1.6 plant has a higher ROI. The same situation is true for the two operating scenarios without backup natural gas except that with these cases, the breakeven power selling price is slightly higher, about 40 \$/MW-hr. 
Table VI.5 compares the power and F-T liquids selling prices required by the Subtask 1.6 and Subtask 2.3 plants to generate a $12 \%$ ROI for the two operating scenarios. At the basic economic conditions shown in Table II.1 (at a 10\% loan interest rate), the Subtask 2.3 Coproduction Plant with backup power purchase requires a 42.0 \$/MW-hr power selling price for a $12 \% \mathrm{ROI}$, and without backup power purchase, the required power selling price is 48.1 \$/MW-hr. These required power selling prices are higher than those for the corresponding Subtask 1.6 cases. With a fixed 27 \$/MW-hr power selling price, the required selling prices of the F-T liquids to produce a $12 \mathrm{ROI}$ are 48.6 and $51.0 \$ / \mathrm{bbl}$ for the cases with and without backup natural gas cases, respectively.

With an $8 \%$ loan interest rate the relative ranking of the cases remains almost the same except that the required selling prices are lower. However, the Subtask 2.3 case with backup natural gas now has a slightly lower power selling price than the Subtask 1.6 case. This is a result of the Subtask 2.3 case having a lower EPC cost than the Subtask 1.6 Case.

Figure VI.11 shows the effect of the liquid fuel precursors selling price on the return on investment versus the power selling price for the Subtask 2.2 Maximum F-T Liquids Case with a $10 \%$ loan interest rate and $2.60 \$ / M M B t u$ natural gas. The solid $30 \$ / \mathrm{bbl}$ line is the same line as shown on the previous figure for the Subtask 2.3 coproduction plant with backup natural gas. The dashed line represents the Subtask 1.6 power plant with backup natural gas. The ROI for the Subtask 1.6 plant has a greater slope versus the power price than that of the Subtask 2.3 plant because the revenue generated from the power sales is a significantly larger portion of the total plant revenue. As such, any change in the power price will have a larger influence on the ROI.

This figure shows that the Subtask 2.3 coproduction plant requires F-T liquids selling prices above $30 \$ / \mathrm{bbl}$ to generate ROls greater than $10 \%$ with power prices below $40 \$ / \mathrm{MW}$-hr. With a 38 \$/MW-hr power selling price, the Subtask 2.3 coproduction plant will have higher ROls that the Subtask 1.6 power plant only when the F-T liquids are selling for $30 \$ / b b l$ or greater. As the power selling price increases, the Subtask 2.3 coproduction plant requires higher F-T liquids prices to be competitive with the Subtask 1.6 plant. At a $50 \$ / \mathrm{MW}-\mathrm{hr}$ power price, the F-T liquids should be about $40 \$ /$ bbl or greater for the Subtask 2.3 plant to have a higher ROI.

After commissioning all plants undergo a shakedown periods during which problem areas are corrected, inadequate equipment is repaired or replaced, and design improvements are made. Also as multiple plants start up and operate, the technology goes through a "learning curve" and improvements are incorporated into the next generation of plants. Consequently, performance is likely to improve as measured by increased capacity and/or improved onstream factors. Figure VI.12 shows the effect of improved syngas availability on the return on investment for the Subtask 1.6 and Subtask 2.3 plants. The abscissa is the single train syngas availability; i.e., that percentage of the time that one syngas train will be delivering syngas at the deign rate. This improved availability can be the result of "learning curve" improvements or design changes that are yet to be developed. For the Subtask 2.3 plant, as the syngas availability improves, the amount of backup natural gas is reduced until it disappears at the unattainable $100 \%$ syngas availability. At the expected $75.7 \%$ single train syngas availability, the Subtask 2.3 plant with backup natural gas requires power selling price of $42.0 \$ / \mathrm{MW}$-hr with $30 \$ / \mathrm{bb} \mathrm{F}-\mathrm{T}$ liquids selling price to generate a $12 \% \mathrm{ROI}$. At an $80 \%$ syngas availability, the required power selling price drops by almost 2 \$/MW-hr to 40.1 $\$ / \mathrm{MW}$-hr. At the unattainable $100 \%$ syngas availability, no backup natural gas is required, and the required power selling price for a $12 \% \mathrm{ROI}$ is $31.6 \$ / \mathrm{MW}-\mathrm{hr}$. 
Without backup natural gas, at the expected $75.7 \%$ single train syngas availability, the Subtask 2.3 plant requires a power selling price of $48.1 \$ / \mathrm{MW}-\mathrm{hr}$ for a $12 \%$ ROI with 30 $\$ /$ bbl F-T liquids. At an $80 \%$ syngas availability, the required power selling price drops by almost $4 \$ \mathrm{MW}$-hr to $44.3 \$ / \mathrm{MW}-\mathrm{hr}$. At the unattainable $100 \%$ syngas availability, it is the same as the case with backup natural gas, 31.6 \$/MW-hr, since at this point, no backup natural gas is required.

Figure V.12 also shows similar curves for the Subtask 1.6 coal IGCC power only plant. At high syngas availabilities (above 85\%) without backup natural gas, the Subtask 2.3 coproduction plant design requires a lower power selling price for a $12 \% \mathrm{ROI}$ than the Subtask 1.6 plant. With backup natural gas, this crossover point (at about $84 \%$ syngas availability) is at a required power selling price of about $38 \$ / \mathrm{MW}-\mathrm{hr}$. This is the same power price where the Subtask 1.6 curve intersects the Subtask 2.3 curve with a 30 \$/bbl liquids price in Figure V.11.

\section{Table VI.5}

Required Power Selling Prices for the for the Subtask 1.6 Power Plant and the Subtask 2.3 Optimized Coal Gasification Power Plant with Liquids Coproduction With and Without Backup Natural Gas

\begin{tabular}{cr}
\multicolumn{2}{c}{ Subtask 1.6} \\
\hline Without & With \\
Backup Gas & Backup Gas
\end{tabular}

With a $10 \%$ Loan Interest Rate

Required Selling Price for a $12 \% \mathrm{ROI}$ of Power with 30 \$/bbl Liquids, \$/MW-hr

Liquds with 27 \$/MW-hr Power, \$/bbl

\section{With a $8 \%$ Loan Interest Rate}

Required Selling Price for a $12 \%$ ROI of Power with 30 \$/bbl Liquids, \$/MW-hr

Liquds with 27 \$/MW-hr Power, \$/bbl
44.37

40.23

$$
--
$$

41.34

37.77

42.93

45.87
Subtask 2.3

\begin{tabular}{rr}
\hline Without & With \\
Backup Gas & Backup Gas
\end{tabular}

$48.06 \quad 42.02$

50.97

48.59

$\begin{array}{llll}-- & -- & 45.87 & 43.69\end{array}$


Figure VI.10

Return on Investment vs. Power Price for the Subtask 2.3 Optimized Coal Gasification Power Plant with Liquids Coproduction and the Subtask 1.6 Nominal 1,000 MW Coal IGCC Power Plant

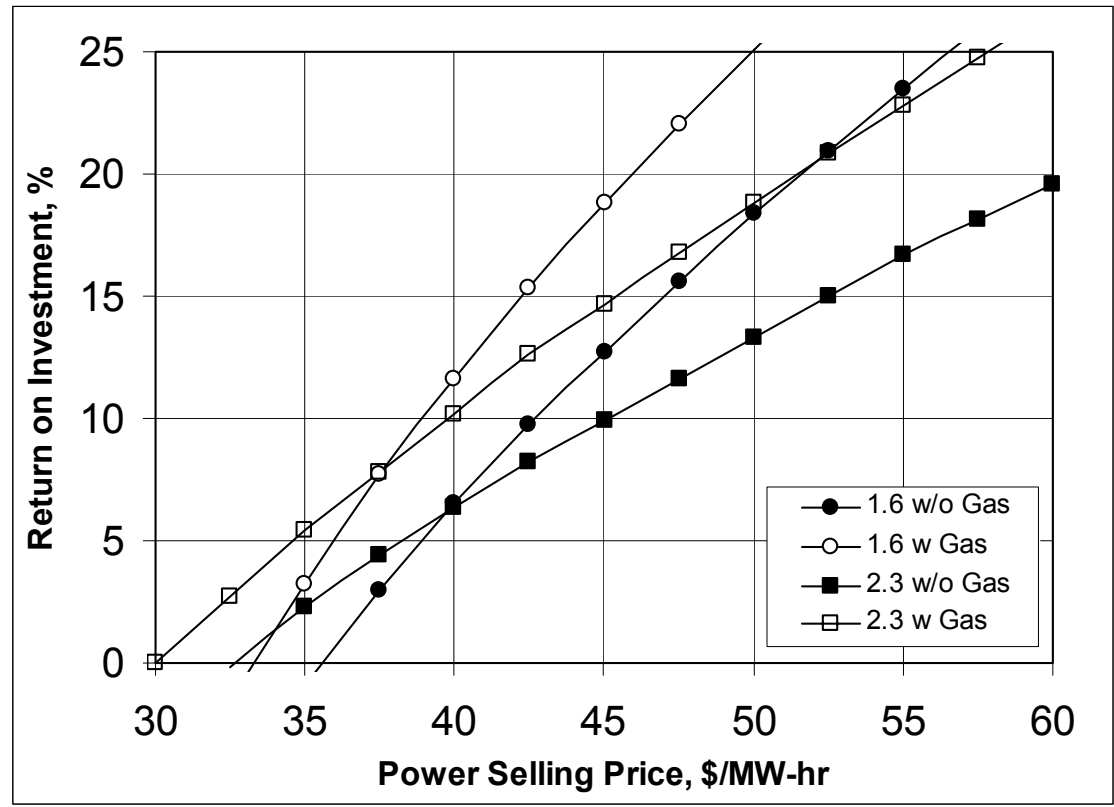

Figure VI.11

Return on Investment vs. Power Price Showing the Effect of the Liquids Price for the Subtask 2.3 Optimized Coal Gasification Power Plant with Liquids Coproduction and the Subtask 1.6 Power Plant

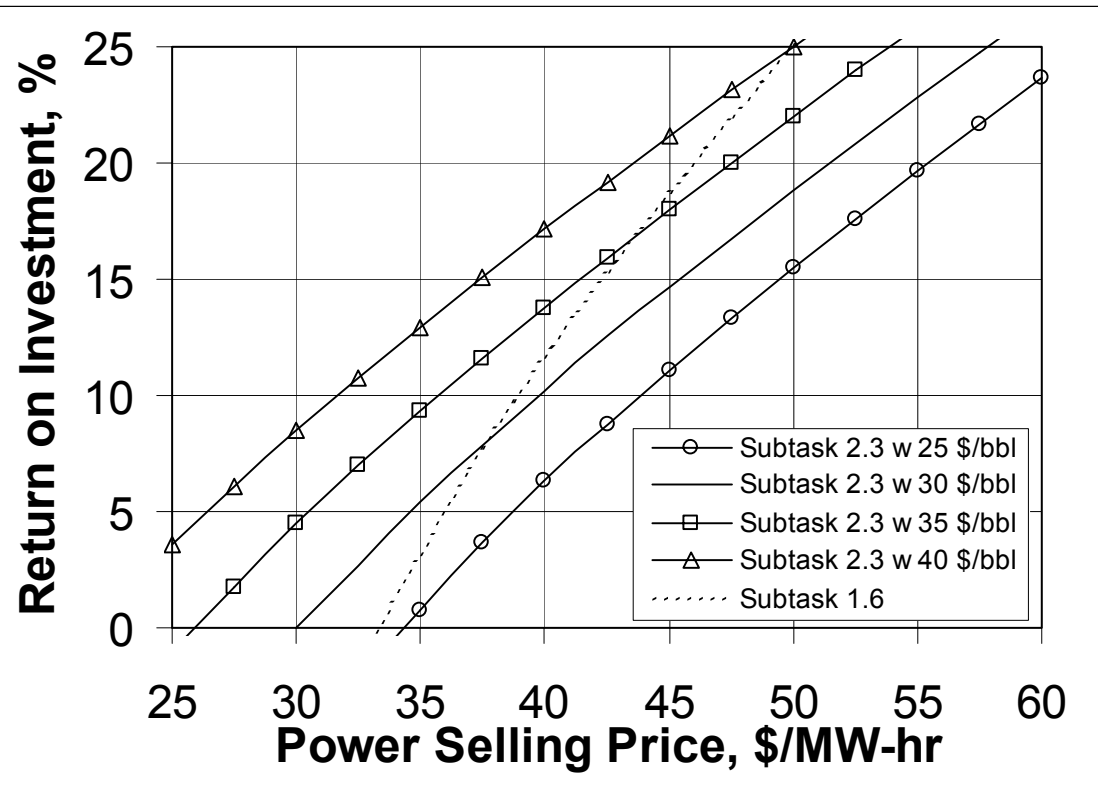


Figure V.12

Effect of Syngas Availability on the Required Power Selling Price for a $12 \%$ Return on Investment for the Subtask 2.3 Optimized Coal Gasification Power Plant with Liquids Coproduction and the Subtask 1.6 Power Plant

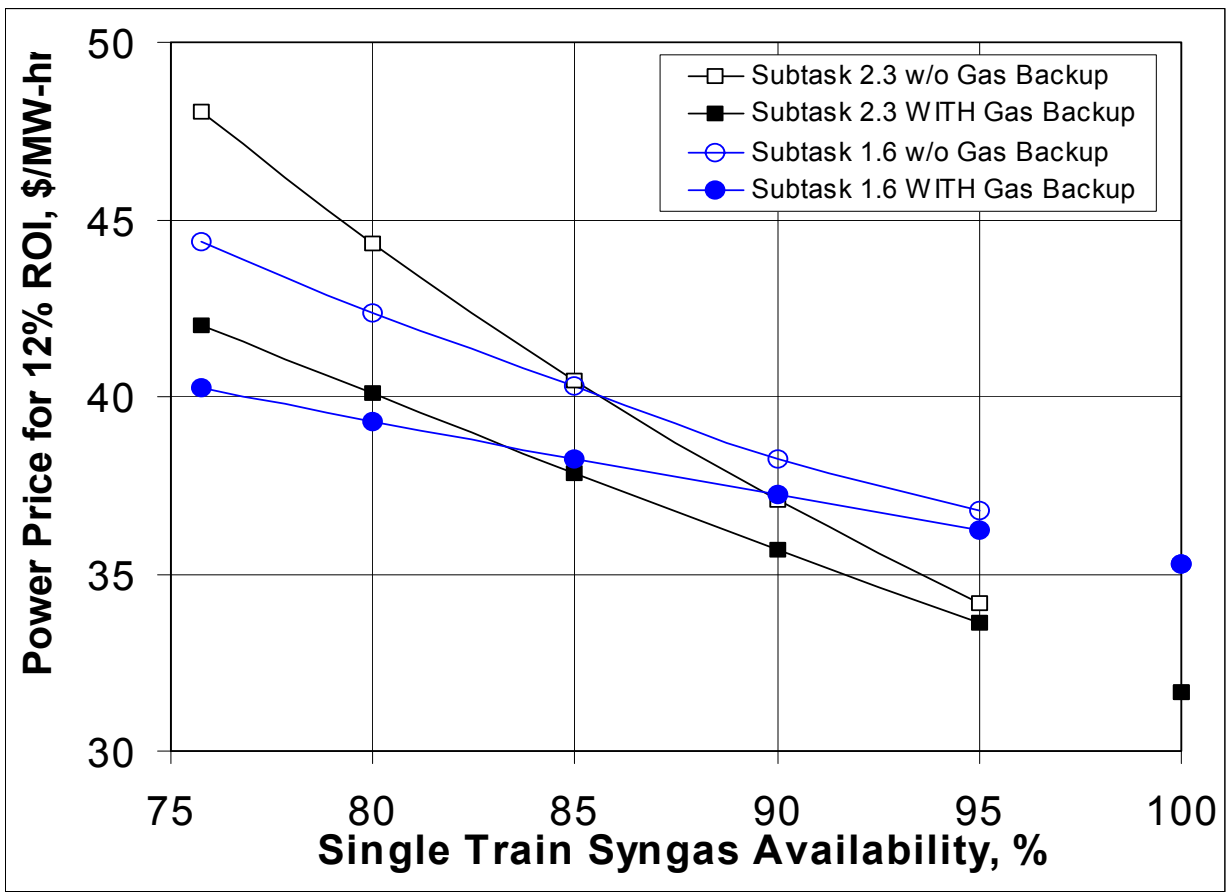




\section{Summary, Conclusions and Recommendations}

\section{VII.1 Summary}

Gasification systems are inherently clean, relatively efficient, and commercially available for converting inexpensive fuels such as coal and petroleum coke into electric power, steam, hydrogen, and chemicals. However, the gasification system also is relatively complex and costly.

Task 1 of this study dealt with the optimization of coal and petroleum coke gasification systems to reduce the cost of power and associated co products primarily by reducing the plant cost. It shows the potential of IGCC based systems to be competitive with, if not superior to, conventional combustion based power systems because of their higher efficiency, superior environmental performance, and competitive cost. Task 2 dealt with the integration of the IGCC plant and a Fischer-Tropsch hydrocarbon synthesis plant for the coproduction of liquid fuel precursors.

\section{Task 1}

Task 1 was divided into nine subtasks. Subtasks 1.1 and 1.2 developed non-optimized designs for coal and petroleum coke IGCC power and coproduction plants. Subtasks 1.3 through 1.7 and 1.3 Next Plant developed optimized designs for coal and coke IGCC power and coproduction plants. Subtask 1.8 performed a review of warm gas cleanup systems. Subtask 1.9 documented the availability analysis study (and results) that was performed as part of the Value Improving Practices portion of the optimization efforts.

Detailed process simulation models were developed for Subtasks 1.1 through 1.7 that provided elementally balanced mass and heat balances. From these balances, P\&IDs, equipment sizes, line sizes, and plant layouts were developed for each case. Coupled with the actual Wabash River cost data, this information allowed detailed cost estimates to be developed with a low degree of uncertainty. This detailed information is confidential.

Subtask 1.1 started from the DOE sponsored Wabash River Coal Gasification Repowering Project (at Terre Haute, Indiana), to develop a design and mid-year 2000 cost estimate for a grass-roots plant equivalent to the Wabash River facility. This case represents the then current Wabash River plant and includes all the modifications and improvements that were made since the initial startup. The $452.6 \mathrm{MM}$ mid-year 2000 dollar cost of the grass-roots plant $(1,681 \$ / \mathrm{kW})$ was developed based on the actual construction cost of the Wabash River facility and subsequent modifications to provide a sound basis for the subsequent cases. $^{20}$

Subtask 1.2 developed a non-optimized design, cost estimate, and economics for a Petroleum Coke IGCC Coproduction Plant processing 5,249 tpd of dry petroleum coke and producing about 79.4 MMscfd of hydrogen and $980,000 \mathrm{lb} / \mathrm{hr}$ of industrial-grade steam $\left(750^{\circ} \mathrm{F} / 700 \mathrm{psig}\right.$ ) in addition to $396 \mathrm{MW}$ of export power. Also it produces $367 \mathrm{tpd}$ of sulfur and $363 \mathrm{MMBtu} / \mathrm{hr}$ of low BTU fuel gas for the adjacent petroleum refinery. The plant is

\footnotetext{
${ }^{20}$ All costs are mid-year 2000 costs. They are presented here to show the relative differences between the cases. Current costs estimates should be developed for any proposed application.
} 
located on the U. S. Gulf Coast. It costs 993.2 MM mid-year 2000 dollars. The discounted cash flow analysis showed that this plant requires an export electric power price of about 43.4 \$/MW-hr to produce a $12 \%$ after tax return on investment.

Subtasks 1.3 through 1.7 developed optimized designs for coal and petroleum coke IGCC plants. Value Improving Practices (VIPs) provided a structured approach to reducing the plant cost for the optimized designs. The use of VIPs outside of a specific project removes the limitations of schedule constraints and allows a more thorough examination of the ideas that were generated during the process. The VIPs team, which consisted of operating and maintenance personnel from the Wabash River plant, Global Energy's gasification experts, and Bechtel's engineers and construction specialists, examined all aspects of the proposed plant and generated almost 300 value engineering ideas. Those that were economically viable were incorporated into the optimized designs. Others are being developed for future applications which will lead to further cost reductions.

Subtask 1.3 and Subtask 1.3 Next Plant developed four optimized designs, cost estimates and economics for Petroleum Coke IGCC Coproduction Plants processing about 5,400 tpd of dry petroleum coke and producing about $80 \mathrm{MMscfd}$ of hydrogen and $980,000 \mathrm{lb} / \mathrm{hr}$ of industrial-grade steam $\left(750^{\circ} \mathrm{F} / 700 \mathrm{psig}\right)$ in addition to electric power. The Subtask $1.3 \mathrm{Next}$ plant processed 5,417 tpd of dry petroleum coke and produced $474 \mathrm{MW}$ of export power and 373 tpd of sulfur. No low BTU fuel gas was exported to the refinery; instead it was used to make additional power.

The petroleum coke IGCC coproduction plants primarily differed in the amount of spare and replicated equipment they contained and the method of particulate removal from the syngas. The Subtask 1.3 plants removed particulates from the syngas by a dry cyclone followed by a wet scrubbing column, and the Subtask 1.3 Next Plant used a dry cyclone followed by a dry char filter system. The Subtask 1.3 Base Case was based on the Wabash River configuration. It contained a spare reactor in each of the two gasification trains. The minimum cost case eliminated the spare reactors. The spare gasification train case added a spare gasification train to the minimum cost case. Availability and discounted cash flow analyses showed that the spare gasification train plant had the lowest required electric power price even though it had the highest plant cost at $812 \mathrm{MM}$ mid-year 2000 dollars.

Based on the above results, the Subtask 1.3 Next Plant was developed containing a spare gasification train, the completely dry particulate removal system described above, and other improvements. The plant cost was reduced to $787 \mathrm{MM}$ mid-year 2000 dollars. The discounted cash flow analysis showed that this plant can export electric power at about 30 \$/MW-hr and still produce a $12 \%$ return on investment. This $13 \$ / \mathrm{MW}$-hr reduction from the Subtask 1.2 power price is a direct result of the effectiveness of the optimization techniques and VIPs that were used.

Subtask 1.4 developed a design, cost estimate, and economics for a future single-train Advanced Coal IGCC Power Plant. This plant processes 3,007 tpd of dry Illinois No. 6 coal and produces $416 \mathrm{MW}$ of export power. It uses an advanced "G/H-class" combustion turbine that is expected to be available at the end of the decade. It cost $465 \mathrm{MM}$ mid-year 2000 dollars $(1,116 \$ / \mathrm{kW})$, and can dispatch power at 42.8 \$/MW-hr while producing a $12 \%$ ROI. With backup natural gas, the export power price can be reduced to 39.8 \$/MW-hr. Compared to a $36 \%$ efficient conventional power plant, the Subtask 1.4 plant will generate $24 \%$ less $\mathrm{CO}_{2}$ because it consumes $24 \%$ less coal. 
Subtask 1.5 compared present day, single-train coal and petroleum coke fueled IGCC power plants highlighting the major differences between the designs, developing cost estimates, and doing a financial analysis for each case. Both plants use the General Electric 7FA+e combustion turbine and are basically are similar in design, but do contain differences. However, future IGCC developments for either fuel generally will benefit the other one. The Subtask 1.5A coal plant cost $375 \mathrm{MM}$ mid-year 2000 dollars $(1,318 \$ / \mathrm{kW})$ and requires a power selling price of 53.9 \$/MW-hr for a $12 \%$ ROI without backup natural gas and 48.9 \$/MW-hr with backup gas. The Subtask 1.5B coke plant cost $367 \mathrm{MM}$ midyear 2000 dollars $(1,260 \$ / \mathrm{kW})$ and requires a power selling price of $43.9 \$ / \mathrm{MW}-\mathrm{hr}$ for a $12 \%$ ROI without backup natural gas and 40.6 \$/MW-hr with backup gas. The major factor for the lower power price for the coke plant is the cheaper coke price. Both power prices are significantly lower than the 67.5 \$/MW-hr required power price for the Subtask 1.1 Wabash River Greenfield Plant without backup natural gas.

Subtask 1.6 developed a current day optimized design, cost estimate and financial analysis for a nominal 1,000 MW coal fed IGCC power plant using four GE 7FA+e combustion turbines. The plant processes 9,266 tpd of dry Illinois No. 6 coal and generates 1,155 MW of export power. It cost 1,231 MM mid-year 2000 dollars $(1,066 \$ / \mathrm{kW})$ and can export power at $44.4 \$ / \mathrm{MW}$-hr without natural gas backup while producing a $12 \% \mathrm{ROI}$. With backup natural gas, the required power price drops to $40.2 \$ / \mathrm{MW}-\mathrm{hr}$ which is almost as low as that of the future Subtask 1.4 single train plant.

Subtask 1.7 developed an optimized design, cost estimate and financial analysis for a single-train coal to hydrogen plant processing 3,007 tpd of dry Illinois No. 6 coal and producing 141 MMscfd of $99.0 \%$ chemical grade hydrogen. Sulfur production is $76.4 \mathrm{tpd}$. The plant costs $530 \mathrm{MM}$ mid-year 2000 dollars and requires a hydrogen selling price of 2.70 $\$ /$ Mscf to produce a $12 \% \mathrm{ROI}$. This is significantly higher than the hydrogen price of 1.30 $\$ /$ Mscfd which was used in the financial analysis for the Subtask 1.3 cases and is based on a $2.60 \$ / M M B t u$ natural gas price. One advantage of a coal based hydrogen plant is that it provides a stable hydrogen cost that is disassociated from the volatile natural gas price.

Subtask 1.8 reviewed the status of warm gas clean-up technology as applicable to coal or coke fueled IGCC power and coproduction plants. The objective is to evaluate developing technologies that operate in the 300 to $750^{\circ} \mathrm{F}$ temperature range, preferably closer to $750^{\circ} \mathrm{F}$, and to determine their potential economic benefit. No technologies were found to be better than the standard amine system currently in use. Selective catalytic oxidation of hydrogen sulfide (SCOHS) systems have the potential to be simple cost effective systems.

Subtask 1.9 developed a report describing the Value Improving Practices availability and reliability design optimization program. Starting from historic Wabash River Repowering Project data, this subtask discussed how the availability analysis and design considerations, such as the expected annual coke consumption, influenced plant performance and sparing philosophy.

In the near term, for plants starting up in the 2005-2008 time period, the E-GAS ${ }^{\mathrm{TM}}$ technology has been demonstrated and commercialized. Achievement of the installed cost goals through application of the optimization techniques shown in the study will be realized in the first plants built, and they will provide a demonstrated basis for additional projects. Operating cost levels already have been demonstrated to a great extent at Wabash River. 
Petroleum coke gasification projects will be the first to enter the marketplace since several of these have already started development. Wabash River has already demonstrated petroleum coke gasification at a commercial scale. The new plants will demonstrate the integration with petroleum refineries and the necessary reliability required to support refinery operations. New capital cost and operating cost standards will be set. Furthermore, they will support the technology and confirm the economics for the coal fueled IGCC power plants that will follow.

The gasification plant concepts developed in this study for the Subtask 1.3 Next Plant (Optimized Petroleum Coke IGCC Coproduction Plant) and the Subtask 1.6 1,000 MW coal power plant have immediate viability in today's market. These plants can compete against most future cost projections for natural gas and power. Other applications will develop as the technology matures.

\section{Task 2}

Task 2 was divided into three subtasks which dealt with converting two of the optimized plants developed during Task 1 into IGCC power plants with the coproduction of liquid fuel precursors.

Starting from the Subtask 1.3 Next Plant, Subtask 2.1 developed a non-optimized design for a petroleum coke gasification power plant with hydrocarbon liquids coproduction by eliminating the export steam and hydrogen production facilities and replacing them with a single-train, once-through Fischer-Tropsch hydrocarbon synthesis plant. A once-through system eliminates the cost of the expensive recycle system which requires recycle gas purification facilities in addition to the recycle compressor. The energy that was used to produce the export steam now is used to generate additional power. This plant produces $617 \mathrm{MW}$ of export power and 4,125 bpd of liquid fuel precursors from slightly less petroleum coke $(5,376$ vs. 5,417 dry tpd) than the Subtask 1.3 Next Plant. On a higher heating value (HHV) basis, this plant has a thermal efficiency $47.9 \%$ when the heating value of the byproduct sulfur is included. It cost 818 MM mid-year 2000 dollars.

Subtask 2.2 developed an optimized design for a petroleum coke gasification power plant with hydrocarbon liquids coproduction by maximizing the liquid fuel precursors production at the expense of power production. In this design, about $92 \%$ of the syngas goes through the once-through slurry-bed F-T hydrocarbon synthesis reactor. The unconverted syngas and light hydrocarbons from the F-T area are mixed with the remaining $8 \%$ of the syngas, compressed, and sent to the single gas turbine for power generation. This plant produces $10,450 \mathrm{bpd}$ of liquid fuel precursors and $367 \mathrm{MW}$ of export power from 5,417 tpd of dry petroleum coke. It has an EPC cost of 735 MM mid-year 2000 dollars. On a higher heating value basis, this plant has a thermal efficiency $56.7 \%$ when the heating value of the byproduct sulfur is included and $54.9 \%$ when the byproduct sulfur is not included. With 27 $\$ / \mathrm{MW}-\mathrm{hr}$ and $30 \$ / \mathrm{bbl}$ liquids, this plant has a $18.2 \% \mathrm{ROI}$, and the Subtask 2.1 plant only has a $9.50 \%$ ROI. (Both cases assume an $80 \%$ loan rate at $10 \%$ annual interest.

Subtask 2.3 developed an optimized design for a coal gasification power plant with hydrocarbon liquids coproduction from the Subtask 1.6 plant using the design approach adopted for the optimized Subtask 2.2 coke plant. The coal gasification capacity of the plant was kept the same as Subtask 1.6. F-T liquids production was maximized, and power production was reduced to only one power block train consisting of two combustion turbines, two HRSGs, and a single steam turbine. The unconverted syngas and light hydrocarbons 
from the F-T synthesis section is compressed and combined with the $18 \%$ of syngas bypassing the F-T reactors to provide fuel for the two combustion turbines.

The plant produces 12,377 bpd of liquid fuel precursors, 675.9 MW of export power, and 237 tpd of sulfur from 9,266 tpd of dry Illinois No. 6 coal. This plant has an EPC cost of 1,159 MM mid-year 2000 dollars. On a higher heating value (HHV) basis, the plant has a thermal efficiency of $53.4 \%$ when the heating value of the byproduct sulfur is included. This thermal efficiency is lower than that of the Subtask 2.2 optimized petroleum coke coproduction plant because this plant produces relatively less liquid fuel and more power that the coke plant. With $30 \$ / \mathrm{bbl}$ liquids and $2.60 \$ / \mathrm{MMBtu}$ natural gas, this plant requires a power selling price of 42 \$/MW-hr to produce a 12\% ROI; whereas the Subtask 1.6 plant requires a power selling price of only $40.2 \$ / \mathrm{MW}-\mathrm{hr}$.

As more IGCC plants, either with or without coproduction facilities, are built and operated, availability should improve which will increase the plant ROI at given power price, or lower the required product selling prices for a given ROI. At low power prices relative to oil prices, IGCC power plants with liquids coproduction will be favored, and conversely when power prices are high relative to oil prices, IGCC power only power plants will be preferred.

Based on the above results, in order for a gasification power plant with liquids coproduction to have a better ROI than a conventional IGCC power plant, the plant design must be balanced. Some features that contribute to this balanced design include

- The use of large, cost efficient gasification trains to minimize cost

- Inclusion of a spare gasification train for maximum availability

- The syngas should have high $\mathrm{CO}$ and $\mathrm{H}_{2}$ contents and a low methane content to allow the F-T area to produce an offgas with a minimal Btu content.

- High conversion in the F-T section so that it can produce an offgas with a high $\mathrm{CO}_{2}$ content for NOx control

- The ability to process all, or almost all, of the syngas in the F-T reactors

- A large, efficient combustion turbine that is correctly sized to process all the fuel gas with minimum additional steam dilution for NOx control

The Subtask 2.2 Optimized Petroleum Coke IGCC Power Plant with Liquids Coproduction does a good job of satisfying most of the above criteria. However, the Subtask 2.3 coal plant produces a syngas with a methane content that is about 2.6 times greater than the syngas produced by the gasification of coke because of the higher volatiles content of the coal. As a result, the F-T offgas has a higher Btu content and requires more steam dilution for NOx control. Furthermore, the total amount of F-T offgas contains too much energy for one GE 7FA+e turbine, and not enough for two turbines. Consequently, about $18 \%$ of the syngas has to be bypassed around the F-T reactors to fully load the two GE 7FA+e turbines. This significantly reduces the liquids production. Ideally, a single larger turbine [or two smaller turbines] that would require bypassing only very little, if any, syngas around the F-T reactors would result in a better balanced plant that could have a better return on investment.

The balanced approach in which the gas turbine fuel gas is diluted with $\mathrm{CO}_{2}$ to a level where only minimal or no additional steam dilution for NOx control also could be applied to an ICGG power plant that co-produces hydrogen (instead of liquid fuel precursors) for power generation with fuel cells. In such a plant, $\mathrm{CO}_{2}$ production by the shift reaction in excess of that needed for NOx control would be captured for possible sequestration. 
Gasification is viewed as the environmentally superior process for power generation from coal. The Wabash River facility demonstrated the superior environmental performance of gasification in terms of SOx, NOx, and particulate emissions. In a carbon-constrained environment, the $\mathrm{CO}_{2}$ easily can be captured for sequestration or other uses. Even without $\mathrm{CO}_{2}$ capture, $\mathrm{CO}_{2}$ emissions are reduced because gasification plants are more efficient than conventional coal power plants. As gasification power plants mature, further efficiency improvements (approaching 50\% on an HHV basis) are expected whereas little, if any, improvement appears likely in conventional plants.

With low coal and coke prices and high oil prices, the return of a gasification power plant can be improved by adding hydrocarbon liquids coproduction. This is especially true for a coke plant associated with a petroleum refinery because besides providing a means of disposing of the byproduct coke, the plant can convert it into liquid hydrocarbons, which when upgraded in the refinery become the main refinery products, liquid transportation fuels.

As natural gas and power prices increase and environmental constraints for coal fired generation plants tighten, coal IGCC will further penetrate the power market. As more coal and coke IGCC plants are built, further improvements can be expected which should lead to additional cost reductions and improved availability that will make IGCC the preferred option for new base-load power plants.

The economics of coal-to-power IGCC facilities may be enhanced by federal and state incentive programs which are aimed at increasing the fuel diversity of our power generation resources. Such programs could speed the wider application of IGCC technologies in new facilities and promote the repowering of older plants. Additional demonstration work may be necessary to convince the financial community of the economic viability of IGCC facilities.

\section{VII.2 Conclusions}

This study has shown that

- Optimization of IGCC plants has resulted in significant capital and operating cost savings.

- Additional cost savings appear likely as some of the concepts developed in this study are researched, developed and implemented.

- The Value Improving Practices used in this study provided a structured method for reducing both the plant cost as well as the operating and maintenance costs.

- Substantial capital cost reductions can be obtained by optimization of the plant layout to reduce the plant size.

- Petroleum coke-fueled IGCC coproduction plants are economically competitive in today's economic environment.

- Power generation by gasification of coal is not yet competitive with coal combustion plants, but the gap has narrowed substantially. Further developments will make IGCC competitive.

- Petroleum coke- and coal-fueled IGCC power plants are very similar. There are differences, but the costs of the two plants are similar.

- Information from the design, construction and operation of petroleum coke gasification plants will further the development and commercialization of coal-fueled plants. 
- Development of a more reliable gasification system with a higher syngas availability will further the development and commercialization of gasification plants and improve their profitability

- The ROI of an IGCC power plant can be improved by the use of backup natural gas to fire the gas turbine when syngas is unavailable.

- As natural gas prices increase, coal-fueled IGCC power plants will be favored over gas-fired combined cycle plants.

- Coproduction of liquid fuel precursors can enhance the economics of IGCC power plants when oil prices are high and power prices are low.

- The balance between power and liquids coproduction to produce an optimum plant design depends upon syngas composition and F-T offgas composition to produce a gas turbine fuel and turbine design in order to minimize steam dilution for NOx control.

\section{VII.3 Recommendations}

Technology development will be the key to the long-term commercialization of gasification technologies and integration of this environmentally superior solid fuels technology into the existing mix of power plants. Based on the results of this study, further research and development in the following areas would be beneficial:

- Development of the " $\mathrm{G} / \mathrm{H}$-class" combustion turbine for syngas applications

- Gasifier advancements including slurry feed vaporization in the second stage

- Demonstration of warm gas clean-up technologies (e.g., SCOHS)

- Testing of advanced wet and dry filtration systems

- Development and implementation of large capacity fuel cells; optimization of the integration of gasification with advanced fuel cell processes

- Develop a lower cost means of producing oxygen such as the ITM ceramic membrane system

- Equipment modifications and revised operating procedures to improve overall plant availability. Such items could include the development of longer lasting refractory, improved more durable burner designs, better heat recovery equipment, and better filtering systems for solids separation.

- Further advances in Fischer-Tropsch technology or other gas-to-liquids technologies for the production of liquid transportation fuels from coal or coke

- Improved Fischer-Tropsch catalysts that produce a product distribution with less methane and light ends and can operate at high once-through conversions

- Verification that activated carbon can reduce the residual sulfur in the syngas going to the F-T reactor to a level where it will not be detrimental to catalyst performance

- Using a two-stage F-T reactor system (either slurry or fixed bed) that maximizes carbon monoxide and hydrogen conversion to produce a gas turbine fuel gas that does not require dilution for $\mathrm{NOx}$ control

- Development of a design for a balanced IGCC Coproduction power plant that coproduces hydrogen based on the balanced approach developed in this study. Excess $\mathrm{CO}_{2}$ produced by the shift reaction above that required for $\mathrm{NOx}$ control in the gas turbine would be captured for possible sequestration. 


\section{References}

The pertinent references to previous work are in footnotes at appropriate places in this report. However, they are repeated here in alphabetical order for convenience of the reader.

Amick, Phil, Testimony before a hearing of The Subcommittee on Energy and Air Quality, The Committee on Energy and Commerce of the U.S. House of Representatives, June 24, 2003, as attached to the testimony of Richard A. Oliver in the previous reference from www.gasification.org.

Global Energy, Inc., "Wabash River Coal Gasification Repowering Project - Final Report," September 2000.

Keeler, Clifton G., "Operating Experience at the Wabash River Repowering Project," 2002 Gasification Technologies Council Conference, San Francisco, CA, October 28, 2002.

Oil and Gas Journal, page 6, Sept 10, 2001, and Houston Chronicle, page 7D, June 15, 2003.

Marano, J. J., Rogers, S., Choi, G. N., and Kramer, S. J., "Product Valuation of Fischer-Tropsch Derived Fuels," ACS National Meeting, Washington, D. C., August 21-6, 1994.

Nexant, Inc., "Financial Model User's Guide - IGCC Economic and Capital Budgeting Evaluation," Report for the U. S. Department of Energy, Contract DE-AMO1-98FE64778, May 2000.

Olliver, Richard A. Testimony before a hearing of The Subcommittee on Energy and Air Quality, The Committee on Energy and Commerce of the U.S. House of Representatives, June 24, 2003, from www.gasification.org.

Research Report AP-4216, "Availability Analysis Handbook for Coal Gasification and Combustion Turbine-based Power Systems," Research Project 1800-1, Electric Power Research Institute, 3412 Hillview Avenue, Pala Alto, CA 94304, August 1985.

Rutkowski, M. D., Klett, M. G. and R. C. Maxwell, "The Cost of Mercury Removal in an IGCC Plant," Gasification Technologies 2002, San Francisco, CA, Oct. 27-30, 2002.

Topical Report - Volume I, "Process Design - Illinois No. 6 Coal Case with Conventional Refining, , Baseline Design/Economics for Advanced Fischer-Tropsch Technology, U. S. Department of Energy, Contract Number DE-AC22-91PC90027, October 1994.

Topical Report No. 20, "The Wabash River Coal Gasification Repowering Project - An Update," U. S. Department of Energy, September 2000.

"Topical Report - Task 1 Topical Report, IGCC Plant Cost Optimization," Gasification Plant Cost and Performance Optimization, United Stated Department of Energy, National Energy Technology Laboratory, Contract No. DE-AC26-99FT40342, May 2002, http://www.netl.doe.gov/coalpower/gasification/projects/systems/docs/40342R01.PDF.

"Topical Report - Task 2 Topical Report, Coke/Coal Gasification With Liquids Coproduction," Gasification Plant Cost and Performance Optimization, United Stated Department of Energy, National Energy Technology Laboratory, Contract No. DE-AC26-99FT40342, September 2003.

U. S. Department of Energy, Energy Information Administration, "Annual Energy Outlook 2001 with Projections to 2020," December 2000, http://www.eia.doe.gov/oiaf/aeo. 


\section{List of Acronyms and Abbreviations}

\begin{tabular}{|c|c|}
\hline${ }^{\circ} \mathrm{C}$ & degrees Celsius \\
\hline${ }^{\circ} \mathrm{F}$ & degrees Fahrenheit \\
\hline$\$$ & United Stated dollars \\
\hline$\$ / b b l$ & United States dollars per barrel \\
\hline$\$ / \mathrm{kW}$ & United States dollars per kilowatt \\
\hline \$/MMBtu & United States dollars per million British thermal units \\
\hline \$/Mscf & United States dollars per thousand standard cubic feet \\
\hline \$/MW-hr & United States dollars per megawatt hour \\
\hline$\$ /$ ton & United States dollars per ton \\
\hline$\%$ & percent \\
\hline$\% / y r$ & percent per year \\
\hline AGR & acid gas removal \\
\hline ASU & air separation unit \\
\hline Atm & atmosphere(s) \\
\hline bbl & barrels \\
\hline bpd & barrels per day \\
\hline bpsd & barrels per stream day \\
\hline BFW & boiler feed water \\
\hline Btu & British thermal unit(s) \\
\hline Btu/scf & British thermal units per standard cubic foot \\
\hline CEM & continuous emission monitoring \\
\hline $\mathrm{CH}_{4}$ & methane \\
\hline $\mathrm{CO}$ & carbon monoxide \\
\hline $\mathrm{CO}_{2}$ & carbon dioxide \\
\hline cos & carbonyl sulfide \\
\hline CT & combustion turbine \\
\hline $\mathrm{CW}$ & cooling water \\
\hline d & day \\
\hline DCF & discounted cash flow \\
\hline DCS & distributed digital control system \\
\hline DOE & Department of Energy \\
\hline EIA & Energy Information Agency \\
\hline E-GAS ${ }^{T M}$ & $\begin{array}{l}\text { name of the gasification technology at Wabash River when } \\
\text { this project started }\end{array}$ \\
\hline EPA & Environmental Protection Agency \\
\hline EPC & engineering, procurement and construction \\
\hline EPRI & Electric Power Research Institute \\
\hline $\mathrm{F}-\mathrm{T}$ & Fischer-Tropsch \\
\hline
\end{tabular}




\begin{tabular}{|c|c|}
\hline $\begin{array}{l}\mathrm{ft}, \mathrm{ft}^{2}, \mathrm{ft}^{3} \\
\text { gal }\end{array}$ & $\begin{array}{l}\text { foot (feet), square feet, cubic feet } \\
\text { gallon(s) }\end{array}$ \\
\hline GE & General Electric \\
\hline GT & gas turbine \\
\hline GTG & gas turbine generator \\
\hline GTL & gas to liquids \\
\hline $\mathrm{H}_{2} \mathrm{O}$ & water \\
\hline $\mathrm{H}_{2} \mathrm{~S}$ & hydrogen sulfide \\
\hline $\mathrm{HHV}$ & higher heating value \\
\hline HP & high pressure \\
\hline $\mathrm{hr}$ & hour(s) \\
\hline HRSG & heat recovery steam generator \\
\hline HTRU & high temperature heat recovery unit \\
\hline HV & high voltage \\
\hline IGCC & integrated gasification combined-cycle \\
\hline in, $\mathrm{in}^{2}, \mathrm{in}^{3}$ & inches, square inches, cubic inches \\
\hline IP & intermediate pressure \\
\hline IRR & internal rate of return \\
\hline $\mathrm{kg}$ & kilogram \\
\hline $\mathrm{KO}$ & knock out \\
\hline $\mathrm{kW}$ & kilowatt \\
\hline kW-hr & kilowatt-hour \\
\hline $\mathrm{kV}$ & kilovolt \\
\hline $\mathrm{lb}$ & pound(s) \\
\hline $\mathrm{lb} / \mathrm{hr}$ & pounds per hour \\
\hline Ib/MMBtu & pounds per million British thermal units \\
\hline Ib/MW-hr & pounds per megawatt hour \\
\hline LP & low pressure \\
\hline L/N & liquid/vapor \\
\hline LHV & lower heating value \\
\hline LPG & liquefied petroleum gas \\
\hline LTHR & low temperature heat removal \\
\hline$M \$$ & thousands of United States dollars \\
\hline MCC & motor control center \\
\hline MDEA & methyldiethylamine, a chemical \\
\hline $\min$ & minute(s) \\
\hline Mlb & thousands of pounds \\
\hline Mlb/hr & thousands of pounds per hour \\
\hline MMlb & millions of pounds \\
\hline MM & million(s) \\
\hline MM\$ & millions of United States dollars \\
\hline
\end{tabular}




\begin{tabular}{|c|c|}
\hline MMBtu & millions of British thermal units \\
\hline MMBtu/bbl & millions of British thermal units per barrel \\
\hline MP & medium pressure \\
\hline Mscf & thousands of standard cubic feet \\
\hline Mscf/hr & thousands of standard cubic feet per hour \\
\hline MW & megawatts \\
\hline MW-hr & megawatt-hours \\
\hline NOx & nitrogen oxides \\
\hline NPV & net present value \\
\hline O\&M & operating and maintenance \\
\hline P\&IDs & piping and instrument drawing \\
\hline $\mathrm{PH}$ & a measure of acidity \\
\hline PLC & programmable logic controller \\
\hline ppm & parts per million \\
\hline ppmv & parts per million by volume \\
\hline ppmvd & parts per million by volume dry \\
\hline PSA & pressure swing adsorption \\
\hline psia & pounds per square inch absolute \\
\hline psig & pounds per square inch gauge \\
\hline ROI & return on investment \\
\hline ROM & run of mine \\
\hline $\mathrm{S} / \mathrm{C}$ & subcontract \\
\hline scf & standard cubic foot (feet) at $60^{\circ} \mathrm{F}$ and 1 atmosphere \\
\hline scfm & standard cubic feet per minute \\
\hline SCOHS & selective catalytic oxidation of hydrogen sulfide \\
\hline $\mathrm{SO}_{2}$ & sulfur dioxide \\
\hline SOx & sulfur oxides \\
\hline ST & steam turbine \\
\hline STG & steam turbine generator \\
\hline SRU & sulfur recovery unit \\
\hline tpd & tons per day \\
\hline VIPs & value improving practices \\
\hline VOC & volatile organic compounds \\
\hline vol & volume \\
\hline wt & weight \\
\hline $\mathrm{yr}$ & year \\
\hline ZLD & zero liquid discharge \\
\hline $\mathrm{ZnO}$ & zinc oxide, a chemical \\
\hline ZnS & zinc sulfide, a chemical \\
\hline
\end{tabular}




\section{Acknowledgements}

The help, assistance, guidance, and support of the following individuals and organizations is hereby acknowledged.

The United States Department of Energy's National Energy Technology Laboratory (DOE/NETL) for their financial support

John Rockey of DOE/NETL for his inspiration, guidance and promotion of this study

Gary Stiegel of DOE/NETL for his ongoing support

The managements of Bechtel, Global Energy and Nexant for their backing and financial support

General Electric for their assistance with the performance of the combustion turbine

Praxair for their assistance with the performance of the air separation unit

UOP for their assistance with the performance of the PSA unit

Aspen Technology, Borsig, Callidus Technologies, Emtrol, Nooter, Süd-Chemie, Svedala, USFilter, and other equipment manufactures and suppliers for their assistance with designs, performance specifications and cost quotations

Finally, we wish to acknowledge the contributions of the following Bechtel, Global Energy and Nexant employees who contributed the diverse talents to this study.

Bechtel

John Bayers

Paul Bean

Raymond Chang

Robert Geosits

Melvin Lane

Thomas Mitchell

Shiyoji Ota

Thressia Reynolds

Peter Richen

Lee Schmoe

Sam Weinstein

Denis Wolf
Global Energy

Phil Amick

David Breton

Newell Carter

Douglas Cousins

Gary Harmond

Ronald Herbanek

Albert Tsang
Nexant

Bob Burdett

Gerald Choi

Sheldon Kramer

Mohammad Nawaz

King Ng

Bin Nguyen

Samuel Tam 


\section{Appendix}

\section{List of Technical Publications}




\section{Appendix}

\section{List of Technical Publications}

As of the publication date of this report, this study has produced six technical presentations and/ or publications. They are:

1. Amick, P., Geosits, R., Kramer, S., Rockey, J., and Tam, S., "IGCC Plant Performance \& Cost Optimization Study", Seventeenth Annual International Pittsburgh Coal Conference, Pittsburgh, PA, September 11-15, 2000.

2. Amick, P., Geosits, R., Herbanek, R., Kramer, S., Rockey, J., and Tam, S., "An Optimized Petroleum Coke IGCC Coproduction Plant", Gasification Technologies Council Conference, San Francisco, CA, October 7-10, 2001.

3. Amick, P., Geosits, R., Kramer, S., and Tam, S., "A Large Coal IGCC Power Plant", Nineteenth Annual International Pittsburgh Coal Conference, Pittsburgh, PA, September 23-27, 2002.

4. Amick, P., Geosits, R., and Kramer, S., "A Coal to Hydrogen Plant", 255th ACS National Meeting (Fuel Synposia), New Orleans, LA, March 23-27, 2003.

5. Amick, P., Geosits, Herbanek, R., Kramer, S., and Tam, S., "An Advanced IGCC Coal Power Plant", Paper 13-1 to be presented at the Twentieth Annual International Pittsburgh Coal Conference, Pittsburgh, PA, September 15-19, 2003.

6. Amick, P., Breton, D., Geosits, R., Kramer, S., and Tam, S., "Coproduction of F-T Liquids and Power by the Gasification of Petroleum Coke and Coal", Paper 13-3 to be presented at the Twentieth Annual International Pittsburgh Coal Conference, Pittsburgh, PA, September 15-19, 2003 


\section{cNexant}

101 Second Street, $11^{\text {th }}$ Floor San Francisco, CA 94105 USA tel: +1 4153691000 fax: +1 4153699700 email: info@nexant.com 